\title{
Network effects in the enterprise wireless PDA market
}

by

Kalyan Siddam

\begin{abstract}
A thesis submitted to the Faculty of Graduate Studies and Research in partial fulfillment of the requirements for the degree of Master of Applied Science in

Technology Innovation Management
\end{abstract}

Department of Systems and Computer Engineering,

Carleton University

Ottawa, Canada, K1S 5B6

December 2008

(C) Copyright 2008 Kalyan Siddam 


$\begin{array}{ll}\begin{array}{l}\text { Library and } \\ \text { Archives Canada }\end{array} & \begin{array}{l}\text { Bibliothèque et } \\ \text { Archives Canada }\end{array} \\ \begin{array}{l}\text { Published Heritage } \\ \text { Branch }\end{array} & \begin{array}{l}\text { Direction du } \\ \text { Patrimoine de l'édition }\end{array} \\ \begin{array}{l}\text { 395 Wellington Street } \\ \text { Ottawa ON K1A 0N4 } \\ \text { Canada }\end{array} & \begin{array}{l}\text { 395, rue Wellington } \\ \text { Ottawa ON K1A 0N4 } \\ \text { Canada }\end{array}\end{array}$

Your file Votre référence ISBN: 978-0-494-47522-5

Our file Notre référence

ISBN: 978-0-494-47522-5

NOTICE:

The author has granted a nonexclusive license allowing Library and Archives Canada to reproduce, publish, archive, preserve, conserve, communicate to the public by telecommunication or on the Internet, loan, distribute and sell theses worldwide, for commercial or noncommercial purposes, in microform, paper, electronic and/or any other formats.

The author retains copyright ownership and moral rights in this thesis. Neither the thesis nor substantial extracts from it may be printed or otherwise reproduced without the author's permission.
AVIS:

L'auteur a accordé une licence non exclusive permettant à la Bibliothèque et Archives Canada de reproduire, publier, archiver, sauvegarder, conserver, transmettre au public par télécommunication ou par l'Internet, prêter, distribuer et vendre des thèses partout dans le monde, à des fins commerciales ou autres, sur support microforme, papier, électronique et/ou autres formats.

L'auteur conserve la propriété du droit d'auteur et des droits moraux qui protège cette thèse. $\mathrm{Ni}$ la thèse ni des extraits substantiels de celle-ci ne doivent être imprimés ou autrement reproduits sans son autorisation.
In compliance with the Canadian Privacy Act some supporting forms may have been removed from this thesis.

While these forms may be included in the document page count, their removal does not represent any loss of content from the thesis.
Conformément à la loi canadienne sur la protection de la vie privée, quelques formulaires secondaires ont été enlevés de cette thèse.

Bien que ces formulaires aient inclus dans la pagination, il n'y aura aucun contenu manquant.

\section{Canada}


The undersigned hereby recommend to

the Faculty of Graduate Studies and Research

acceptance of the thesis

Network effects in the enterprise wireless PDA market

submitted by

Kalyan Siddam

in partial fulfillment of the requirements for the degree of Master of Applied Science in Technology Innovation Management

Victor Aitken, Department Chair

Professor J. R. Callahan, Thesis Supervisor

Carleton University

December 2008 


\begin{abstract}
The enterprise wireless personal digital assistant (PDA) market continues to attract high profile entrants like Apple Inc. Companies like Research In Motion (RIM) have captured significant market share, while companies like Palm Inc. have lost their lead. The enterprise wireless PDA market is considered a networked market. Understanding the network effects and their strategic implications in the enterprise wireless PDA market is a key for all stakeholders in this market.
\end{abstract}

This research studies the network effects in the enterprise wireless PDA market using a simulation model developed using the system dynamics framework. The model produces behaviors that qualitatively explain the success or failure of an enterprise wireless PDA platform. The results of this research suggest that the success of an enterprise wireless PDA platform has an endogenous component, which is found in the interaction of positive feedbacks that accelerate the adoption and negative feedbacks that lead to decline. 


\section{Acknowledgements}

The past two years have been a great learning and rewarding experience for me. This research would not have been possible without the advice, assistance, encouragement and support from the following people.

I would like to express my sincere gratitude to my supervisor John Callahan, for his guidance, support, patience and encouragement throughout this research. I am also thankful to Professors Tony Bailetti, Steven Muegge, Stoyan Tanev, Thomas Kunz, and Douglas King for their advice, guidance and constructive suggestions at various stages of this research.

Using the system dynamics method for my research was a challenging and rewarding experience. I would like to thank Ivan Taylor for his guidance and expert advice. I would also like to thank all my interview participants for sharing their experience and insightful feedback on this research despite of their hectic schedules. Without their help this research would be unfinished.

I would like to take an opportunity to thank my family, friends and colleagues for their constant support and source of encouragement though out this journey. 


\section{Table of contents}

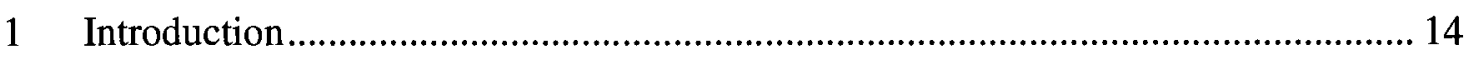

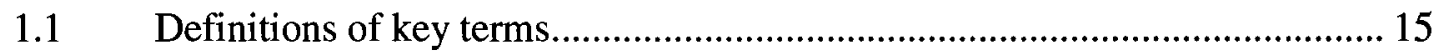

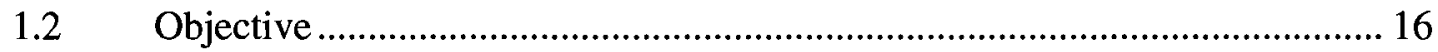

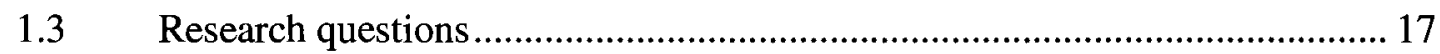

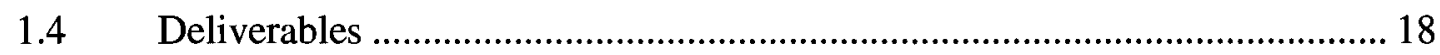

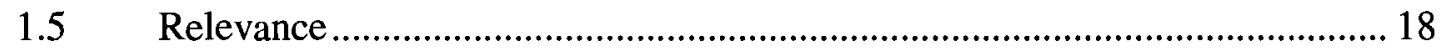

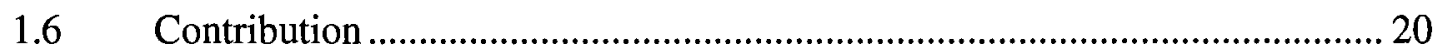

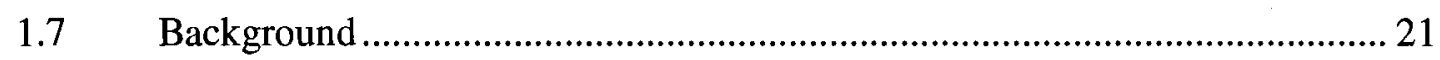

1.7.1 Brief review of the enterprise wireless PDA market ............................. 21

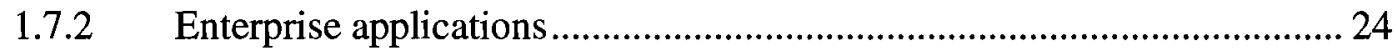

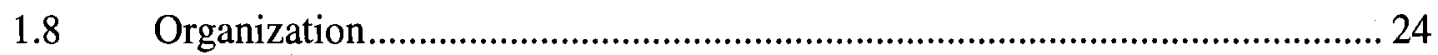

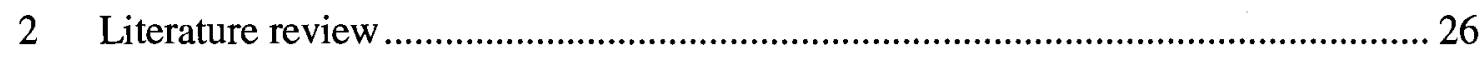

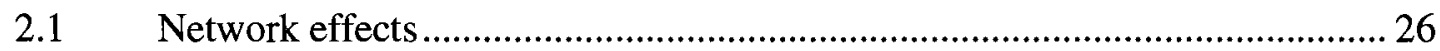

2.2 Technology life-cycle and company strategy ............................................ 30

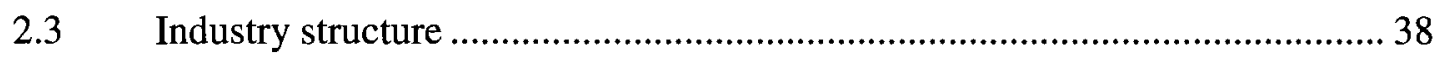

2.4 Lessons learned from the literature review .......................................... 40

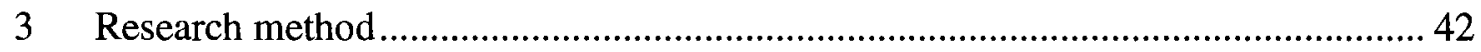

Rationale for using system dynamics ................................................... 46

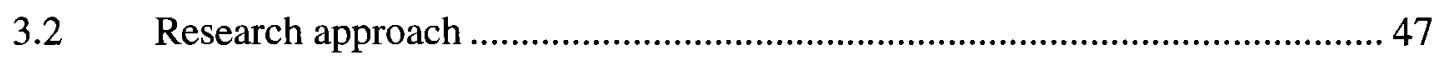

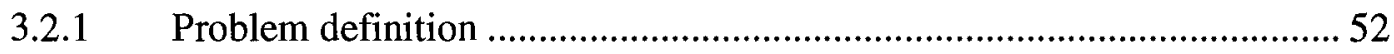

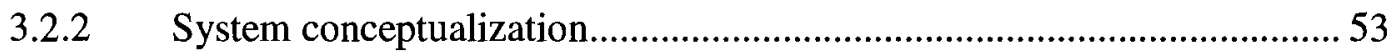


3.2.3 Model formulation .............................................................................. 54

3.2.4 Simulation and policy analysis ............................................................ 57

4 A case study on enterprise wireless PDA market ...................................................... 58

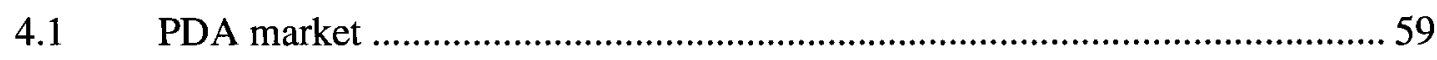

4.2 Network effects in enterprise wireless PDA market.......................................... 63

4.2.1 Leverage existing infrastructure and applications ..................................... 63

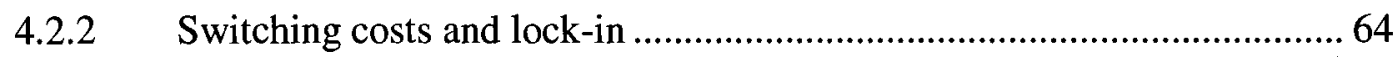

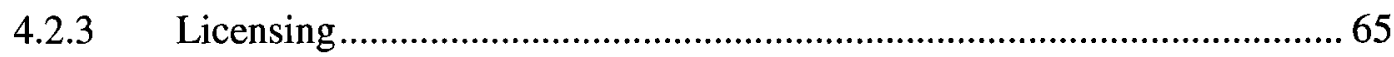

4.2.4 Developer population and tools ........................................................... 66

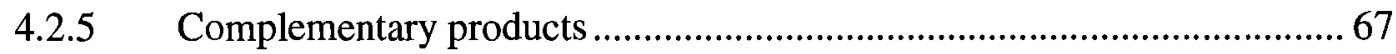

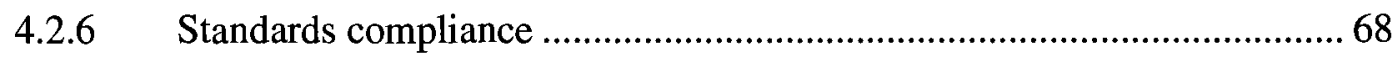

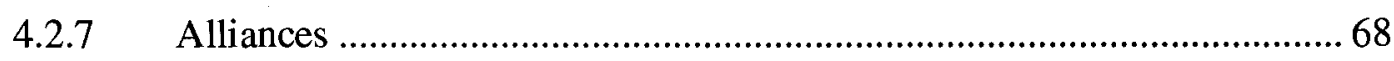

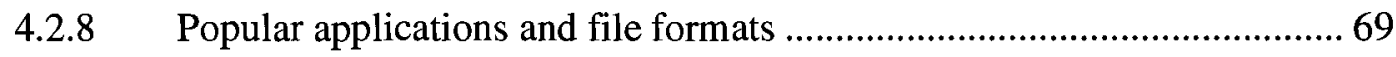

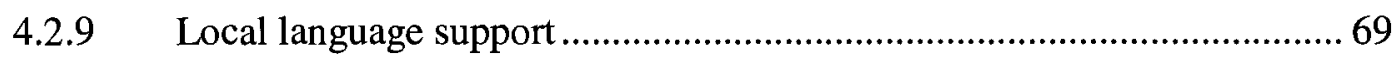

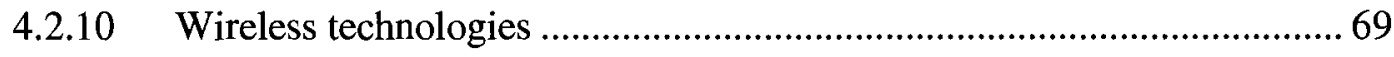

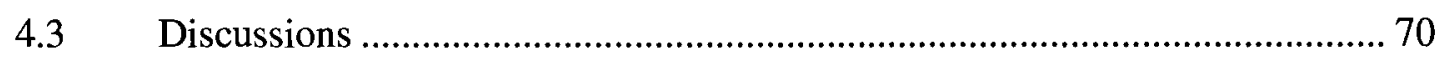

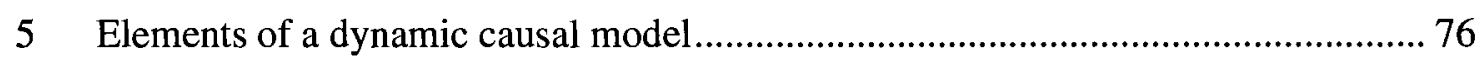

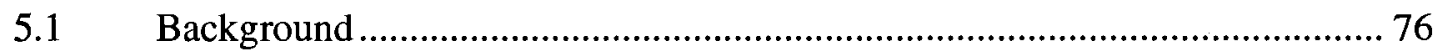

5.2 Fieldwork on the dynamics of the enterprise wireless PDA market............... 77

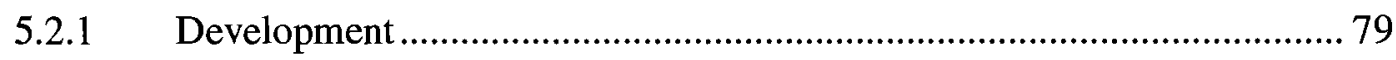


5.2.2 Adoption

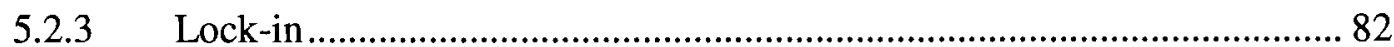

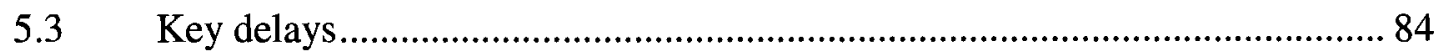

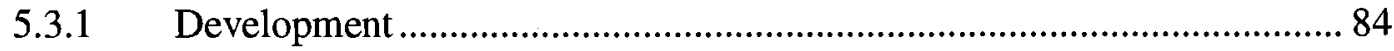

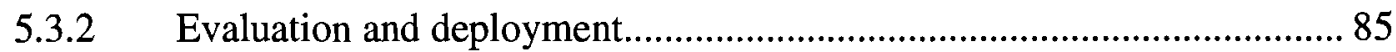

6 A systems model of enterprise wireless PDA market.............................................. 86

6.1 Subsystems in a dynamic causal model ........................................................ 86

6.2 Resource structure of the enterprise wireless PDA system .............................. 89

6.3 Behavioral foundations of the causal model.................................................. 92

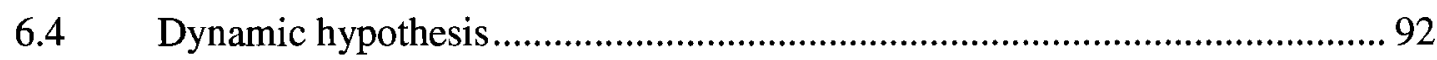

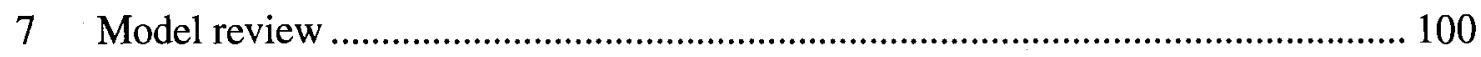

7.1 Approach to model review......................................................................... 100

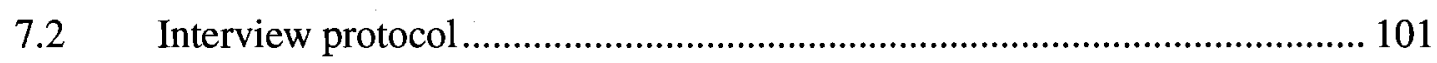

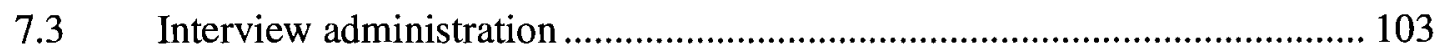

7.4 Expert reaction to model structure .................................................................. 104

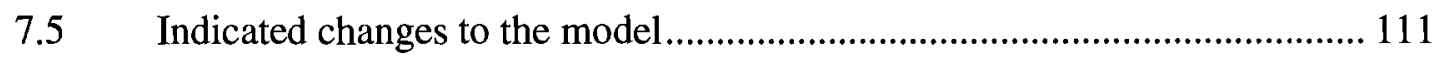

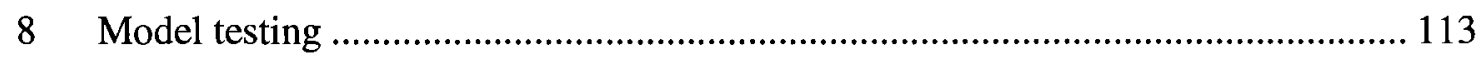

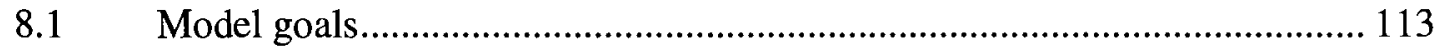

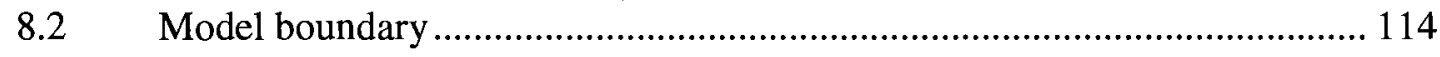

8.3 Model testing .......................................................................................... 119

9 Model simulation and scenario analysis ............................................................ 122

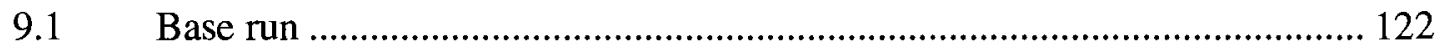




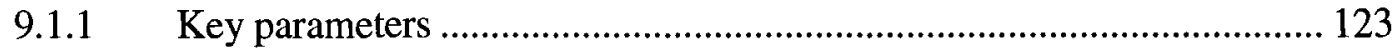

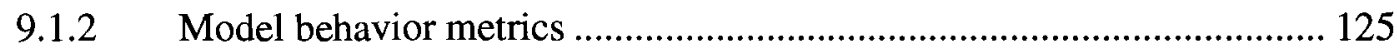

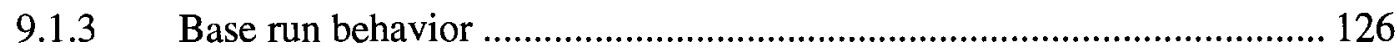

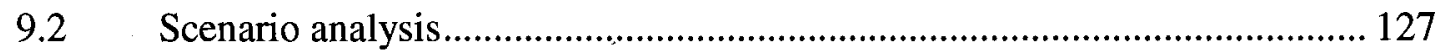

9.2.1 Target PDA Platform market entry, switching costs scenarios ............... 127

9.2.2 Comparison of market entry, switching costs scenarios with base run .. 128

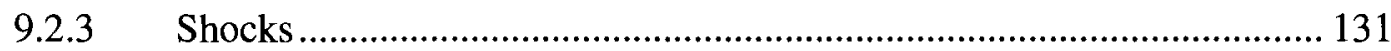

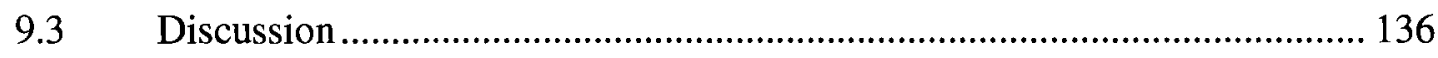

10 Conclusions, limitations, and future research .................................................. 137

10.1 Answers to research questions .................................................................. 137

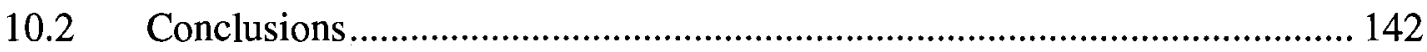

10.3 Contribution ............................................................................................. 143

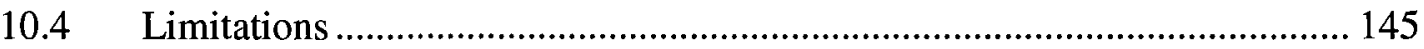

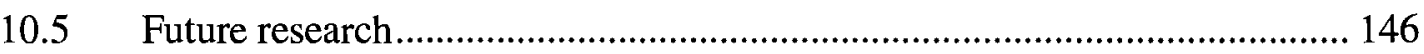

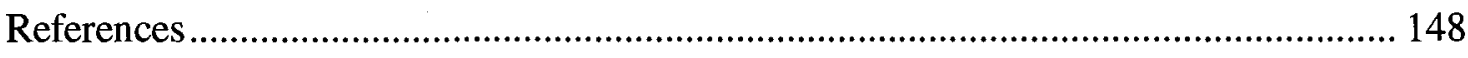

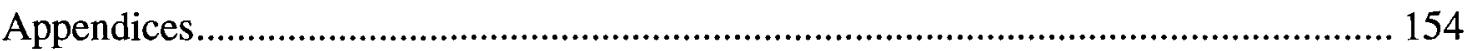




\section{List of tables}

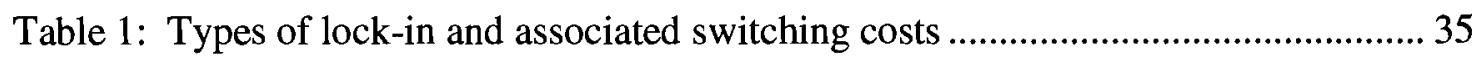

Table 2: Research objectives, associated activities and outcomes ............................. 45

Table 3: Modeling steps and potential qualitative methods...................................... 49

Table 4: System dynamics modeling stages, inputs and outputs ................................ 51

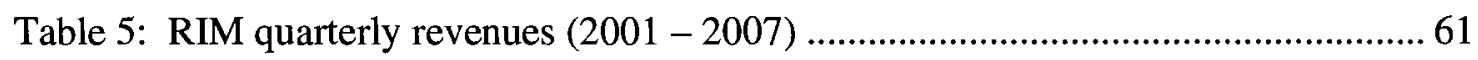

Table 6: RIM revenues, BlackBerry enterprise servers and devices $(2001-2007) \ldots \ldots . .62$

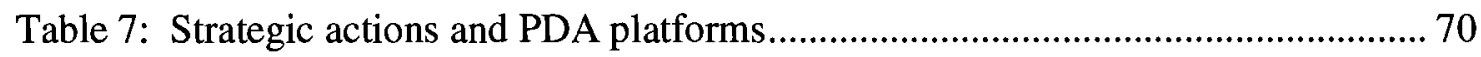

Table 8: Mapping of insights gained from literature review with that of case study ...... 75

Table 9: Experts' reactions to alliances and developer loops .................................... 104

Table 10: Experts' reactions to enterprise server and PDA application loops .............. 106

Table 11: Experts' reactions to enterprise adoption and switching loop ...................... 107

Table 12: Experts' reactions to PDA user adoption and switching loop ..................... 108

Table 13: Experts' reactions to carrier adoption and switching loop .......................... 109

Table 14: Experts' reactions to $3^{\text {rd }}$ party PDA device licensing and switching loop .... 110

Table 15: Experts' reaction to the causal loop explanation ...................................... 111

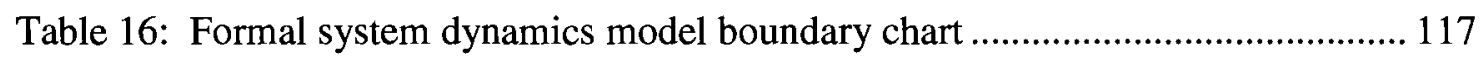

Table 17: Parameters and default values for the base run ..................................... 124

Table 18: Market entry and switching costs scenarios ........................................... 128

Table 19: Summary of results for market entry and switching costs scenarios............. 131

Table 20: Summary of results for market shock scenarios ...................................... 135 
Table 21: Sources of lock-in and switching costs for enterprises, PDA users and carriers 


\section{List of figures}

Figure 1: High level network diagram of enterprise wireless PDA market.................... 21

Figure 2: Product architectures and integration ...................................................... 31

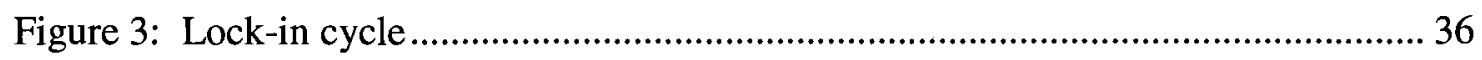

Figure 4: Overview of the system dynamics modeling approach ................................ 48

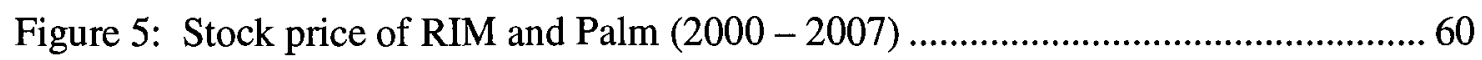

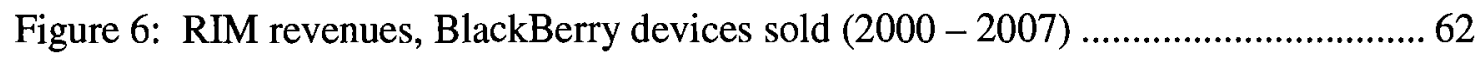

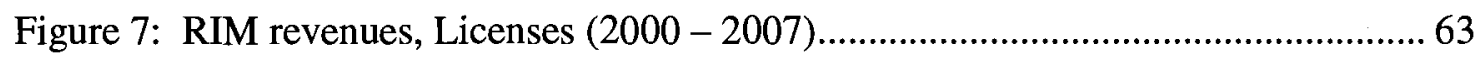

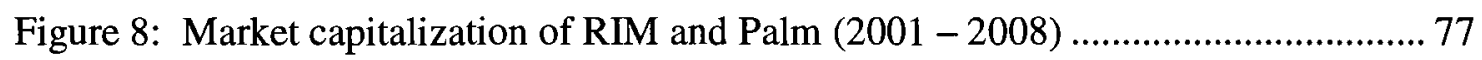

Figure 9: Subsystem diagram of enterprise wireless PDA market ............................ 88

Figure 10: Dynamic resource view of enterprise wireless PDA market...................... 90

Figure 11: Feedback structure of developers, alliances, server and PDA application in enterprise wireless PDA market …............................................................... 95

Figure 12: Feedback structure in enterprise wireless PDA market - enterprises ........... 96

Figure 13: Feedback structure in enterprise wireless PDA market - PDA users ........... 97

Figure 14: Feedback structure in enterprise wireless PDA market - carriers................ 98

Figure 15: Feedback structure in enterprise wireless PDA market - licenses ............... 99

Figure 16: Base run simulation results - enterprises ............................................ 157

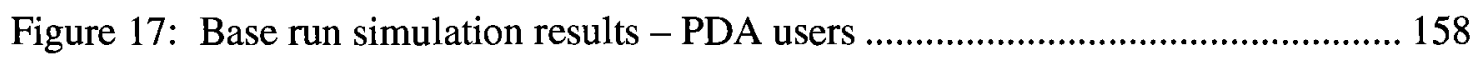

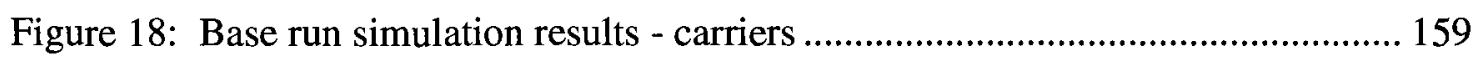

Figure 19: Market entry time and switching costs simulation results - enterprises....... 160

Figure 20: Market entry time and switching costs simulation results - PDA users ...... 161 
Figure 21: Market entry time and switching costs simulation results - carriers

Figure 22: Market shock scenario simulation results - enterprises.

Figure 23: Market shock scenario simulation results - PDA users .......................... 164

Figure 24: Market shock scenario simulation results - carriers 165 


\section{List of appendices}

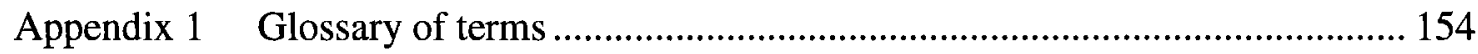

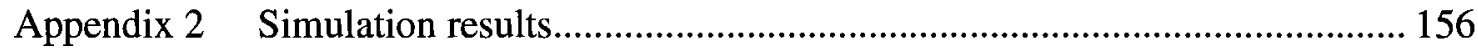

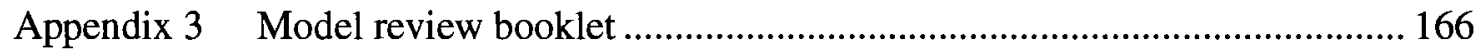




\section{$1 \quad$ Introduction}

This research studies the network effects and their strategic implications in the market for enterprise wireless personal digital assistants (PDAs). The enterprise wireless PDA market continues to be of interest to researchers and entrepreneurs, highlighted with the recent entry of high profile players like Apple Inc in this market. Wireless PDA market is considered as the next-big-thing ${ }^{1}$ and is expected to surpass the personal computer (PC) industry in terms of number of units sold ${ }^{2}$. The enterprise wireless PDA market is considered a networked market, bringing products and innovations to market in a networked market need different strategies (Chakravorti, 2004; Arthur, 1996).

It is important to understand how network effects in the enterprise wireless PDA market affect stakeholders and how sources of lock-in and switching costs impact stakeholders. The role of network effects and their strategic implications are of interest to researchers and stakeholders including enterprises, PDA users, enterprise wireless PDA platform manufacturers, and public policy-makers. This research studies the network effects and their strategic implications using a simulation model developed using the system dynamics (SD) framework.

\footnotetext{
${ }^{1}$ Source: "The Next Big Thing Forget Wi-Fi. The real wireless revolution is being driven by the cell phone--and is already creating rich opportunities for huge players and small startups alike". CNN Money, July 1, 2003. http://money.cnn.com/magazines/business $2 /$ business 2 archive/2003/07/01/345280/index.htm ${ }^{2}$ Source: "beyond the desktop". US Navy, last accessed: October 27, 2008. http://www.chips.navy.mil/archives/02_spring/index2_files/beyond_the_desktop.htm
} 


\subsection{Definitions of key terms}

For the purpose of this research, a wireless PDA device is a wireless handheld device that offers cellular, fax, Internet, and computing. This includes wireless PDA devices such as the BlackBerry ${ }^{3} 71 x x$ by Research In Motion (RIM) and Treo ${ }^{4} 700 \mathrm{w}$ by Palm Inc. These devices are also known as smartphones.

The network effect is the effect on the value of a product or service to one user that depends on how many other users use it (Shapiro \& Varian, 1999). Network effects can be positive or negative; direct or indirect. An example of a direct network effect is a Fax machine, exchange of files - due to use, purchasing, compatibility, etc. An example of an indirect network effect is a hydrogen filling station: a lack of them due to complementary goods, services, etc. An example of a negative network effect is traffic congestion.

The lock-in is the phenomenon once a user has chosen a technology or a format for keeping information, switching to a different technology or a different format can be very expensive. As the information unlikely to get transferred perfectly, incompatibilities to other related complementary and durable assets, and retraining (Shapiro \& Varian, 1999), causing the user to effectively lock-in to that technology or format.

\footnotetext{
${ }^{3}$ Registered trademark of Research In Motion, http://www.rim.com/

${ }^{4}$ Registered trademark of Palm Inc, http://www.palm.com/
} 
The switching cost is the cost a user must incur when the user of an information system decides to switch from one information system to another.

The target wireless PDA platform is a wireless PDA platform that is of interest to this research, success of which is being studied.

The competitor wireless PDA platform is the wireless PDA platform(s) that competes with the target wireless PDA platform.

The stakeholders in the enterprise wireless PDA market include enterprise PDA manufacturers, enterprises, enterprise software vendors, carriers and PDA users.

\subsection{Objective}

The enterprise wireless PDA market is considered networked market. An understanding of the network effects in this market is key to the wireless PDA manufacturers and other stakeholders in this market. Companies like Research In Motion (RIM) have captured significant market share ${ }^{5}$, while companies like Palm Inc. have lost their lead.

The objective of this research is to develop and simulate a model of network effects in enterprise wireless PDA market using Systems Dynamics (SD) framework. The model captures the network effects and sources of lock-in for each stakeholder in this market.

\footnotetext{
${ }^{5}$ Source: IDC: RIM captures more than half of smartphone market. Washington Post, September 08, 2008. http:/www.washingtonpost.com/wp-dyn/content/article/2008/09/08/AR2008090802119.html
} 
The model suggests that a successful enterprise wireless PDA platform not only need to increase the switching costs for its user, it also need to find ways to decrease the switching costs for the users of the competitor's wireless PDA platforms.

The existing literature on network effects in the PDA market, explains about how hardware evolution impacts application availability and vice-versa (e.g., Nair, Chintagunta, \& Dube, 2004).

This research attempts to enhance the understanding of the network effects in the enterprise wireless PDA software market and their strategic implications by developing a qualitative model that describes how these network effects and switching costs affect wireless PDA manufacturers, enterprises, and carriers.

\subsection{Research questions}

This thesis answers the following research questions:

1) How do network effects in the enterprise wireless PDA market affect stakeholders?

2) How do sources of lock-in and switching costs impact stakeholders? 


\subsection{Deliverables}

This research has the following deliverables:

1) A System dynamics (SD) model for studying the network effects in the enterprise wireless PDA market.

2) Simulation runs of the model to explore the impact of network effects on stakeholders in the enterprise wireless PDA market.

3) A case study on two wireless PDA platforms.

\subsection{Relevance}

This research is relevant for at least four groups. The first group is managers of technology suppliers, system suppliers and wireless service providers. Standardized mobile operating system (OS) can reduce costs; deliver more value-added applications and services ${ }^{6}$. Suppliers do not want to be left out when a dominant design is materializing and switching costs cause inefficiencies (Farrell \& Shapiro, 1988). Finally, an understanding how network effects influence new technology adoption may give crucial advantage over competition (Majumdar \& Venkataraman, 1998). According to Katz \& Shapiro (1986), the technologies that are sponsored have better adoption rates in

\footnotetext{
${ }^{6}$ Source: Smartphones escalate OS wars. Wireless Week, January 01, 2007. http://www. wirelessweek.com/article.aspx?id=78468
} 
markets with network effects, e.g., Symbian OS holds a solid $65 \%$ market share ${ }^{7}$ due to its sponsorship by Nokia, et. al.

The second group that this research is relevant for is enterprise and retail consumers of wireless PDA devices. Consumers want to lever their existing infrastructure and avoid investing in systems that could be incompatible with other consumers' systems, resulting in lock-in (Farrell \& Klemperer, 2007). Consumers will also want to lever their existing infrastructure.

The third group that this research is relevant for is academic researchers. Researchers are interested in the role of network effects in different markets. There is new and growing empirical literature on network theory that could provide additional information on network effects, standards formation, and technology choice by organizations. Such data based studies can answer questions about the complex competitive dynamics that characterize industries ruled by network effects (Suraz, 2005). Open compatibility standards lead to expanded network externalities and change the nature of competition (Shapiro, 2000).

The final group that this research is relevant for is public policy-makers such as the Federal Trade Commission (FTC) and the Federal Communication Commission (FCC) that are mandated to ensure consumer's interests are preserved and healthy competition exists in markets.

\footnotetext{
${ }^{7}$ Source: Mobile platforms: Symbian, that 'European operating system', December 01, 2006. http://www.computerweekly.com/Articles/2006/12/01/217955/mobile-platforms-symbian-that-europeanoperating.htm
} 


\subsection{Contribution}

This research offers at least three contributions to the academic literature and management practice.

First, this research develops a system dynamics model showing the key feedback loops between key stakeholders in the enterprise wireless PDA market.

Second, this research provides identification, analysis and strategic implications of network effects, lock-in and switching costs on stakeholders in enterprise wireless PDA platform.

Third, it provides a list of strategic actions involving network effects by two important wireless PDA platforms.. 


\subsection{Background}

\subsubsection{Brief review of the enterprise wireless PDA market}

Figure 1 shows a high-level view of the key stakeholders in the enterprise wireless PDA market.

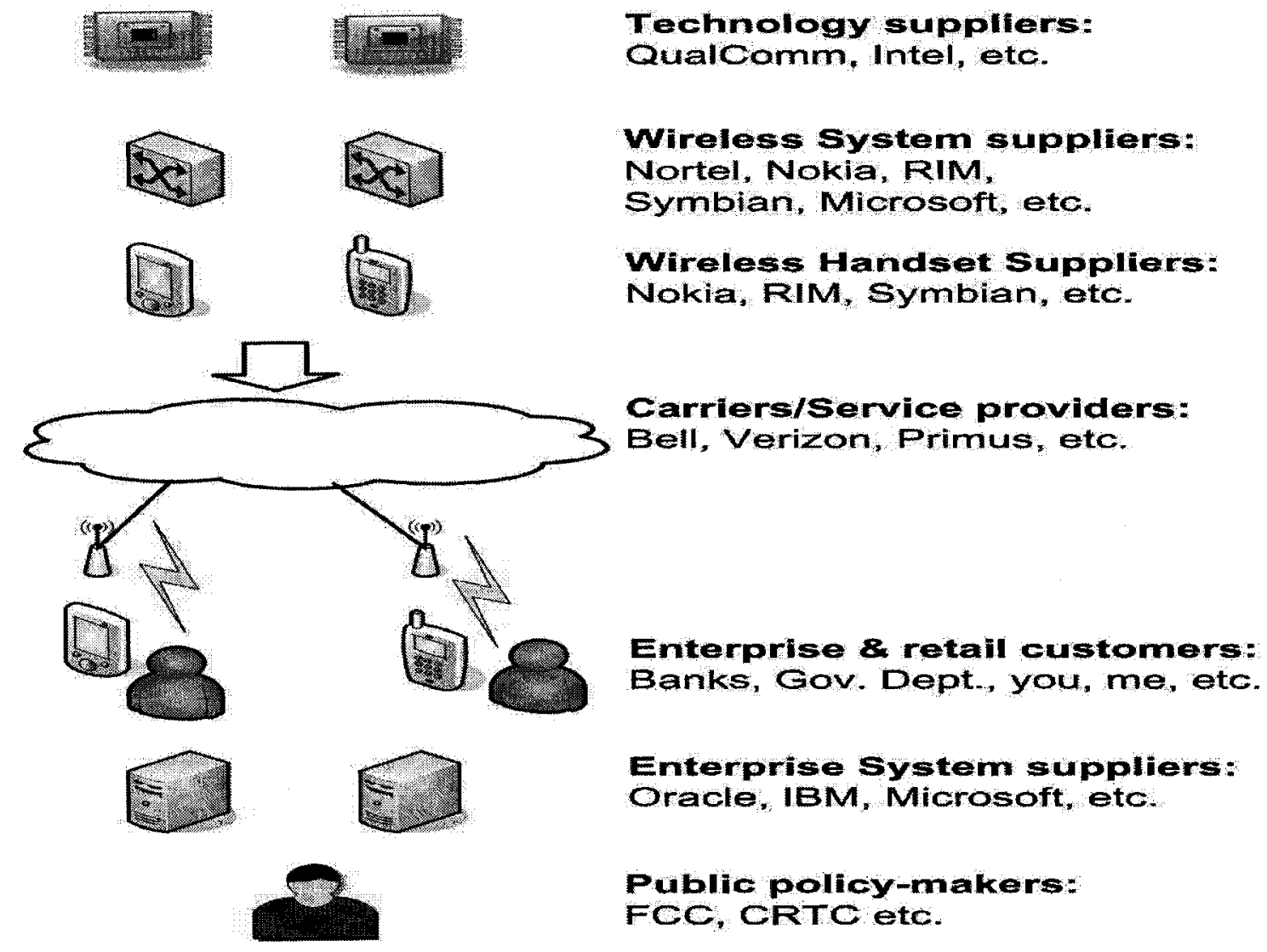

Figure 1: High level network diagram of enterprise wireless PDA market

Traditional wireless networks are voice networks and supporting data over these networks often required the services providers to overlay separate data networks over the voice networks. 
The wireless communication networks have undergone changes for four generations. They are as follows:

The $1^{\text {st }}$ generation $(1 \mathrm{G})$ the earlier wireless communication networks were point-to-point or point-to-multi-point networks, for example Advanced Mobile Phone System (AMPS). These communication networks shared the same frequency. Simultaneous use of the frequency resulted in interfering with others using the same frequency.

The $2^{\text {nd }}$ generation $(2 \mathrm{G})$ wireless communication networks are the digital networks, for example, the Code Division Multiple Access (CDMA) and Global System for Mobile communications (GSM). The $2 \mathrm{G}$ wireless networks allowed efficient sharing of the frequency by more than one user by better allocation of frequencies between users in small coverage areas known as cells. The enhanced $2^{\text {nd }}$ generation $(2.5 \mathrm{G})$ wireless networks, for example, General Packet Radio Service (GPRS), Enhanced Data rates for Global Evolution (EDGE). This generation of the wireless networks brought internet protocol (IP) based packet services.

The $3^{\text {rd }}$ generation ( $3 \mathrm{G}$ ) wireless communication networks, for example, Universal Mobile Telecommunications System (UMTS) continued the packet based evolution and offer enhanced data rates. 
The $4^{\text {th }}$ generation ( $\left.4 \mathrm{G}\right)$ wireless communication networks, for example, Long Term Evolution (LTE), Evolved UMTS Terrestrial Radio Access (E-UTRA) offer flat IP based networks and open interfaces based system nodes in the network with the goal of being able to mix and match equipment from more than one vendor ${ }^{8}$.

Wireless service providers are often challenged to meet users demands for higher performance (e.g., higher data rates, longer battery life, less dropped calls, etc.) than what is offered by these technologies while continuing to efficiently use bandwidths. These often conflicting demands require the wireless service providers to enforce tighter control on the types of devices and applications supported in their networks.

The wireless (or cellular) market, with its roots in the telephone industry, has traditionally been vertically integrated (Oliver \& Scheffman, 1995). Vertical integration refers to the extent to which resources in successive stages of the production and sale of a good are owned in common within a single firm (Alchian, 1995).

With the maturity of telephone and wireless technologies, and the introduction of government deregulation legislations, incumbent service providers had to allow access to their network to their competitors. This resulted in modularization of telephone and wireless technologies.

\footnotetext{
${ }^{8}$ Source: “Nortel's Strategy for Evolution to LTE", last accessed: January 16, 2008. http://www.nortel.com/corporate/investor/events/011608/collateral//te_teach_in_v72.pdf and "3GPP Long Term Evolution", last accessed: October 12, 2008.

http://en.wikipedia.org/wiki/3GPP_Long_Term_Evolution
} 
The battle for deregulation and competition continue in the wireless market; while parts of the system continue to be vertically integrated.

\subsubsection{Enterprise applications}

Enterprises typically have client-server software applications. These software applications are important to the day to day operations of the enterprises. The server software runs on a centralized server and serves several remote clients. Client applications are often running on individual employee's desktop or accessed via a web browser. Some of the popular client-server applications are e-mail (e.g., Microsoft Exchange $^{9}$ ), databases (e.g., Oracle ${ }^{10}$ ), customer relationship management (e.g., SAP ${ }^{11}$ ). The wireless PDA platforms enable enterprise applications to be available remotely on a wireless PDA device.

\subsection{Organization}

This research is organized into ten sections. Section 1 introduces the objective, research questions, deliverables, relevance and contribution of this research. Section 2 reviews the literature in the area of network effects, industry structure, technology life cycle and company strategy. Section 3 presents the method used to conduct this research. Section 4 provides the case study of two popular wireless PDA platforms. Section 5 presents

\footnotetext{
${ }^{9}$ Registered trademark of Microsoft Corporation, http://www.microsoft.com/

${ }^{10}$ Registered trademark of Oracle Corporation, http://www.oracle.com/

${ }^{11}$ Registered trademark of SAP AG, http://www.sap.com/
} 
elements of the dynamic causal model using the insights gained from Section 2 and 4 combined with the interviews with 3 experts in the enterprise wireless PDA market. Section 6 provides the subsystems of the enterprise wireless PDA market and discusses the formal system dynamics model. Section 7 presents how the model was reviewed. Section 8 presents various tests used to increase the confidence of the model. Section 9 presents simulation results under various scenarios. Section 10 presents conclusions, describes the limitations of this study, and identifies future research opportunities. Lastly, the Appendixes contain the simulation results and model review questionnaire. 


\section{$2 \quad$ Literature review}

This chapter is organized into six sections. The first section reviews the existing literature on network effects. The second section reviews the technology life-cycle and the strategies in the markets with network effects. The third section reviews the industry structure. Lastly, the fourth section provides a summary of lessons learned from the literature review.

\subsection{Network effects}

When the value of a product or service to one user depends on how many other users use it we can say the network effects ${ }^{12}$ are in play (Shapiro \& Varian, 1999).

In recent years, Wireless PDA devices have gained greater adoption among business and retail consumers. For example PDA shipments grew 42.7\% in 2006 compared to 2005 and shipments are expected to grow (Cozza \& Kort, 2007). Another example is Microsoft's attempt to leverage their dominance in the PC market in the enterprise wireless PDA market (Yankee Group, 2001), while Ericsson, Nokia, Motorola and Psion have formed a joint venture to release Symbian OS for wireless handheld devices, to combat Microsoft's dominance in the field.

\footnotetext{
${ }^{12}$ Network effects is also referred in the literature as network externalities, demand-side economies of scale
} 
In his seminal paper, Arthur (1996) discussed how a product, company or technology can get ahead of its competitors by chance or clever strategy. And how increasing returns can magnify this advantage, and the product or company or a technology can go on to lock in the market. Technological products do not stand alone. They depend of the existence of other products and other technologies and require different strategies to be successful.

Companies in the markets with network effects influence expectations, facilitate coordination, and achieve compatibility. Coordination required by systems competition is often more extensive and explicit, employing tools including common ownership of various components suppliers, long-term contracts, and industry-wide standard-setting bodies (Katz \& Shapiro, 1994).

Sales of the enterprise wireless PDA market have doubled in $2008^{13}$, and are expected to continue to grow. In this growing competitive market, it is important to understand what role network effects play, and find out how various stakeholders can lever these network effects to their advantage.

As suggested by (Shapiro \& Varian, 1999: 177) in a winner-take-all market, the technology starting with an initial lead, perhaps $60 \%$ of the market can grow to nearly $100 \%$, while the technology starting with $40 \%$ of the market can decline to $10 \%$. Considering other things being equal, it is better to be connected to a bigger network than

\footnotetext{
${ }^{13}$ Source: Gartner: Smart phone sales double in North America. USA Today, June 06, 2008. http://www.usatoday.com/tech/products/2008-06-06-1187969115_x.htm
} 
a smaller one, as bigger networks can generate the positive feedback. Positive feedback makes the strong get stronger and the weak get weaker.

Srinivasan, Lilien \& Rangaswamy (2004) suggest that the survival of a pioneer in a networked market depends on networked utility that results from other users in the network. Pioneers that focused on promoting and delivering network utility to customers survived, but firms that focused on only the standalone utility tended to fail.

Lee, Lee, \& Lee (2006) found that purchase decisions in markets with network effects may not always be based on the installed-base of a given technology. Customer's selection of a technology is sometimes influenced more by the opinions and choices of his or her acquaintances than by the size of an installed base. This "local bias" may be seen prominently in products or services with direct network effects (e.g., exchanging files). Adoption of products is affected by virtual connections between players, e.g., Internet and online commerce (Chakravorti, 2004).

However, in markets with indirect network effects (e.g., PC or a PDA), the decision to purchase also depends on the availability of particular software products tailored to that individual's needs. When the importance of compatibility is high, the effect of local bias in a highly clustered network is diluted, making the market tip toward a single dominant technology (Lee et. al., 2006). 
Suraz (2005), states that strength of ties is typically measured as a function of frequency of contact, although it may also comprise reciprocal obligations, emotional intensity, and intimacy. Research on the strength of strong ties has pointed out that a small network with strong ties will be particularly valuable in facilitating organizations' attempts to adopt their core features in response to environmental change.

Markets with network effects do not always result in "winner-take-all" conditions. One reason for this is switching costs and local bias. Overemphasizing the installed base, while ignoring network structure, can mislead practitioners (Lee et. al., 2006).

Suraz (2005) found that market conditions can lead to multiple equilibriums. If customers' decisions are based not on the overall installed base, but on the base in a specific part of the network with which they have strong ties, then the notions of excess inertia and critical mass should be reconsidered when it comes to technology selection. Industries in which weak ties predominate would revert to a monolith that cannot be broken into parts on the basis of tie strength.

The probability that a user chooses a given technology over competing alternatives is positively associated with the relative network size of that technology in a specific part of the total network where the user has strong ties (Suraz, 2005).

Strong-ties network effects are stronger than classical network effects as a predictor of the probability that a user chooses a given technology over competing alternatives. 
Transparency of the underlying technology (e.g., CDMA, GSM) could lead to the user adopting a technology without realizing that their technological choice is irreversible i.e., they are locked in to that technology (Suraz, 2005).

The importance of complementors, technological superiority, and vendor credibility are important in customers' choice. Small networks characterized by strong ties tend to be more valuable for organizations than large networks with weak ties, particularly under conditions of environmental change and uncertainty (Suraz, 2005).

Suraz (2005) states that, if the strength of network effects varies with the different stages of an industry value chain, then it follows that some technologies could be locked out of an industry in its upstream stages, before end customer dynamics kick off.

\subsection{Technology life-cycle and company strategy}

Satyanarayanan (1996) has shown that the capabilities offered by wireless handheld devices continue to be challenged due to the constraints intrinsic to mobile devices. For example, limited capabilities, finite energy source.

In spite of the technological advances made in handheld and wireless technologies, the demands placed on the mobile devices continue to challenge the capabilities offered by mobile devices. This may indicate that the mobile PDA market favors interdependent 
architectures, integrated companies and companies that offering functionality and reliability.

Christensen, Raynor \& Verlinden (2001) suggested that when technology does not offer the performance that the market is demanding, the market-forces drive towards an integrated product. While on the other hand, if the performance offered by the technology is more than what the market is demanding, then the market-forces drive towards a modular product (see Figure 2).

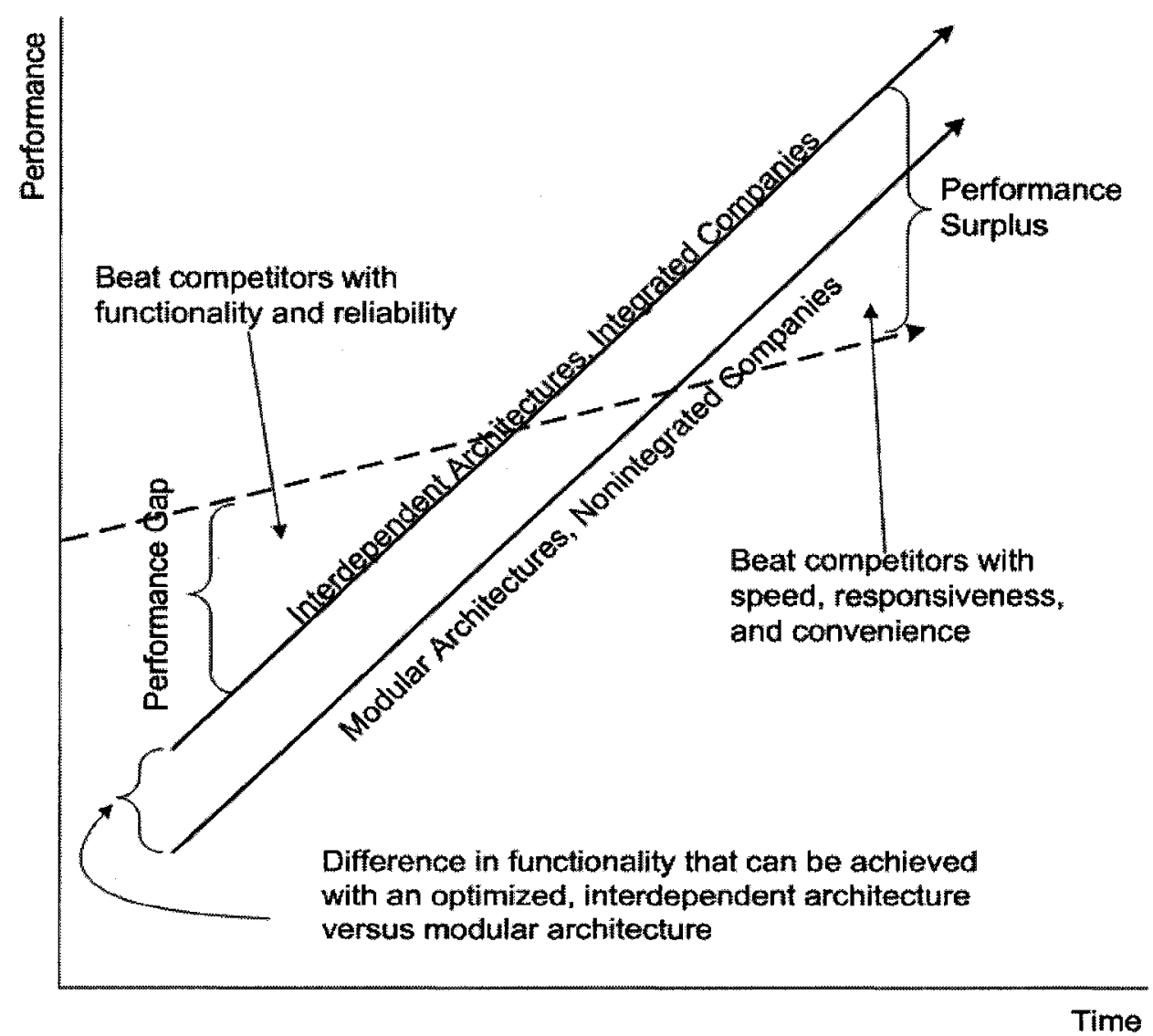

Figure 2: Product architectures and integration

Adapted from: Christensen \& Raynor (2003: 127) 
Industry analysts acknowledge that an integrated solution is superior in the enterprise wireless PDA market. For example, Rob Enderle, industry analyst at the Enderle Group said $^{14}$ :

"The advantage that RIM holds over Microsoft is that RIM makes both the software and hardware. It also offers the services to help companies deploy the devices, providing a cohesive single offering."

The enterprise wireless PDA market is considered a networked market, bringing products and innovations to market in a networked market need different strategies (Chakravorti, 2004; Arthur, 1996).

Competitive strategies are unique in markets with network effects. Chakravorti (2004) says that to ensure the adoption of a new product, the innovator must analyze the causes of the existing equilibrium and carefully deconstruct it. The innovator must then try to create a new status quo by getting a large number of network participants to choose its product as their new "best" choice. Companies often have to strike agreements with other players or make sacrifices if they want to tip the balance in favor of their offerings.

Market's hostility towards innovations is stronger when players are interconnected. In a networked market, each participant will switch to a new product only when it believes others will do so too (Chakravorti, 2004).

\footnotetext{
${ }^{14}$ Source: "New Microsoft software takes aims at RIM customers", 22 October 2007, Reuters News. http://www.reuters.com/article/ousiv/idUSN2227924420071023
} 
"Get-big-fast" strategies are not always the right strategy in markets with network effects. Market dynamics and the rate of capacity adjustments need to be studied before rapidly expanding capacity, cutting prices, and exploiting positive feedbacks faster than rivals (Sterman, Henderson, Beinhocker, \& Newman, 2007).

Companies use several tactics to limit the adoption of a standard. One tactic is to avoid the compatibility between the company's product and the new standard. Another tactic is to launch better products than those of the sponsor of the new standard. Finally, another tactic is to adopt the new technology to rely on installed base of customers or reputation to overcome the sponsor of the standard. When a firm is unable to strongly influence the market to adopt the standard, it faces a great uncertainty. Then an efficient trade-off lies in trying to appear at the same time different from competitors and similar to them, looking both for differentiation and legitimacy (Lecocq \& Demil, 2006).

In a standards war conditions offering discounts to attract large, visible, or influential customers is unavoidable. Before offering deep discounts, firms should answer these questions. First, will the customer base the firm's target customer base use the product and generate the positive network externalities for other high paying customers? Second, how much is it really worth for the firm to build their installed base? Third, where is the offsetting revenue stream, and when will it arrive? Fourth, is the firm is being overly optimistic (Shapiro \& Varian, 1999)? 
Arthur (1996) states that, a new product often has to be two or three times better in some dimension - price, speed, and convenience - to dislodge a locked-in rival. Technological products do not stand alone. To succeed, a company needs to manage the cross-product positive feedbacks actively to lock-in its market. In fact, technological ecologies are now the basic units for strategy in the knowledge-based world. Players compete not by locking in a product on their own but by building webs - loose alliances of companies organized around a mini-ecology - that amplify positive feedbacks to the base technology.

Markets with strong network effects result in consumers placing high value on compatibility. However supporting compatibility can be rather expensive and may not be the right strategy depending on the market conditions (Shapiro \& Varian, 1999).

Arthur (1996) suggests that, to be successful in the knowledge-based markets, the following questions needs to be answered: Do I understand the feedbacks in my market? Which ecologies am I in? Do I have the resources to play? What games are coming next?

As the number of users increase in a network positive feedback may decrease. Incentives to reduce propensity of free-riding in large networks may be necessary (Asvanund, Clay, Ramayya \& Smith, 2004). 
Shapiro \& Varian (1999: 116) state that customer lock-in is the norm in the information economy. Table 1 shows the various types of lock-in and the associated switching costs.

\begin{tabular}{|c|c|c|}
\hline Type of lock-in & Definition & Switching costs \\
\hline $\begin{array}{l}\text { Contractual } \\
\text { commitments }\end{array}$ & $\begin{array}{l}\text { A contractual commitment to } \\
\text { buy from a specific supplier }\end{array}$ & or liquidated damages \\
\hline $\begin{array}{l}\text { Durable } \\
\text { purchases }\end{array}$ & $\begin{array}{l}\text { Need for purchasing follow- } \\
\text { on products that work with } \\
\text { durable equipment }\end{array}$ & $\begin{array}{l}\text { Replacement of equipment; tends to } \\
\text { decline as the durable ages }\end{array}$ \\
\hline $\begin{array}{l}\text { Brand specific } \\
\text { training }\end{array}$ & $\begin{array}{l}\text { Training required to work } \\
\text { with a new brand of product } \\
\text { with equal proficiency }\end{array}$ & $\begin{array}{l}\text { Learning a new system, both direct } \\
\text { costs and Lost productivity' tends to } \\
\text { rise over time }\end{array}$ \\
\hline $\begin{array}{l}\text { Information and } \\
\text { databases }\end{array}$ & $\begin{array}{l}\text { Information and databases } \\
\text { stored in specialized/ } \\
\text { proprietary format }\end{array}$ & $\begin{array}{l}\text { Converting data to new format; tends } \\
\text { to rise over time as collection grows }\end{array}$ \\
\hline $\begin{array}{l}\text { Specialized } \\
\text { suppliers }\end{array}$ & $\begin{array}{l}\text { Ability of a new suppliers to } \\
\text { offer comparable equipment }\end{array}$ & $\begin{array}{l}\text { Funding of new supplier; may rise } \\
\text { over time if capabilities are hard to } \\
\text { find/maintain }\end{array}$ \\
\hline Searching costs & $\begin{array}{l}\text { Costs incurred by buyers and } \\
\text { sellers to find each other and } \\
\text { establish a business } \\
\text { relationship }\end{array}$ & $\begin{array}{l}\text { Combined buyer and seller search } \\
\text { costs; includes learning about quality } \\
\text { of alternatives }\end{array}$ \\
\hline $\begin{array}{l}\text { Loyalty } \\
\text { programs }\end{array}$ & $\begin{array}{l}\text { Programs that reward } \\
\text { customers to buy from single } \\
\text { vendor }\end{array}$ & $\begin{array}{l}\text { Any lost benefits from incumbent } \\
\text { supplier, plus possible need to } \\
\text { rebuild cumulative use }\end{array}$ \\
\hline
\end{tabular}

Table 1: Types of lock-in and associated switching costs

Adapted from: (Shapiro \& Varian, 2003: 117) 
Switching costs are significant, and corporate information officers (CIOs) think seriously before changing systems (Shapiro \& Varian, 2003: 11). Shapiro \& Varian (1999) state that switching costs grow or shrink with time and follows predictable pattern. Figure 3 shows different phases in a customer lock-in cycle: (i) the brand selection phase is when the customer chooses a new brand. When a customer picks a specific brand the first time, that customer will not have preference for any specific brand based on lock-in.

Customers only get lock-in by virtue of choices they make. (ii) the customer actively uses the new brand and takes advantage of whatever special offers that made available during the sampling phase. (iii) customers move into entrenchment phase when they really gets used to the new brand, develops a preference for that brand over others, and becomes locked in to that brand by making complementary investments. Suppliers usually tries to drag out this phase and delay active consideration of other brands, hoping that customer's switching costs will go up. (iv) customers move into the lock-in phase when the switching costs become prohibitively expensive. Following the first round around this lock-in cycle, customer returns to the brand selection phase, during the subsequent brand selection phase, the customer's switching costs are higher than the previous round and influence the subsequent purchase decisions.

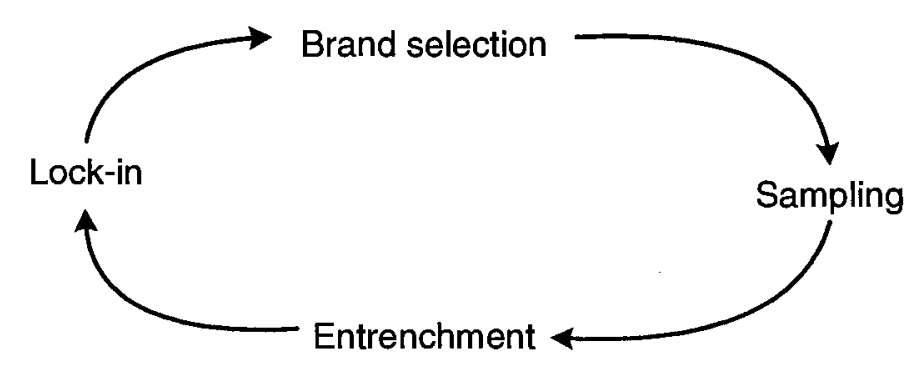

Figure 3: Lock-in cycle

Adapted from: Shapiro \& Varian (1999: 132) 
Switching costs work in a nonlinear way. It is ten times harder to convince ten people connected in a network to switch to a different incompatible network than convincing one customer to switch. This is because it is difficult to coordinate the switching.

When pursuing property rights strategy, incumbents can license their technologies to deter competitors from investing in their own technologies. Opening a standard is not only a matter of increasing quality but also a way to attract coopetitors and produce positive feedbacks in terms of installed-base customers or producers (Lecocq \& Demil, 2006). Lecocq \& Demil (2006) also point out that, in the standards wars, some particular resources and assets play a crucial role. The sponsor of the technology can benefit from pioneering advantages, proposing a greater number of complementary products can convince the consumers to adopt a technology. Also, the trademarks or reputation of a firm impact the creation of positive anticipation from consumers.

Chakravorti (2004) suggests that, in order for innovations to be successful in the networked markets, an innovator needs to align with power players (also known as network hubs) in the network. Through these hubs, the innovator can reach virtually everyone in the network in a short series of steps and induce them to change behaviors and get to the desired endgame. However, most companies do not realize that it is difficult for innovations to gain footholds or develop critical mass without creating benefits for the hubs. Smart companies get the hubs to back them by positioning their innovations as complements to the power players' products and by giving power players a 
share of the value created by the innovation. To create momentum for a new product, the innovator must orchestrate changes in three core groups: the players that add to the innovation's benefits, the players that act as channels to adopters, and the adopters themselves.

The more externalities are created, the more a standard will be a success in terms of diffusion and the more it will feed further externalities for coopetitors and consumers. The more a standard is a success, the more it develops the resources of the sponsor in terms of installed base of consumers, reputation, or legitimacy (Lecocq \& Demil, 2006).

\subsection{Industry structure}

Porter (1980) recommends that a sound understanding of the fundamental economics of an industry, or the structure of an industry, is one of the primary building blocks in formulating the strategy of a company. It provides the basis for identifying risks and opportunities, and usually helps to define the overall thrust of strategies that must be considered in detail. Further, it provides an indication of the objectives that can reasonably be expected to avoid setting unrealistic goals that can demoralize an organization. Industry structure can be studied using Porter's model (Porter, 1980). Competitive actions (e.g., "standards wars") by stakeholders impact the industry structure. 
Economides \& Katsamakas (2006) state that, the profits in an industry depend on the industry structure. Among the industry structures - vertically-integrated proprietary, vertically-disintegrated proprietary, and open source platform with proprietary applications, total industry profits are highest for the vertically integrated proprietary industry structure. Alchian (1995) states that, a vertically-integrated industry structure strives when it is difficult to specify, measure and enforce the promised performance in transactions across markets or firms. On the other hand, vertical disintegration is efficient if the desired successive services can be easily specified, measured and enforced.

When a company cannot influence the market by contributing significantly to the emergence of a new standard, it usually avoids being locked out, by splitting its own capacities into two standards. Imposing a standard often requires alliances with other companies to promote the new technology. If the customers do not anticipate the success of a technology, the technology will fail. So, the sponsor of a new standard has to rapidly develop complementary products to generate positive anticipations. As the returns increase, the leader has an advantage over competitors and benefits from a large installedbase of customers (Lecocq \& Demil, 2006).

In markets with increasing returns, Arthur (1996) suggests there are several reasons for some markets to be subjected to increasing returns: (i) up-front costs - causing a barrier to enter the market for new entrants (ii) network effects - products in an increasing returns market need to be compatible with network of users, as the products gain 
prevalence, the more likely it will emerge as a standard (iii) customer lock-in - due to the costs associated with replacing a product the increasing returns markets are subjected to lock-in.

\subsection{Lessons learned from the literature review}

The lessons learned from the different streams of literature reviewed in this section are:

1) Markets with network effects need different strategies to bring innovations to market. "Get-big-fast" strategies are not always the right strategy in the markets with network effects and network effects do not always result in a winner-take-all market.

2) Choose the modular or integrated architecture based on the performance demands of the market and what the current technology can offer.

3) Word of mouth feedback significantly contributes to the adoption in the networked markets.

4) Licensing of technologies allows flexibility and deters competitors from investing or developing their own technologies.

5) Lock-in is the norm in the networked markets.

6) Transparency of the underlying technologies can lead users to adopt a technology without realizing they are locked-in to that technology. For example, a GSM-based wireless PDA user may unknowingly get locked-in to the wireless PDA platform that the PDA is based on.

7) The likeliness that a user adopts a technology depends on the size of the network for that technology within the total network where the user has strong ties. 
8) For a technology to be successful in a networked market, it needs to create value to the power players in the network.

9) Performance demands of a product in the market and the product architectures are interrelated. Integrated architectures succeed in markets that demand higher performance than what technology can deliver; on the other hand modular architectures succeed in the markets that are contended with the performance delivered by existing technology. 


\section{$3 \quad$ Research method}

This chapter is organized into three sections. In the first section I present the rational for using system dynamics. In the second section I present the research approach used. Lastly, in the third section I present the implementation.

To produce the deliverables of this research, several research activities are undertaken as detailed in Table 2. I started the research by conducting a literature review in the areas of network effects, technology life-cycle and company strategy, and industry structure. Following the literature review, I developed a case study of two popular wireless PDA manufacturers to understand network effects and their potential for strategic advantage. Following the case study, I conducted informal discussions and interviews with managers who have extensive experience in the enterprise wireless PDA market. During these interviews, I sought to validate my findings from the case study, and to understand the structure and the relationships between stakeholders of the market. Using the knowledge gained from this exercise, I developed a first draft of the subsystem diagram showing the stakeholders and the transactions between them.

Having gained an understanding of the relationships between the various market stakeholders, I started looking for a research framework that could help me effectively model the stakeholders together with feedbacks and delays in their interactions. In the spring of 2007, my supervisor introduced me to the System Dynamics (SD) framework 
along with a reference to a thesis using SD that he had supervised (Yepez, 2004). I used this thesis as a reference during my research.

I started a self-learning exercise using online and library SD resources in the summer of 2007. At that time I contacted Ivan Taylor, a local System Dynamics practitioner with several years of experience in this field, through the System Dynamics group in Ottawa. After a couple of meetings, he agreed to provide coaching and guidance during my research. This research applies the system dynamics framework (Forrester, 1995; Richardson \& Pugh, 1981; Sterman, 2000) to study the network effects in the enterprise wireless PDA market.

In the summer of 2007, my supervisor introduced me to the research and development (R\&D) Director of a wireless PDA manufacturing company. The discussions with this contact proved very valuable in setting the direction and scope of the research.

In the spring of 2008 , I created my first skeleton SD model based on case studies and preliminary interviews. After a series of five interviews and refinements, I used this first model to develop a formal SD model. I calibrated the formal model using the quarterly financial data of a specific wireless PDA manufacturer. I then used this formal SD model to generate insights and answer the research questions.

Using the initial model as a basis, I conducted a series of structured interviews with persons having extensive experience in enterprise wireless PDA market and continue to 
refine both the subsystem diagram and the initial model to final subsystem diagram and a formal model.

After further refinements, modeling, calibration and structured interviews a formally reviewed system dynamics model was developed. This final model has been used to simulate different scenarios and their strategic implications. 


\begin{tabular}{|c|c|c|}
\hline Objective & Activity & Outcome \\
\hline $\begin{array}{l}\text { Develop an understanding on } \\
\text { network effects, strategies in } \\
\text { markets with network effects, } \\
\text { technology life-cycle, industry } \\
\text { structure }\end{array}$ & $\begin{array}{l}\text { Reviewing literature; } \\
\text { writing }\end{array}$ & $\begin{array}{l}\text { Summary of insights } \\
\text { from the extant literature }\end{array}$ \\
\hline $\begin{array}{l}\text { Develop a case study of two } \\
\text { popular enterprise PDA } \\
\text { platforms in North America } \\
\text { detailing actions considering } \\
\text { network effects, sales data }\end{array}$ & $\begin{array}{l}\text { Reading press releases, } \\
\text { industry publications, } \\
\text { proprietary data bases, } \\
\text { writing }\end{array}$ & $\begin{array}{l}\text { A case study on two } \\
\text { enterprise wireless PDA } \\
\text { platforms }\end{array}$ \\
\hline $\begin{array}{l}\text { Describe enterprise wireless } \\
\text { PDA market - history, } \\
\text { stakeholders and } \\
\text { interrelationships }\end{array}$ & $\begin{array}{l}\text { Reading publicly available } \\
\text { information; discussions } \\
\text { with market experts; } \\
\text { writing }\end{array}$ & $\begin{array}{l}\text { Sub-system diagram of } \\
\text { enterprise wireless PDA } \\
\text { market }\end{array}$ \\
\hline $\begin{array}{l}\text { Develop systems dynamics } \\
\text { model of the enterprise wireless } \\
\text { PDA market }\end{array}$ & $\begin{array}{l}\text { Learning systems } \\
\text { dynamics; interviewing } \\
\text { experts; model coding, } \\
\text { review and testing }\end{array}$ & $\begin{array}{l}\text { Final sub-system } \\
\text { diagram, formal model } \\
\text { of enterprise wireless } \\
\text { PDA market; } \\
\text { suggestions for model } \\
\text { extension and simulation } \\
\text { scenario considerations }\end{array}$ \\
\hline Simulation of scenarios & SD simulation & $\begin{array}{l}\text { Simulation results under } \\
\text { different scenarios }\end{array}$ \\
\hline $\begin{array}{l}\text { Develop managerial insights } \\
\text { from validated simulations }\end{array}$ & $\begin{array}{l}\text { Thinking; discussions with } \\
\text { market experts; writing }\end{array}$ & $\begin{array}{l}\text { Enhanced understanding } \\
\text { of the enterprise wireless } \\
\text { PDA market dynamics }\end{array}$ \\
\hline
\end{tabular}

Table 2: Research objectives, associated activities and outcomes 


\subsection{Rationale for using system dynamics}

System dynamics (SD) was developed by Jay W. Forrester in the 1950s (Forrester, 1995).

SD gives us a way to see through chaos, understand complexities and to manage better.

System dynamics framework is used for analyzing problems with transient nature and study complex systems with networks of feedback. A system level view of components, interactions and delays can give good understanding of the system and can enable to implement better policies.

Davis, Eisenhardt \& Bingham (2007) maintain that simulation methods contribute effectively to theory development. SD simulation method is particularly applicable for understanding the behavior of systems with complex causality and timing.

The system dynamics approach applies to dynamic problems arising in feedback systems. The purpose of the system dynamics modeling is to gain understanding, so that the problem to which the model is addressed may be solved or minimized. A system dynamics model exposes its assumptions about a problem for criticism, experimentation, and reformulation (Richardson \& Pugh, 1981).

System dynamics takes the philosophical position that feedback structures are responsible for the changes we experience over time. The premise is that dynamic behavior is a consequence of system structure. System dynamics allows studying closed loop systems. System dynamics proposes that the problems observed in the system are being caused by 
agents inside (i.e., endogenous to) the system. The feedback structure of a system generates its behavior (Sterman, 2000).

An understanding behavior of feedback system is a goal of the system dynamics approach. The feedback structures of real problems are often so complex that the behavior they generate over time can usually be traced only by simulation (Richardson \& Pugh, 1981: 7).

System dynamics models can be a qualitative model or a quantitative model (Coyle, 1999). This research uses a qualitative approach to model development (Luna \& Lines, 2003), to develop a formal model of enterprise wireless PDA market dynamics to study the network effects and their strategic implications.

\subsection{Research approach}

This research uses the system dynamics modeling approach from Richardson \& Pugh (1981) for developing the model, which stresses the iterative approach to the model development. Richardson \& Pugh (1981: 16) notes:

"At a number of stages along the way one's the understanding of the system and the problems are enhanced by the modeling process, an understanding further aids the modeling effort is increased. Done properly, a system dynamics study should produce policy recommendation that can be presented, explained, and defended without resorting to the formal model. The model is a means to an end, and that end is understanding." 


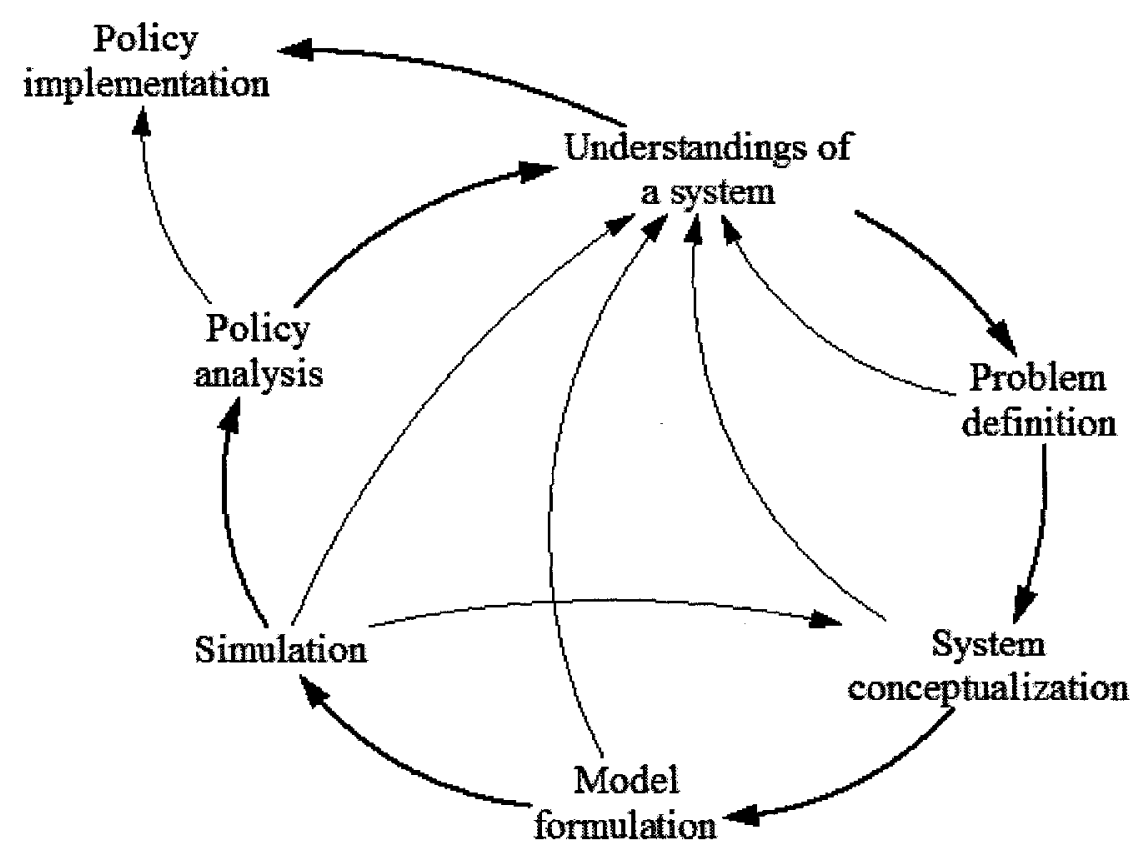

Figure 4: Overview of the system dynamics modeling approach

Adapted from: Richardson \& Pugh (1981: 17)

Luna \& Lines (2003) had developed an extensive review of best practices for collecting and analyzing qualitative data for system dynamics modeling. This research uses those best practices. Interviews are considered best method for Model conceptualization, Model formulation and, Model testing. Table 3 lists potential qualitative methods for the system dynamics modeling. 


\begin{tabular}{|c|c|c|}
\hline \multicolumn{2}{|c|}{ Steps in the modeling process } & $\begin{array}{l}\text { Qualitative methods potentially } \\
\text { useful }\end{array}$ \\
\hline \multirow[t]{2}{*}{ Conceptualization } & Problem definition & \multirow{2}{*}{$\begin{array}{l}\text { Techniques that can be used for } \\
\text { problem identification and } \\
\text { elaboration of a dynamic } \\
\text { hypothesis: } \\
\text { - Interviews } \\
\text { - Oral history } \\
\text { - Focus groups } \\
\text { - Hermeneutics } \\
\text { - Discourse analysis } \\
\text { - Content analysis }\end{array}$} \\
\hline & System conceptualization & \\
\hline Formulation & Model formulation & $\begin{array}{l}\text { Techniques to obtain parameters } \\
\text { and policies: } \\
\text { - Interviews } \\
\text { - Focus and Delphi groups } \\
\text { - Content analysis } \\
\text { - Participant observation }\end{array}$ \\
\hline \multirow[t]{2}{*}{ Testing } & $\begin{array}{l}\text { Analysis of model } \\
\text { behavior }\end{array}$ & \multirow{2}{*}{$\begin{array}{l}\text { Techniques to obtain expert } \\
\text { judgment about model behavior } \\
\text { structure and behavior: } \\
\text { - Interviews } \\
\text { - Focus groups } \\
\text { - Delphi groups } \\
\text { - Experimental approaches }\end{array}$} \\
\hline & Model evaluation & \\
\hline
\end{tabular}

Table 3: Modeling steps and potential qualitative methods

Adapted from: Luna \& Lines (2003) 
I interviewed three domain experts in the enterprise wireless PDA market who work at a wireless PDA manufacturer. It was agreed that only publically available information would be shared during these interviews, due to the confidentiality nature of the information. These interviews focused on the network effects in the enterprise wireless PDA market during $1999-2007$. The start of the study period corresponds to the year in which the wireless PDA manufacturer had entered the enterprise wireless PDA market with their successful enterprise wireless PDA platform. The end of the study period corresponds to the year in which the data collection has ended. The following table shows the various stages of this study along with various research activities conducted. 


\begin{tabular}{|c|c|c|}
\hline $\begin{array}{l}\text { System dynamics } \\
\text { modeling stage }\end{array}$ & Inputs & Outputs \\
\hline Problem definition & $\begin{array}{l}\text { Literature review, case } \\
\text { study data and initial } \\
\text { contacts }\end{array}$ & $\begin{array}{l}\text { Define problem dynamically by } \\
\text { identifying: } \\
\text { ○ Time horizon } \\
\text { ○ Key variables and reference } \\
\text { modes } \\
\text { ○ Key delays }\end{array}$ \\
\hline $\begin{array}{l}\text { System } \\
\text { conceptualization }\end{array}$ & $\begin{array}{l}\text { Literature review, case } \\
\text { study data, SD coaching and } \\
\text { interviews }\end{array}$ & $\begin{array}{l}\text { Model purpose and system } \\
\text { boundary } \\
\text { - Feedback structures using causal } \\
\text { loop diagrams } \\
\text { - Define dynamic hypothesis }\end{array}$ \\
\hline Model formulation & $\begin{array}{l}\text { Historical data, SD } \\
\text { coaching and interviews }\end{array}$ & $\begin{array}{l}\text { - Translate model structure into } \\
\text { equations } \\
\text { - Validated model structure and } \\
\text { loop explanations with experts } \\
\text { - Test model }\end{array}$ \\
\hline Simulation & $\begin{array}{l}\text { Formal SD model and } \\
\text { historic data }\end{array}$ & - Base run \\
\hline Policy analysis & $\begin{array}{l}\text { Simulation scenarios based } \\
\text { on based on market entry, } \\
\text { switching costs and shocks }\end{array}$ & $\begin{array}{l}\text { Analysis of model behavior } \\
\text { under different scenarios }\end{array}$ \\
\hline $\begin{array}{l}\text { Understandings of } \\
\text { a system }\end{array}$ & $\begin{array}{l}\text { Insights from modeling and } \\
\text { simulation runs }\end{array}$ & $\begin{array}{l}\text { Enhanced understanding of role } \\
\text { of network effects, lock-in and } \\
\text { switching costs in the enterprise } \\
\text { wireless PDA market }\end{array}$ \\
\hline
\end{tabular}

Table 4: System dynamics modeling stages, inputs and outputs 


\subsubsection{Problem definition}

The first stage of the research was the identification of an interesting problem in the technology diffusion and network externalities, a topic of mutual interest to my supervisor and me. This was accomplished by studying the various news sources, market trends and literature. During this stage the wireless PDA market was growing and Microsoft's Windows Mobile was gaining market share ${ }^{15}$ in the wireless PDA market. It was unclear if Microsoft's gains in this market were due its monopoly in the Personal Computer (PC) market and the associated network externalities. Given the nature of the problem, system dynamics was identified as a suitable methodology to explore this research.

Once the research problem was identified, a research proposal discussing the research problem, method and deliverables was prepared.

The draft model of the enterprise wireless PDA market was developed after the review of literature, market reports on enterprise wireless PDA market, news articles, case study, and informal interviews with experts in the enterprise wireless PDA market with backgrounds in the marketing and research \& development.

During this step, the key variables along with their reference modes (i.e., patterns over time) were identified. Specifying the time horizon, graphing important variables, and

\footnotetext{
${ }^{15}$ Microsoft's Windows Mobile operating system accounted for $54.2 \%$ of PDA platforms sold in the second quarter 2006. Source: "Wireless providers push PDA shipments to new high". http://www.computerworld.com/action/article.do?command=viewArticleBasic\&articleId=9002243
} 
inferring graphs of other significantly related variables, produced the problem focus for this study.

\subsubsection{System conceptualization}

During this stage, I started a self-study of the System Dynamics framework and made initial discussions with experts in the field of wireless technologies and enterprise wireless PDA market were contacted. These initial contacts helped in scoping the research problem.

Parallel to these initial discussions; I started to look for local system dynamics experts and fortunately made contact with Ivan Taylor, a Senior System Dynamics consultant. Ivan provided much needed model coaching and guidance during this stage.

Forrester (1994) recommends a case study as a good way to conceptualize systems. During the system conceptualization stage, I started the case study on the two wireless PDA platforms; (i) BlackBerry by RIM and (ii) Palm OS by Palm Inc. This case study included detailed examination of the press releases by each of these companies (19962007: Palm and 1999 - 2007: RIM), market research (e.g., IDC, Gartner), and quarterly financial reports of each of these companies.

By the end of this case study, a draft system dynamics model was ready. Causal-loop diagrams are used in this step of the model conceptualization and to facilitate discussions 
during the interviews. This draft model developed in this step captures the network effects in the enterprise wireless PDA market with key variables, and their causal relationships. This model includes the key variables and causal relationships identified from literature review, news articles, analyst reports, and case studies. At this point I started to look for contacts at wireless PDA manufacturing companies.

\subsubsection{Model formulation}

The following selection criteria were used for selecting the data sources for this study:

- Industry sector: Enterprise wireless PDA market in North America.

- Period: $1999-2007$.

- Sample: Enterprise wireless PDA platforms - Palm OS and BlackBerry.

- Participants: Experts with extensive knowledge in the enterprise wireless PDA market with backgrounds in the marketing and R\&D.

The observations from the earlier step were used to develop the focus for the formal interviews. The formal interviews were focused around the following topics and focused on validating and refining causal loop diagrams and SD models, identifying new variables, reference modes for the variables and, momentum policies:

- Network effects

- Adoption

- Lock-in, switching costs 
For the research, the interviewees included participants with marketing and R\&D background from a local wireless PDA manufacturer. Interviewees ranged from product line managers to directors of R\&D. Each of the participants had years of experience in this market. Each of the participants was contacted in person for interviews. During this phase, both my supervisor and my system dynamics mentor had accompanied me to the formal structural interviews with the wireless PDA manufacturer on separate occasions. Their participation gave additional rigor to the process. It was mutually agreed that no confidential information would be shared by the participant. Interviews will be conducted according to accepted interviewing best practices (Foddy, 1993) and included open-ended questions to get participants perceptions, and probing questions to get specific details. Each interview lasted around 1 to 2 hours and the summaries of discussions were transcribed and sent to the participant via electronic mail (e-mail) to ensure that no part of the discussion was misinterpreted or lost.

The initial set of interviews helped to iteratively refine the subsystem diagram and capture the mental models of these experts of the enterprise wireless PDA market dynamics using the causal loop diagrams.

Richardson \& Pugh (1981) suggest assembling the model in pieces and testing the behavior of the growing structure in stages, even if is possible to build a model all at once. 
This interview process resulted in a better understanding of the system and the development of a formal system dynamics model representing the network effects in the enterprise wireless PDA market with the valuable coaching from my system dynamics mentor. This model helped to capture the network effects in the enterprise wireless PDA market. Keeping the technological advantages of a wireless PDA platform aside, this model helped me to understand the factors that may help the success of an enterprise wireless PDA platform. This formal model is the iterative evolution of the draft model developed in the earlier step. Each iteration of model development and review resulted in an enhanced model and defined the boundary more effectively.

At the end of these series of interviews, the formal SD model was coded. This is a fully specified formal model, complete with initial conditions, equations, and variables. This was reviewed by my SD mentor and found to be satisfactory.

The final stage of the research included evaluation and critique of the model structure, its behavior (e.g., reproducing the reference modes of key variables) by the previously participated experts. The model was divided into logical subsystems. I used the causal loop diagrams during these interviews to facilitate discussion and analysis; accompanied with interactive demonstration to elicit qualitative information ${ }^{16}$ from participants.

The interviews were conducted in person with three participants. The interviews were coded under two dimensions. First, the general impressions about each microstructure of

\footnotetext{
${ }^{16}$ Sterman (2000: 585) recommends using interactively eliciting qualitative information from individual experts or small groups with firsthand experience in the system for validating the model.
} 
the model were gathered. Second, suggestions about any changes and improvements to the model were encouraged. This resulted in valuable feedback to further refine the variables and causal relationships in the formal model of the network effects in the enterprise wireless PDA market. During this process only two changes to the model were suggested.

The formal model was tested following the best modeling practices suggested by Sterman (2000). Testing included extreme conditions tests and other structural tests required to discover the flaws in the model and build confidence on the model results. The model was ready for simulation and analysis after the review process and tests were completed.

\subsubsection{Simulation and policy analysis}

The base run of the formal model was calibrated using the historic data. This base run was compared with eight scenarios based on the market entry and various shock scenarios to develop deeper understanding of the network effects, lock-in, switching costs and their strategic implications in the enterprise wireless PDA market. 


\section{A case study on enterprise wireless PDA market}

This chapter is organized as follows. First, I provide a background on the enterprise wireless PDA market and the key stakeholders. Second, I describe a case of network effects in the PDA market based on the wireless PDA platforms Palm, BlackBerry. Finally, I discuss the finding of this case and how they relate to the development of a dynamic causal model of network effects in the enterprise wireless PDA market.

In this chapter the history of two popular enterprise wireless PDA platforms is presented. The case study is based on the market dynamics of the enterprise wireless PDA platforms: BlackBerry and Palm OS between January 1999 and December 2007. This case study contributes to the development of a dynamic causal model to understand the network effects in the enterprise wireless PDA market.

This case study is based on an extensive review of (i) archives of press releases by wireless PDA platforms BlackBerry, Palm (ii) market research publications by market research firms like Gartner and (iii) discussions with practitioners in enterprise wireless PDA market with extensive experience in marketing and R\&D. 


\subsection{PDA market}

Early PDA devices started surfacing in the markets in $1993^{17}$. Manufacturers of these early PDA devices had attempted to enter the PDA market with an objective to position their PDA devices as a replacement to the personal computer. Their attempts have failed and resulted in the departure of the very high profile players like HP, Apple, etc. from the PDA market.

Palm Inc. having recognized the mistakes of the earlier players had positioned their PDA as an extension to the personal computers and the PDA market had finally taken off in $1996^{18}$. After having established the PDA market in 1996, Palm Inc had enjoyed PDA market leadership through 2000.

The early PDA devices are standalone devices and provided mainly the personal information management (PIM) functionality like phone book, calendar, etc. The PDA device with wireless connectivity was introduced by Palm Inc. in 2000 . The wireless connectivity was provided via an add-on dial-up modem ${ }^{19}$.

In line with the recommendations made by Christensen, et. al. (2001), Christensen \& Raynor (2003) - RIM choose to deliver an end-to-end fully integrated BlackBerry

\footnotetext{
${ }^{17}$ Source: "History of the Personal Digital Assistant", last accessed: October 01, 2008. http://www.handango.com/PDAHistory.jsp

${ }^{18}$ Source: "History of the Personal Digital Assistant", last accessed: October 01, 2008. http://www.handango.com/PDAHistory.jsp

${ }^{19}$ Source: "New Sleek Palm m500 and m505 Handhelds Add Expansion, Mobile Connectivity and Vibrant Color", March 19, 2001. http://www.palm.com/us/company/pr/2001/031901b.html
} 
solution. In contrast, Palm had chosen a strategy to separate its Palm OS platform business and the handset businesses to make them independent ${ }^{20}$.

The enterprise wireless PDA market can be segmented into enterprise, prosumer (professional-consumer) and consumer segments ${ }^{21}$. PDA market has several key players: PDA device manufacturers (e.g., Nokia), PDA platform manufacturers (e.g., Symbian), applications developers (e.g., Salesforce.com) and wireless service providers (e.g., Bell, Verizon). This case study focuses on the enterprise wireless PDA market segment specifically on the wireless PDA platform manufacturers and their actions in gaining market share. Figure 5 shows the stock price for RIM and Palm during the study period.

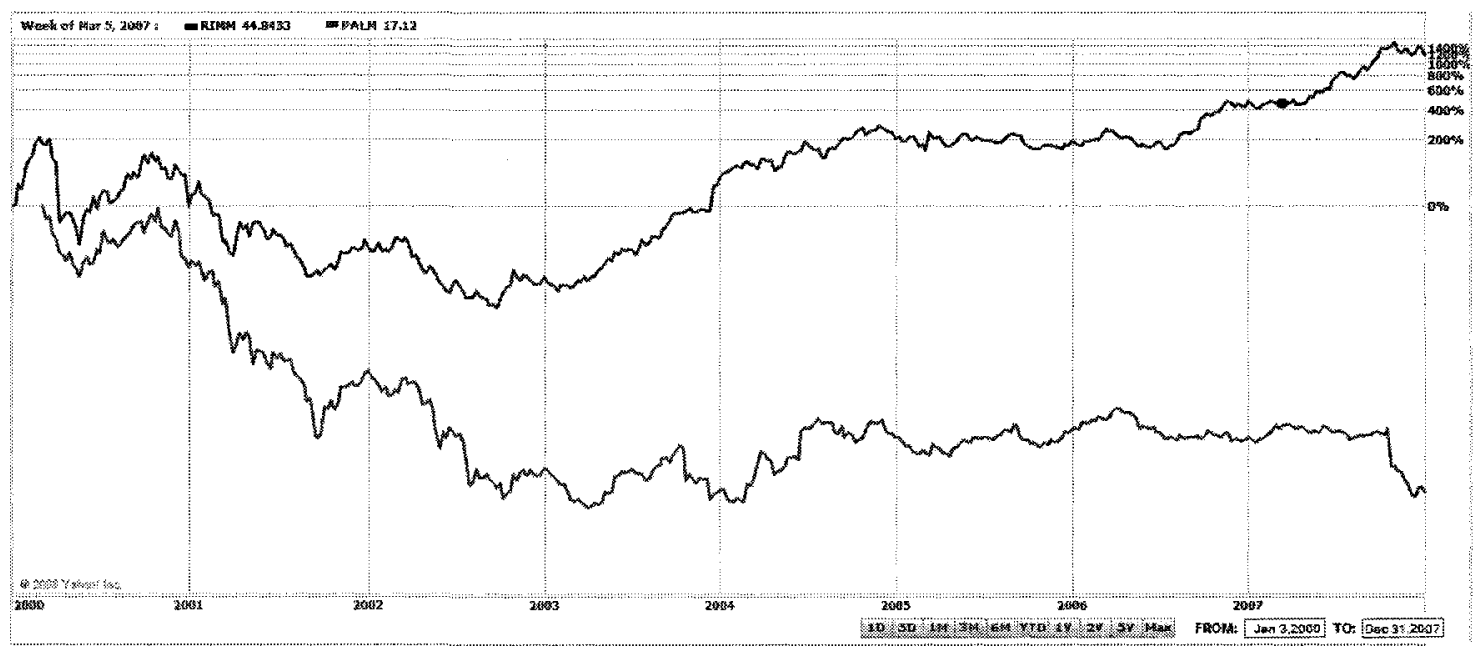

Figure 5: Stock price of RIM and Palm (2000 - 2007)

Source: Yahoo! Finance, http://finance.yahoo.com, last accessed: March 03, 2008

\footnotetext{
${ }^{20}$ Source: "Palm to separate OS business", last accessed: October 01, 2008. http://news.cnet.com/Palm-toseparate-OS-business/2100-1040_3-270722.html

${ }^{21}$ Source: "Research In Motion 2007 annual report", last accessed: October 01, 2008.

http://www.rim.com/investors/pdf/2007rim_ar.pdf
} 
Figure 5 lists the quarterly revenues of RIM from year 2001-2007.

\begin{tabular}{|c|c|c|c|c|c|c|}
\hline \multirow[t]{2}{*}{ Year } & \multirow[t]{2}{*}{ Time } & \multirow{2}{*}{$\begin{array}{l}\text { Revenue } \\
\text { (\$Thousands) }\end{array}$} & \multicolumn{4}{|c|}{ Revenue streams (\$Thousands) } \\
\hline & & & $\begin{array}{l}\text { BlackBerry } \\
\text { Handhelds }\end{array}$ & Service & $\begin{array}{l}\text { Software } \\
\text { licenses }\end{array}$ & Others \\
\hline \multirow[t]{5}{*}{2007} & YE & $\$ 3,000,000.00$ & $\$ 2,182,500.00$ & $\$ 555,000.00$ & $\$ 172,500.00$ & $\$ 90,000.00$ \\
\hline & $4 Q$ & $\$ 930,400.00$ & $\$ 679,192.00$ & $\$ 176,776.00$ & $\$ 46,520.00$ & $\$ 27,912.00$ \\
\hline & $3 \mathbf{Q}$ & $\$ 835,100.00$ & $\$ 626,325.00$ & $\$ 141,967.00$ & $\$ 41,755.00$ & $\$ 25,053.00$ \\
\hline & $2 Q$ & $\$ 658,500.00$ & $\$ 474,120.00$ & $\$ 125,115.00$ & $\$ 39,510.00$ & $\$ 19,755.00$ \\
\hline & $1 Q$ & $\$ 613,100.00$ & $\$ 435,301.00$ & $\$ 116,489.00$ & $\$ 42,917.00$ & $\$ 18,393.00$ \\
\hline \multirow[t]{5}{*}{2006} & YE & $\$ 2,100,000.00$ & $\$ 1,464,750.00$ & $\$ 393,750.00$ & $\$ 162,750.00$ & $\$ 78,750.00$ \\
\hline & $4 Q$ & $\$ 561,200.00$ & $\$ 392,840.00$ & $\$ 117,852.00$ & $\$ 28,060.00$ & $\$ 22,448.00$ \\
\hline & $3 Q$ & $\$ 560,600.00$ & $\$ 392,420.00$ & $\$ 106,514.00$ & $\$ 39,242.00$ & $\$ 22,424.00$ \\
\hline & $2 Q$ & $\$ 490,100.00$ & $\$ 343,070.00$ & $\$ 88,218.00$ & $\$ 39,208.00$ & $\$ 19,604.00$ \\
\hline & $1 Q$ & $\$ 453,900.00$ & $\$ 313,191.00$ & $\$ 77,163.00$ & $\$ 49,929.00$ & $\$ 13,617.00$ \\
\hline \multirow[t]{5}{*}{2005} & YE & $\$ 1,350,000.00$ & $\$ 931,500.00$ & $\$ 239,625.00$ & $\$ 128,250.00$ & $\$ 50,625.00$ \\
\hline & $4 Q$ & $\$ 404,800.00$ & $\$ 267,168.00$ & $\$ 68,816.00$ & $\$ 56,672.00$ & $\$ 12,144.00$ \\
\hline & $3 Q$ & $\$ 365,900.00$ & $\$ 259,789.00$ & $\$ 62,203.00$ & $\$ 25,613.00$ & $\$ 18,295.00$ \\
\hline & $2 Q$ & $\$ 310,200.00$ & $\$ 220,242.00$ & $\$ 55,836,00$ & $\$ 24,816.00$ & $\$ 9,306.00$ \\
\hline & $1 Q$ & $\$ 269,600.00$ & $\$ 183,328.00$ & $\$ 51,224.00$ & $\$ 24,264.00$ & $\$ 10,784.00$ \\
\hline \multirow[t]{5}{*}{2004} & $\mathbf{Y E}$ & $\$ 594,600.00$ & $\$ 334,462.50$ & $\$ 179,866.50$ & $\$ 47,568.00$ & $\$ 32,703.00$ \\
\hline & $4 Q$ & $\$ 210,600.00$ & $\$ 138,996.00$ & $\$ 48,438.00$ & $\$ 16,848.00$ & $\$ 6,318.00$ \\
\hline & $3 \mathbf{Q}$ & $\$ 153,900.00$ & $\$ 86,184.00$ & $\$ 44,631.00$ & $\$ 13,851.00$ & $\$ 9,234.00$ \\
\hline & $2 Q$ & $\$ 125,700.00$ & $\$ 66,621.00$ & $\$ 40,224.00$ & $\$ 11,313.00$ & $\$ 7,542.00$ \\
\hline & $1 Q$ & $\$ 104,500.00$ & $\$ 52,250.00$ & $\$ 38,665.00$ & $\$ 6,270.00$ & $\$ 7,315.00$ \\
\hline \multirow[t]{5}{*}{2003} & YE & $\$ 306,700.00$ & $\$ 121,913.25$ & $\$ 129,580.75$ & $\$ 31,436.75$ & $\$ 23,769.25$ \\
\hline & $4 Q$ & $\$ 87,500.00$ & $\$ 40,250.00$ & $\$ 35,875.00$ & $\$ 5,250.00$ & $\$ 6,125.00$ \\
\hline & $3 Q$ & $\$ 74,200.00$ & $\$ 27,454.00$ & $\$ 32,648.00$ & $\$ 8,162.00$ & $\$ 5,936.00$ \\
\hline & $2 Q$ & $\$ 73,400.00$ & $\$ 27,158.00$ & $\$ 31,562.00$ & $\$ 8,074.00$ & $\$ 6,606.00$ \\
\hline & $1 Q$ & $\$ 71,600.00$ & $\$ 27,924.00$ & $\$ 29,356.00$ & $\$ 9,308.00$ & $\$ 5,012.00$ \\
\hline \multirow[t]{5}{*}{2002} & $\mathbf{Y E}$ & $\$ 294,100.00$ & $\$ 218,369.25$ & $\$-$ & $\$-$ & $\$ 29,410.00$ \\
\hline & $4 Q$ & $\$ 66,100.00$ & $\$ 54,202.00$ & $\$-$ & $\$-$ & $\$ 11,898.00$ \\
\hline & $3 Q$ & $\$ 70,900.00$ & $\$ 58,138.00$ & $\$-$ & $\$-$ & $\$ 4,254.00$ \\
\hline & $2 Q$ & $\$ 80,100.00$ & $\$ 54,468.00$ & $\$-$ & $\$-$ & $\$ 6,408.00$ \\
\hline & $1 Q$ & $\$ 77,000.00$ & $\$ 50,050.00$ & $\$-$ & $\$-$ & $\$ 6,160.00$ \\
\hline \multirow[t]{5}{*}{2001} & YE & $\$ 221,300.00$ & $\$ 118,395.50$ & $\$-$ & $\$-$ & $\$ 24,896.25$ \\
\hline & $4 Q$ & $\$ 90,100.00$ & $\$ 43,248.00$ & \$- & $\$-$ & $\$ 6,307.00$ \\
\hline & $3 Q$ & $\$ 61,600.00$ & $\$ 36,344.00$ & $\$-$ & $\$-$ & $\$ 3,696.00$ \\
\hline & $2 Q$ & $\$ 42,500.00$ & $\$ 24,225.00$ & $\$-$ & $\$-$ & $\$ 2,975.00$ \\
\hline & $1 Q$ & $\$ 27,100.00$ & $\$ 13,550.00$ & $\$-$ & $\$$ & $\$ 6,775.00$ \\
\hline
\end{tabular}

Table 5: RIM quarterly revenues (2001 - 2007)

Source: RIM financial data at http://www.sec.gov/edgar/searchedgar/ companysearch.htm, last accessed: March 03, 20081 


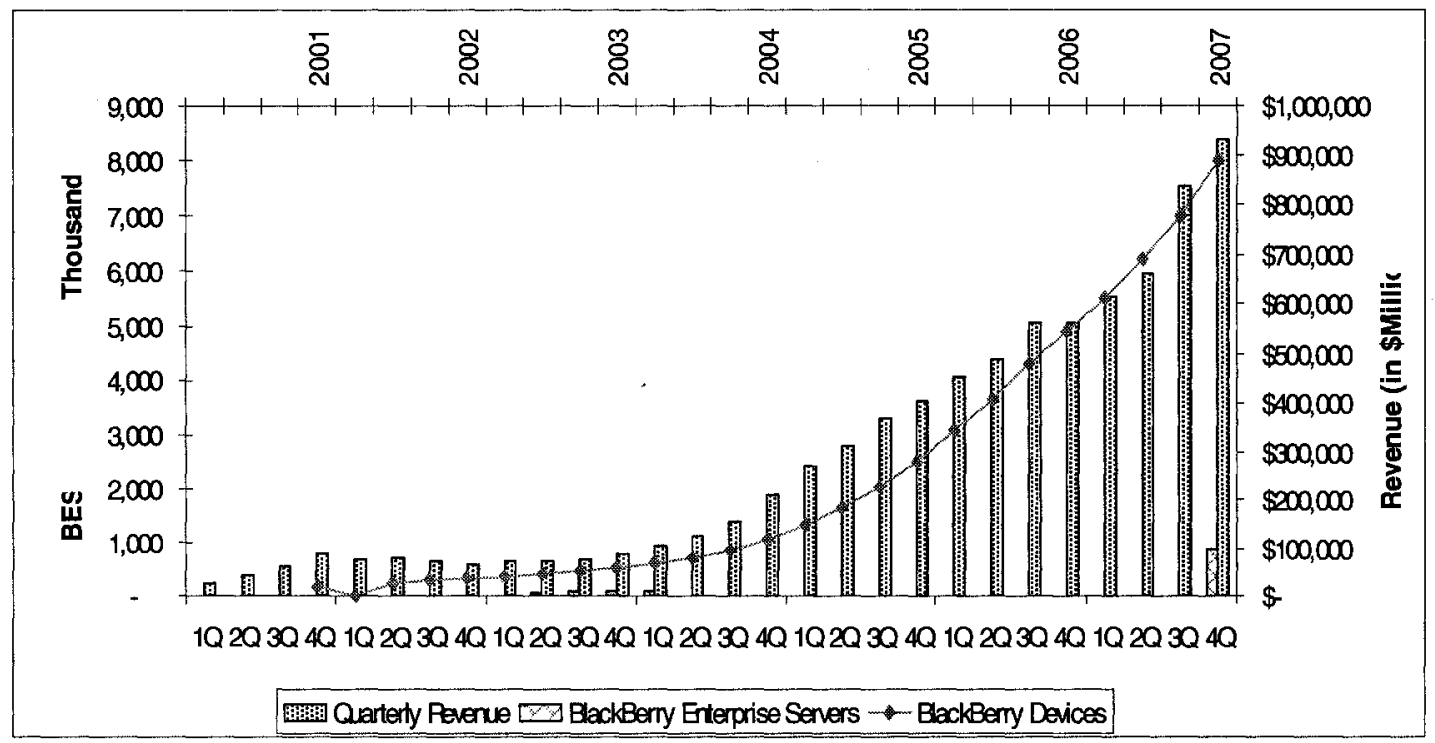

Table 6: RIM revenues, BlackBerry enterprise servers and devices (2001 - 2007)

Source: RIM financial data at EDGAR, http://www.sec.gov/edgar/searchedgar/ companysearch.htm, last accessed: March 03, $2008 \mathrm{l}$

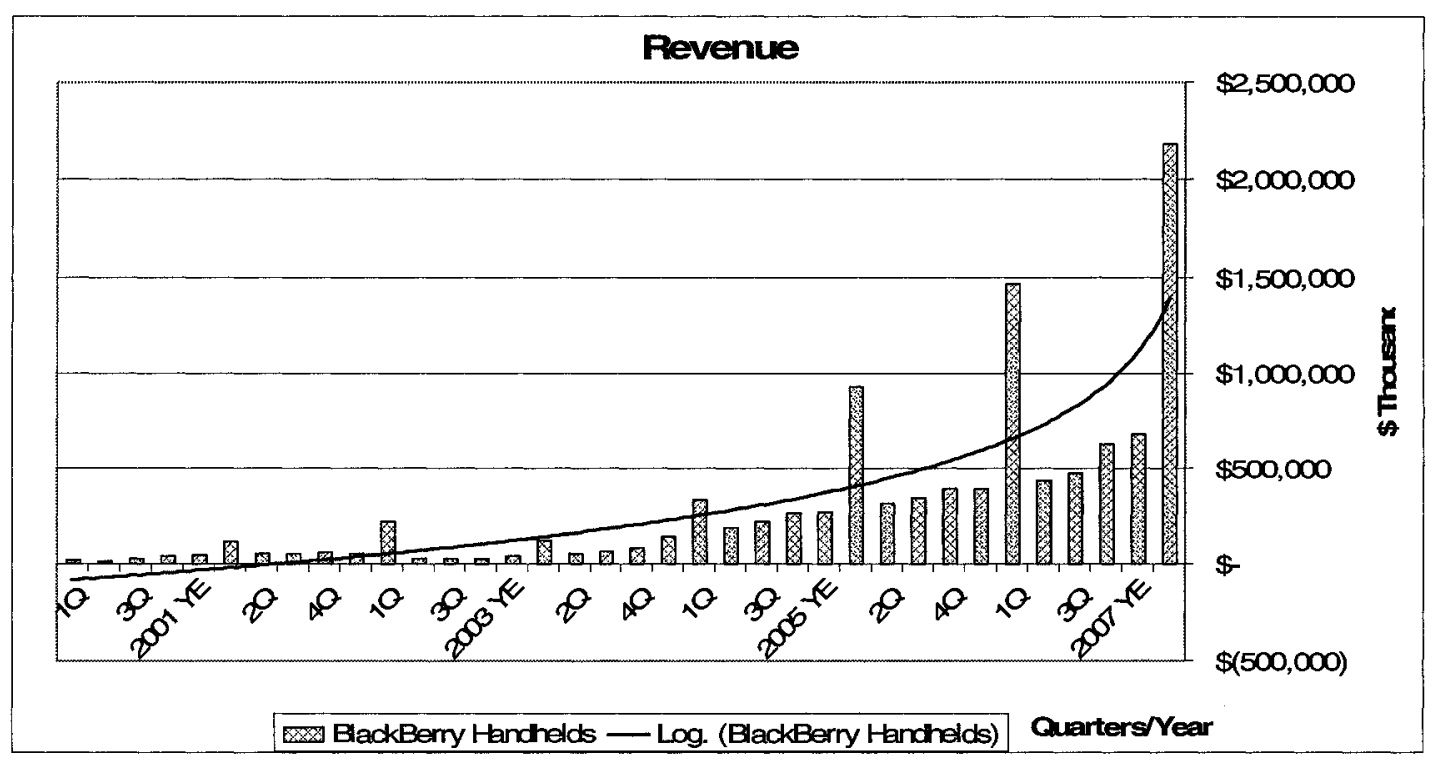

Figure 6: RIM revenues, BlackBerry devices sold (2000 - 2007)

Source: RIM financial data at EDGAR, http://www.sec.gov/edgar/searchedgar/ companysearch.html, last accessed: March 03, 2008 


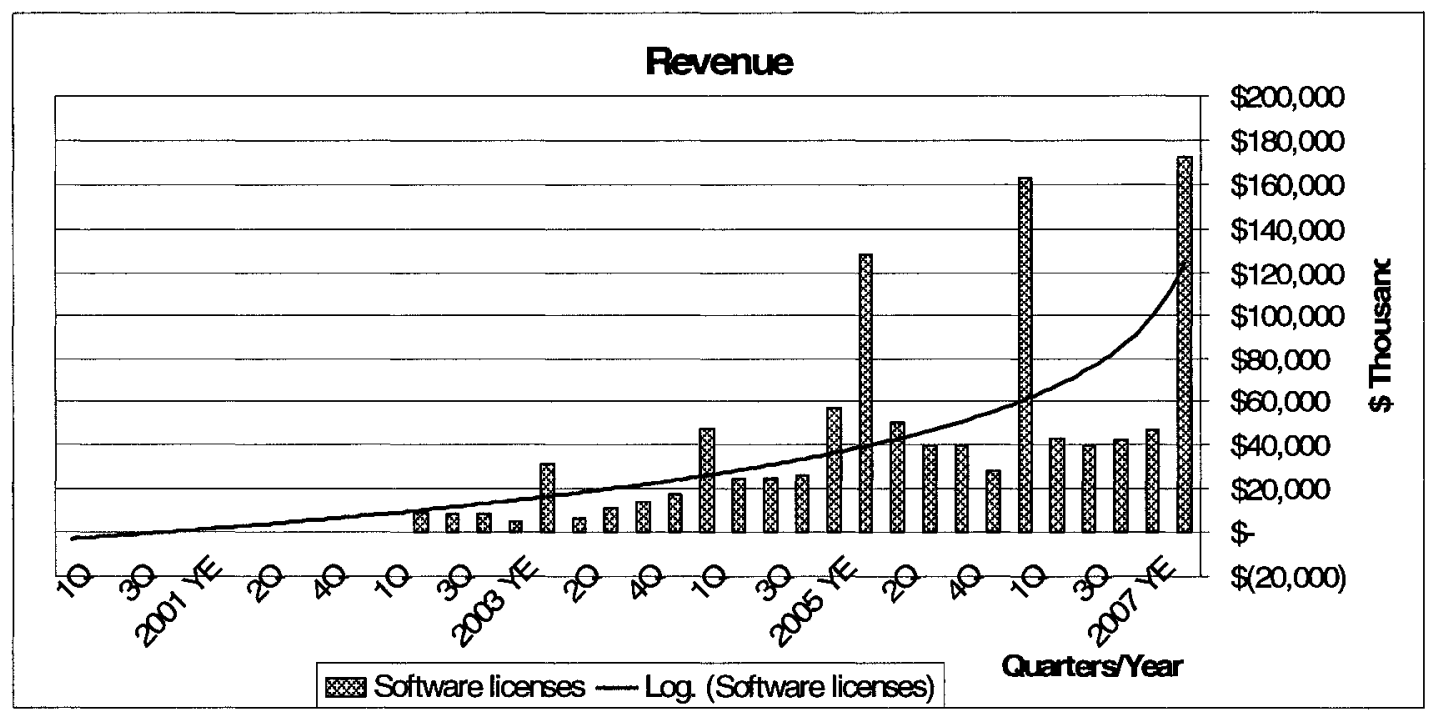

Figure 7: RIM revenues, Licenses $(2000-2007)$

Source: RIM financial data at EDGAR, http://www.sec.gov/edgar/searchedgar/ companysearch.htm, last accessed: March 03, 20081

\subsection{Network effects in enterprise wireless PDA market}

The enterprise wireless PDA market size in North America has been consistently growing in recent past (Cozza \& Kort, 2007). The market is dynamically evolving, once top players have lost their dominance and market share, while new players are gaining market share. This section will show the strategies involving network effects that various PDA platform manufacturers had used within the study period.

\subsubsection{Leverage existing infrastructure and applications}

This is probably the most sought-after feature that PDA platform manufacturers have implemented on their platform. For example, RIM and Palm's support for Microsoft 
Exchange for e-mail; RIM's support for Lotus Notes, IBM Lotus Domino, Microsoft Exchange, Novell GroupWise, etc.

The e-mail and calendar systems from IBM, Microsoft and Novell, together, make up approximately $94 \%$ of the commercial e-mail and calendar market by seat count (Cain, 2007). It is no surprise that the PDA platform manufacturers want to make their platform compatible to these existing infrastructures, in order to address large market segment.

\subsubsection{Switching costs and lock-in}

RIM introduced BlackBerry Enterprise Server (BES) in May 1999. By delivering a fully integrated BlackBerry solution using the BES, RIM is able to deliver maximum performance from its wireless PDA platform. RIM's BlackBerry solution has both the technological and business factors in its favor. In the markets with network effects, vendors often attempt to lock-in their customers. The BES enabled RIM successfully lock-in its enterprise customers.

In January 2002, Palm attempted to bring its own backend server, the Wireless Messaging Server, in response to RIM's BES. However, it was considered inferior to RIM's BES solution 22 .

${ }^{22}$ Source: Can Palm serve two masters?, http://www.networkworld.com/net.worker/columnists/2002/0204kistner.html 


\subsubsection{Licensing}

To gain a much broader market share and to discourage their competition from developing competing technologies, the PDA platform manufacturers had made their solution available for their competitor's devices.

Research in Motion (RIM) had started licensing their BlackBerry technology in April 2000, since the introduction of BlackBerry in 1999. RIM's licensing agreements include BlackBerry Connect and BlackBerry Built-In. BlackBerry Connect allows $3^{\text {rd }}$ party device manufacturers to support BlackBerry services on their devices. BlackBerry BuiltIn allows device manufacturers to incorporate BlackBerry applications (e.g., BlackBerry Browser) on their own devices. It has become increasingly clear from the RIM press announcements, the new licensing agreements that RIM is attempting to make BlackBerry platform available on more handheld devices and platforms, including its competition like Symbian and Windows mobile.

Similarly Palm Inc. had licensed Palm technologies to its competitor's devices. Palm's licensing included Palm OS - enabling competitor devices to install Palm OS on competitor devices. Licensing Palm OS allowed Palm Inc. to gain market share with respect to the number of devices using the Palm OS and generated positive word of mouth. 
In contrast to Palm's licensing of Palm OS, RIM's licensing enabled BlackBerry technology on many competitor's wireless PDA devices; generated positive word of mouth for the BlackBerry platform and also lock-in to the BlackBerry platform as every BlackBerry licensed device would require a BlackBerry Enterprise Server license.

\subsubsection{Developer population and tools}

An open standard based developer environment is one of the network effects that PDA manufacturers are trying to lever. In this case study, RIM clearly stands out in their efforts to lever this network effect.

RIM first announced its Java 2 Micro Edition (J2ME) developer kit in June 2000, less than a year after the release of its BlackBerry platform. It is clear from the press releases that RIM wants to make its platform based on the popular Java to lever the millions of Java developers worldwide. In later attempts to reach broader developer community RIM had made its BlackBerry developer tools available to other popular languages like .NET, .ASP (e.g., BlackBerry plug-in for Eclipse and Microsoft Visual Studio).

Free tools like integrated development environment (IDE), simulators for developing software for the specific PDA platforms are common between Palm and RIM.

Developer conferences, certification, contests and, awards are also common theme between RIM and Palm to encourage developer interest in their platform and generate 
developer word of mouth feedback. RIM's recent announcement to support Eclipse plugin $^{23}$ continues to highlight this trend.

\subsubsection{Complementary products}

Support for standards compliant accessories is another, common theme among Palm and RIM. For example, support secure digital (SD) card and Bluetooth.

In the press releases that announced the support for these complementary products, it was mentioned that each of these companies want to give the flexibility to their customers of reusing their existing hardware where possible.

Alliances to promote complementary products are unique to Palm. Some of the examples are: Palm \& Panasonic alliance to push SD technology, Wireless access on Palm PDA via compatible phone or 56k modem. However, by the time RIM had started making strides in the market; these complementary products have become standard features on wireless PDAs.

${ }^{23}$ Source: RIM Announces BlackBerry JDE Plug-in for Eclipse, http://press.rim.com/release.jsp?id=1473 


\subsubsection{Standards compliance}

RIM's consistent efforts to make its BlackBerry platform standards compliant are noticeable. These efforts not only are around the interworking protocols (e.g., GSM, CDMA, TCP/IP, VoIP, SIP, WAP) they had made consistent efforts to make BlackBerry platform compliant to various standards around the services that BlackBerry offers (e.g., FIPS, Triple DES, AES - for security) - important aspects for enterprises.

\subsubsection{Alliances}

With $3^{\text {rd }}$ party software vendors: An alliance with $3^{\text {rd }}$ party software vendors to bring popular enterprise software to their PDA platform is another noticeable action to lever network effects. Some of these alliances are between RIM and Novarra (formally Neomar) to enhance support for Lotus Sametime for BlackBerry; RIM and Aether systems to deliver Siebel eBusiness applications on BlackBerry. Similarly Palm Inc. had formed alliances with other software vendors including Siebel.

With hardware, semiconductor manufacturers: An alliance with hardware and semiconductor manufacturers to optimize wireless experiences is observed. For example, Palm OS ready program with partners like Intel, ATI, MediaQ, Motorola, Samsung and Texas Instruments; RIM's partnership with Analog Devices for custom designed processor for optimal system performance, partnership with HP to bring wireless printing to BlackBerry platform. 


\subsubsection{Popular applications and file formats}

Clear efforts to gain larger user base by bringing support for popular applications (i.e., applications with huge use base) and file formats was observed in common between Palm and RIM. Some of the examples are: Palm's agreement with AOL to support AIM instant messaging, RIM's agreement with Yahoo! to bringing in better wireless experiences and support for popular file formats like Microsoft Word.

\subsubsection{Local language support}

Support for local language capabilities is another theme that Palm and RIM had followed.

\subsubsection{Wireless technologies}

Both the PDA platforms in the case study had made their platforms work on many underlying wireless technologies (e.g., GSM/GPRS, CDMA, UMTS, and WLAN). It is noticeable that among the available underlying wireless technologies, when these companies first came to market with wireless PDA devices, they had initially supported GSM technology - a widely developed wireless technology than the CDMA technology. 


\subsection{Discussions}

The case study attempts to find the role of network effects in the success or failure of an enterprise wireless PDA platform by studying Palm and BlackBerry wireless PDA platforms.

Table 7 summarizes the strategic actions observed from the case study and if it was observed with BlackBerry or Palm OS or both wireless PDA platforms.

\begin{tabular}{|l|c|c|}
\hline \multirow{2}{*}{ Strategic actions } & \multicolumn{2}{|c|}{ Observed with PDA platform } \\
\cline { 2 - 3 } & BlackBerry & Palm OS \\
\hline Leverage existing infrastructure and applications & Yes & Yes \\
\hline Switching costs and lock-in & Yes & No \\
\hline Licensing & Yes & Yes \\
\hline Developer population and tools & Yes & Yes \\
\hline Complementary products & Yes & Yes \\
\hline Standards compliance & Yes & No \\
\hline Alliances - with 3rd party software vendors & Yes & Yes \\
\hline $\begin{array}{l}\text { Alliances - with hardware, semiconductor } \\
\text { manufacturers }\end{array}$ & Yes & Yes \\
\hline Popular applications and file formats & Yes & Yes \\
\hline Local languages & Yes & Yes \\
\hline Wireless technologies & Yes & Yes \\
\hline
\end{tabular}

Table 7: Strategic actions and PDA platforms 
The actions each of these wireless PDA platforms attempting to lever using the factors considered network effects can be divided into two broad categories (i) increasing the adoption of the wireless PDA platform and (ii) lock-in the users to the wireless PDA platform.

For any wireless PDA platform to be successful, it needs to have a pool of developers to fuel development of the applications for the wireless PDA platform. Wireless PDA platforms are supporting popular languages, familiar development tools, simulators and integrated development environment in order to attract large number of developers. While the developer conferences and developer contests have generated the word of mouth feedback among the developers.

Enterprises have existing infrastructure and applications that is critical to their day-to-day operation. Both the Palm and BlackBerry wireless PDA platform manufacturers attempted to bring compatibility to existing infrastructure and applications. Notably, those enterprise applications with large installed base were among the first to be supported on the wireless PDA platforms. By bringing support for these applications with large installed base of users enabled to (i) address larger market segment and (ii) enable generating more word of mouth feedback.

In the same line of leveraging the existing infrastructure, licensing allowed access to competitor PDA platform without throwing away existing infrastructure. Licensing not 
only gave flexibility to enterprise consumers by allowing them to use $3^{\text {rd }}$ party PDA devices, it also allowed users of competitor PDA platforms to try the other wireless PDA platforms without having to incur upfront infrastructure costs.

Furthermore, compliance to standards, support for popular file formats and complementary products increase the adoption of a wireless PDA platform.

Finally, once an enterprise adopts a wireless PDA platform, the wireless PDA manufacturers attempt to lock in that enterprise to the wireless PDA platform. Before the introduction of the BlackBerry platform, enterprise wireless PDA solutions are based on independent handsets. Comparatively the switching costs of standalone wireless PDA solutions are less. For example, BlackBerry Desktop Software allows wireless PDA users to easily migrate any data from the competitor wireless PDA platforms like Palm or Windows Mobile to BlackBerry ${ }^{24}$.

Table 8 summarizes the insights from the literature review and map them to the insights generated from this case study. The findings of this case study combined with the findings of the interview data is used to develop a formal simulation model that is presented in the next chapter. This model considers the role of network effects in the success of a enterprise wireless PDA platform.

${ }^{24}$ Source: BlackBerry Desktop Software, http://na.blackberry.com/eng/services/desktop/ 


\begin{tabular}{|c|c|}
\hline Insights from literature review & Insights from case study \\
\hline $\begin{array}{l}\text { Products in networked market do not standalone they depend on } \\
\text { existence of other products }\end{array}$ & $\begin{array}{l}\text { Leveraging existing applications: Support existing enterprise } \\
\text { applications that are widely deployed }\end{array}$ \\
\hline Company strategy shall depend on the structure of an industry & $\begin{array}{l}\text { Wireless technologies: Carriers support only one wireless } \\
\text { technology like GSM, CDMA }\end{array}$ \\
\hline $\begin{array}{l}\text { Companies in markets with network effects strive to influence } \\
\text { expectations, facilitate coordination, and achieve compatibility }\end{array}$ & $\begin{array}{l}\text { Popular file formats and applications: Millions of PDF, Word } \\
\text { documents exchanged daily, use Yahoo, Google } \\
\text { Alliances: To facilitate coordination and achieve compatibility }\end{array}$ \\
\hline $\begin{array}{l}\text { It is difficult for innovations to gain footholds or develop critical } \\
\text { mass without creating benefits for the power players }\end{array}$ & Alliances: To create complementing products and solutions \\
\hline $\begin{array}{l}\text { To create momentum for a new product, the innovator must } \\
\text { orchestrate changes in the players that add to the innovation's } \\
\text { benefits, the players that act as channels to adopters and the } \\
\text { adopters themselves }\end{array}$ & $\begin{array}{l}\text { Developer population and tools: Carrier specific features, } \\
\text { developer conferences, tools - Supporting popular languages } \\
\text { (e.g., Java, .NET) and tools (e.g., Eclipse) to lever millions of } \\
\text { developers }\end{array}$ \\
\hline $\begin{array}{l}\text { Get-big-fast strategies are not always the right strategy in markets } \\
\text { with network effects }\end{array}$ & $\begin{array}{l}\text { Not observed. Case study did not indicate either of the wireless } \\
\text { PDA platforms trying the get-big-fast strategy }\end{array}$ \\
\hline $\begin{array}{l}\text { Companies that focus on promoting and delivering network utility } \\
\text { to customers succeed while companies that focus on only the } \\
\text { standalone utility tend to fail }\end{array}$ & $\begin{array}{l}\text { Not observed. However it may be argued that RIM's } \\
\text { BlackBerry solution provided network utility compared to Palm } \\
\text { OS's standalone utility }\end{array}$ \\
\hline
\end{tabular}




\begin{tabular}{|c|c|}
\hline Network effects do not always result in a winner-take-all market & $\begin{array}{l}\text { Not observed. However based on quarterly finance reports, } \\
\text { enterprise wireless PDA market has not been a winner-take-all } \\
\text { market }\end{array}$ \\
\hline $\begin{array}{l}\text { Technology licensing allows flexibility and deters competitors from } \\
\text { developing their own technologies }\end{array}$ & $\begin{array}{l}\text { Licensing: Both PDA platforms licensed their technologies to } \\
\text { 3rd party vendors }\end{array}$ \\
\hline $\begin{array}{l}\text { Performance demands of a product in market and architecture of a } \\
\text { product are interrelated }\end{array}$ & $\begin{array}{l}\text { Not observed. However RIM's BlackBerry platform is known } \\
\text { for its end to end integrated solution }\end{array}$ \\
\hline $\begin{array}{l}\text { Coordination required by systems competition is often more } \\
\text { extensive and explicit, employing tools including common } \\
\text { ownership of various components suppliers, long-term contracts, } \\
\text { and industry-wide standard-setting bodies }\end{array}$ & $\begin{array}{l}\text { Standards compliance: Standards generate network effects and } \\
\text { benefit entire market (e.g., GSM) } \\
\text { Alliances: Alliances with 3rd party software and hardware } \\
\text { vendors }\end{array}$ \\
\hline $\begin{array}{l}\text { Word of mouth feedback contributes to adoption in networked } \\
\text { markets }\end{array}$ & $\begin{array}{l}\text { Developer population and tools: PDA platform sponsored } \\
\text { conferences (e.g., Wireless World Research Forum and } \\
\text { BlackBerry developer conference by RIM) }\end{array}$ \\
\hline $\begin{array}{l}\text { Customer's technology selection is influenced more by the opinions } \\
\text { and choices of his or her acquaintances, where he or she has strong } \\
\text { ties, than by the size of the installed base }\end{array}$ & Local language: Supporting local language \\
\hline $\begin{array}{l}\text { Decision to adopt in markets with indirect network effects also } \\
\text { depends on availability of complementary products, technology } \\
\text { superiority, and vendor credibility }\end{array}$ & $\begin{array}{l}\text { Complementary products: Both the platforms supported } \\
\text { complementary products }\end{array}$ \\
\hline
\end{tabular}




\begin{tabular}{|l|l|}
$\begin{array}{l}\text { Reputation of a firm impact the creation of positive anticipation } \\
\text { from consumers }\end{array}$ & Not observed \\
\hline Lock-in is a norm in markets with network effects & $\begin{array}{l}\text { Switching costs and lock-in: RIM attempts to lock-in adaptors } \\
\text { to their BlackBerry platforms }\end{array}$ \\
\hline Switching costs influence adoption & $\begin{array}{l}\text { Switching costs and lock-in: BlackBerry platform increases } \\
\text { switching costs of its adaptors, at the same time trying to lower } \\
\text { the switching costs for its competitor PDA platforms }\end{array}$ \\
\hline
\end{tabular}

Table 8: Mapping of insights gained from literature review with that of case study 


\section{$5 \quad$ Elements of a dynamic causal model}

This chapter is organized into three sections. In the first section I provide background. In the second section I present the content analysis of the data obtained from the intensive interviews with experts in the enterprise wireless PDA market. These interviews contributed to the development of the dynamic causal model for understanding the dynamics of the network effects in the enterprise wireless PDA market. Lastly, in the third section I present the key delays in the enterprise wireless PDA market.

\subsection{Background}

The enterprise wireless PDA market experienced a dramatic change in the recent past. Wireless PDA platforms that were once leading the market had lost their lead and their very survival was being questioned. On the other hand, new entrant took the market share from the incumbent and continues to lead.

Markets with network effects are resistant to change (Shapiro \& Varian, 1999;

Chakravorti, 2004). In order to attract the user of the current technology or solution away to a the new technology or solution, there needs to be at least two or three fold better in dimension and price, speed or convenience (Arthur, 1996). Switching costs are among the several reasons for this resistance. In spite of this inherent resistance in the enterprise wireless PDA market, RIM has managed to capture significant market share. 
Figure 8 shows the historic average closing price for Palm and RIM. Palm had a market capital of $\$ 29$ billion in 2001 compared to only $\$ 731.88$ million at the end of 2007 . While RIM has enjoyed an increase in market capital from \$220 million in 2001 compared to \$41.23 billion in 2007.

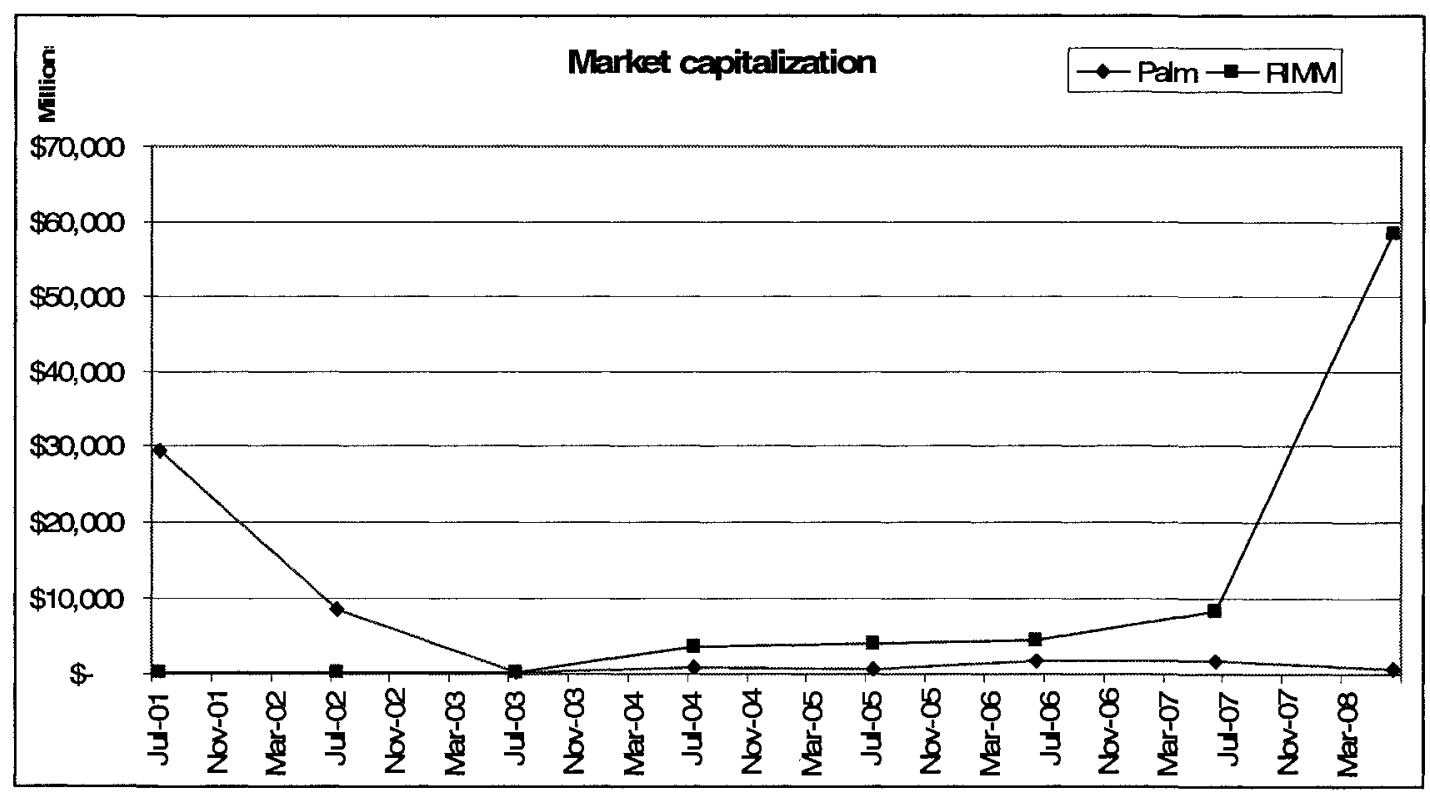

Figure 8: Market capitalization of RIM and Palm (2001 - 2008)

Source: SEC, http://www.sec.gov/(Outstanding stocks from company filings) and Google! Finance, http://finance.google.com (historical stock prices)

\subsection{Fieldwork on the dynamics of the enterprise wireless PDA market}

I investigated the role of network effects in the success of an enterprise wireless PDA platform by interviewing the experts knowledgeable in the enterprise wireless PDA market. The interview participants included experts with years of experience in the enterprise wireless PDA market with backgrounds in marketing and R\&D. These interviews were both formal and informal. 
The goal of these interviews was to indentify the mental models that experts in the enterprise wireless PDA market use to guide strategic decisions. In this process, I was interested in finding (i) positive feedback (ii) negative feedback (iii) sources of lock-in and (iv) critical delays in the enterprise wireless PDA market that drive the success or failure of an enterprise wireless PDA platform.

My approach to the interviews was intended to gain a clear understanding of what the experts think the reasons for the success of BlackBerry platform, to gain an understanding of the rational behind some of the strategic actions considering network effects that RIM had taken, and other factors that may be not obvious but important for success in markets with network effects. The aim during the interviews was to identify the key variables that stakeholders regard as relevant for the research.

The following recount of experts' views is organized in three broad categories to study the network effects in the enterprise wireless PDA market namely: development (applications, developers and tools), adoption, and lock-in. I was interested in finding the key variables and the relationships between these key variables. In particular, factors that may explain the success of an enterprise wireless PDA platform. The following sections summarize the highlights from the interviews. 


\subsubsection{Development}

A technological solution cannot be successful without addressing the needs of the market segment it is trying to address.

\section{Applications:}

Supporting an enterprise application is not simply developing the support for the specific applications, the architecture of the enterprise wireless PDA platform need to be secure and robust to convince the enterprises to trust their data and networks to the wireless solution. A marketing expert explains:

"Enterprises take every effort to secure their corporate networks. A wireless PDA platform can not be the weak link in their infrastructure. Security is key to the success of any wireless PDA platform. To penetrate some parts of the market segment. For example, we had spent considerable resources to get the Federal Information Processing Standards (FIPS) certification in order to be able to sell to the government departments."

A marketing expert explains:

"Enterprises have client-server applications that are core to their businesses. The wireless PDA devices extend these applications and make them available remotely in a secure and efficient manner on the wireless PDA devices."

"Higher the popularity of the server software (e.g., Microsoft Outlook) sooner the support for that application on the wireless PDA platform"

An Enterprise wireless PDA platform needs to offer flexibility and extensibility, a marketing expert explains: 
“... obviously one can not predict all the use cases of these server applications, wireless PDA platform need to be a secure, flexible and extensible”.

\begin{abstract}
Alliances:
On the alliances and independent software vendors (ISV), one of the experts said:

"ISVs play a key role in the success of our wireless PDA platform. These ISVS are keys to the successful deployment of the wireless PDA platform. They not only bring support for new applications to our wireless PDA platform, they also provide Enterprises needed support and training."
\end{abstract}

A senior licensing team leader concurred. Alliances bring a lot of value to the wireless PDA platform.

"Alliances bring support for the backend/ server applications on the wireless PDA platform. Alliances provide training on how to manage BES backend server software."

Enterprise wireless PDA platform attract ISVs, however the attractiveness to the platform depends on the attractiveness of making profit from participation. A marketing expert explains:

"I expect the number of ISVs contributing to your platform to over shoot and then eventually stabilize at some level as that space (number of alliances) becomes too crowded and the opportunities to gain from the alliance reduce". 


\section{Developers:}

Any software development project needs an adequate pool of developers. Attracting developers to develop applications for the wireless PDA platform is an important consideration. A marketing expert said:

"We organize developer conferences and contests to attract the developer community".

Developers actively developing applications for the wireless PDA platform often also come from outside the platform owner. A marketing expert said:

"The ISVs contribute valuable resources (developers) to develop applications for your platform".

\section{Tools and simulators:}

Reducing the development time and reducing the time for members of the design team to be productive is one of the important factors.

"By supporting the popular languages, integrated development environment and simulators the rate at while applications can be developed can be increased".

\subsubsection{Adoption}

Word of mouth plays a key role in the adoption of the enterprise wireless PDA platform. A seasoned marketing expert said:

"Word of mouth plays key role in the adoption. BlackBerry has become an iconic and social status. Let's say, an executive who is on plane or at a conference comes across another executive making effective use of his or her 
time without having to use a laptop and fumbling to find a wireless connection. That feedback certainly has a positive influence on the adoption."

"BlackBerry has come to become a social status or iconic. This does play quite a significant factor in the adoption."

Compared to an individual user, enterprises often have an elaborated evaluation process to adopt a wireless PDA platform. A seasoned marketing expert said:

"Enterprises often have elaborated evaluation procedures before adopting any solutions. We are aware of enterprises considering deploying a wireless PDA platform often talks to other enterprises that have already adopted a wireless PDA platform to seek their experiences. This word of mouth feedback plays role in adoption is during the evaluation of the enterprise wireless PDA platforms."

Before anyone adopts a wireless PDA platform, it needs to have a basic set of applications.

"Several factors influence the adoption of enterprise wireless PDA platform. For example, support for popular file formats, standards compliance, applications, word of mouth feedback, complementary products"

\subsubsection{Lock-in $^{25}$}

What are the sources of lock-in and switching costs in the enterprise wireless PDA market? One of the marketing experts said:

\footnotetext{
${ }^{25}$ This research draws from the sources of lock-in from Shapiro and Varian (1999)
} 
"Each of the stakeholders has different sources of lock-in. And each of these sources applies to these stakeholders at a different magnitude"

“... some of the sources of lock-in are not significant (e.g., Durable purchases) in this market."

Enterprises want to leave their options open. They do not want to lock-in to one supplier. Moreover enterprises may want to have the flexibility to buy handheld devices from different vendors. As one of the marketing expert puts it:

"Licensing provides enterprises with flexibility of a broader range of handheld devices. Some enterprises have preferences to buy other handheld devices... for various reasons (e.g., user preference, cost). Our licensing allows these enterprises to continue use our wireless solution, without having to buy our handsets."

Licensing not only provides flexibility for the wireless PDA users, it can also drive revenue from the sale of licenses. As one of the expert says:

"Licensing increases word of mouth feedback. Thought it does not increase the BlackBerry Enterprise Server sales, it also drives the BES user license sales".

Switching costs for enterprises is significant compared to an individual user. As one of the expert says:

"Switching costs for enterprises is significant, enterprises would not consider switching to another platform and, it requires significant cost justification (e.g., re-training, lost productivity, service disruption)"

“...ongoing support costs are not a significant factor for an enterprise to consider switching to different PDA platform" 
Another marketing expert said:

"Perception of high lock-in can sometime be a deterrent for adoption".

\subsection{Key delays}

The following sections identify the key delays in the enterprise wireless PDA market.

\subsubsection{Development}

\section{Alliances \& Developers:}

When a developer starts to develop software for the wireless PDA platform, it may take sometime for that developer to be productive. Similarly delays are applicable for ISVs. As one of the expert says:

"By adopting standard development languages and tools you can reduce the time it requires for a member of the development team to be contributing"

\section{Applications:}

Application development for the wireless PDA platform takes time, but efficiencies can be gained by parallel backend and client. As one the export says:

"Application development happens in parallel for the backend and the wireless client" 


\subsubsection{Evaluation and deployment}

Evaluation and deployment delay is defined as the time it takes for an enterprise from the time it first started actively looking for a wireless PDA platform and to the time it had successfully deployed the enterprises wireless PDA platform. Similar delays are applicable for switching from one wireless PDA platform to another. As an expert says:

"Enterprises often have elaborated evaluation procedures before adopting any solutions... This delay also plays a key role in an enterprise switching from one wireless PDA platform to another."

The next chapter combines these observations from the interviews into a form simulation model. This model considers the interactions of development, adoption, and lock-in the structure of the system. 
This chapter is organized into four sections. In the first section I present the subsystems in the enterprise wireless PDA market. The nature of the feedback process in the structure of the system suggests that the success factors of an enterprise wireless PDA market may be endogenous. In the second section I present the resource structure of the enterprise wireless PDA market, showing the flow of resources between stakeholders in the enterprise wireless PDA market. In the third section I present the factors influencing the enterprise decision to adoption of a wireless PDA platform. Lastly, in the fourth section I present the dynamic hypothesis that may explain the network effects in the enterprise wireless PDA market affecting the success of a wireless PDA platform.

\subsection{Subsystems in a dynamic causal model}

System Dynamics provides the framework to model the mental models, including feedbacks, time delays, accumulations and non-linearities. System Dynamics has a rich tradition in exploring technology diffusion and adoption ${ }^{27}$ in the products that exhibit network externalities (Sterman, 2000; Größler, Thun, \& Milling, 2001; Oliva, Sterman, \& Giese, 2003).

\footnotetext{
${ }^{26}$ The system dynamics model in this research was coded using the Vensim PLE software by Ventana Systems, Inc. http://www.vensim.com/

${ }^{27}$ This research draws from and extends the basic diffusion model in the Modeling Guide of the Vensim PLE System Dynamics software.
} 
I used system dynamics to explore the dynamics of adoption of wireless PDA platform at the industry level. Drawing on Warren (2008), I modeled the exchange of resources in the enterprise wireless PDA industry as the interaction of market participants Enterprises, Enterprise server software vendors, Independent software vendors, Wireless PDA platform of interest, Competitor PDA platforms and, Carriers (i.e., wireless service providers). The structure of the system helped to explore how the interaction of these participants may contribute to the success of a wireless PDA platform.

Figure 9 depicts the links between various stakeholders in the enterprise wireless PDA market. Key stakeholders in this market can be grouped in six basic subsystems, as follows:

1) Enterprises - this group represents the companies that has either currently adopted a wireless PDA platform or considering in future.

2) Enterprise server software vendors - this group represents the companies that develop and sell server software for the Enterprises, e.g., Oracle - database (DB), Microsoft Exchange e-mail.

3) Independent software vendors - this group represents the companies that customize the server and wireless software solutions for Enterprises, e.g., Novarra.

4) Target wireless PDA platform - the wireless PDA platform that I want to study to understand the role of network effects in the success there of, e.g., RIM's BlackBerry.

5) Competition PDA platforms - this group represents the competitors wireless PDA platforms, e.g., Palm, Windows Mobile. 
6) Carriers - this group represent the telecommunications and Internet Service Provides that offer the wireless PDA platform and the wireless (cellular, internet) connectivity; and offer the wireless services (hosted e-mail, text messaging) on the PDA platform. This group acts as a gatekeeper, i.e., any wireless PDA platform has to be supported by this group on their wireless network. An enterprise typically would buy the wireless PDA devices and associated software from this group and would pay ongoing fees for continued use of wireless PDA devices and the services.

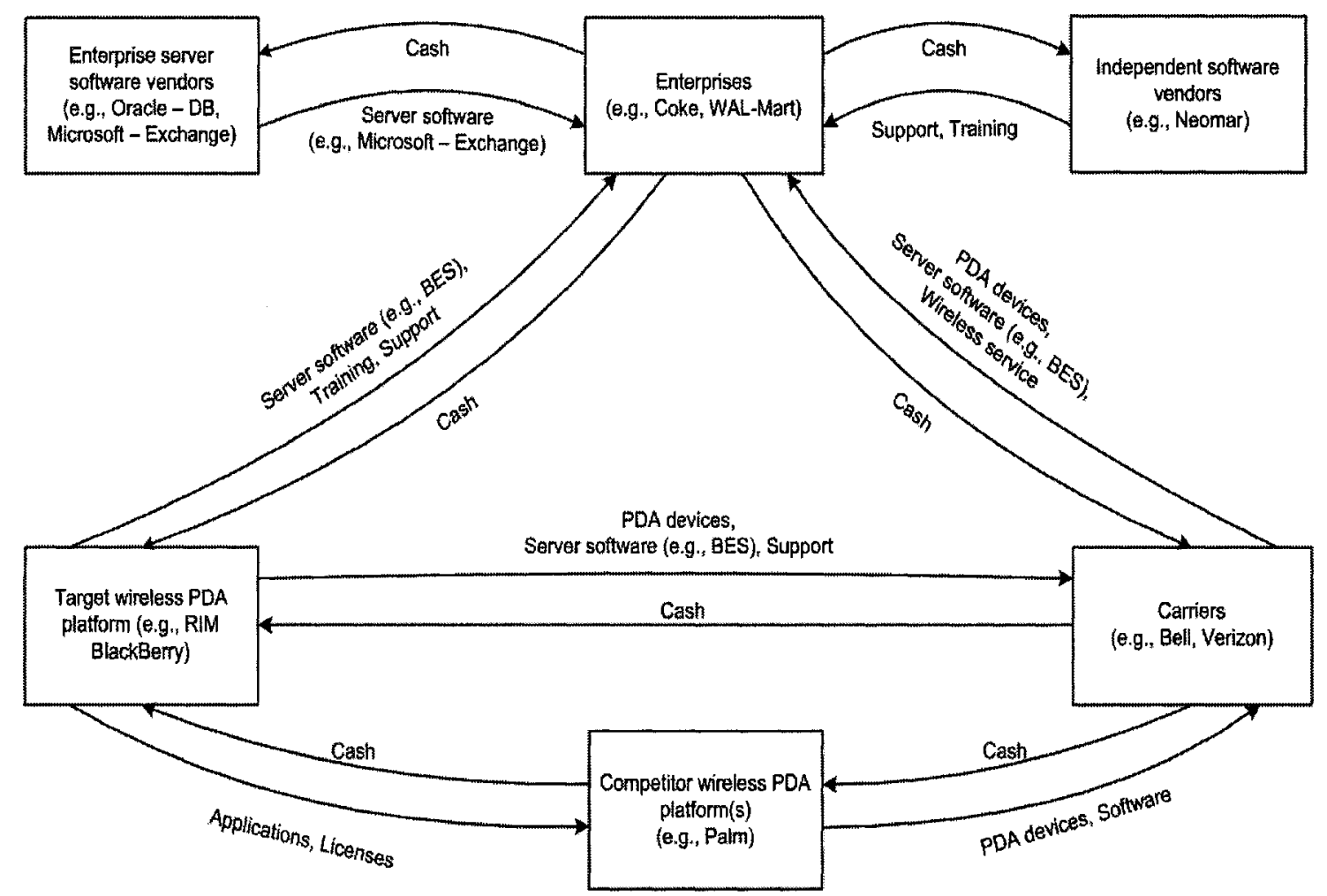

Figure 9: Subsystem diagram of enterprise wireless PDA market 


\subsection{Resource structure of the enterprise wireless PDA system}

Figure 9 depicts an enterprise wireless PDA system structure that shows the flows of resources among the subsystems. As show in this figure, the cash flows from Enterprises, Carriers, Competitor PDA Platform(s) to Target PDA platform. The flow of components of wireless PDA system (e.g., Server software, PDA devices) flows from Target PDA platform to Enterprises, Competition PDA Platform(s), and Carriers. The flows between Enterprises, Enterprise server software vendors and, Independent software vendors are not directly connected with the target wireless PDA platform.

Figure 10 depicts a dynamic resource system view of the enterprise wireless PDA industry. The boxes represent the stocks of resources, while the valves represent the inflows and outflows controlling those resources. These stocks and flows represent some of the key variables used in the model. 

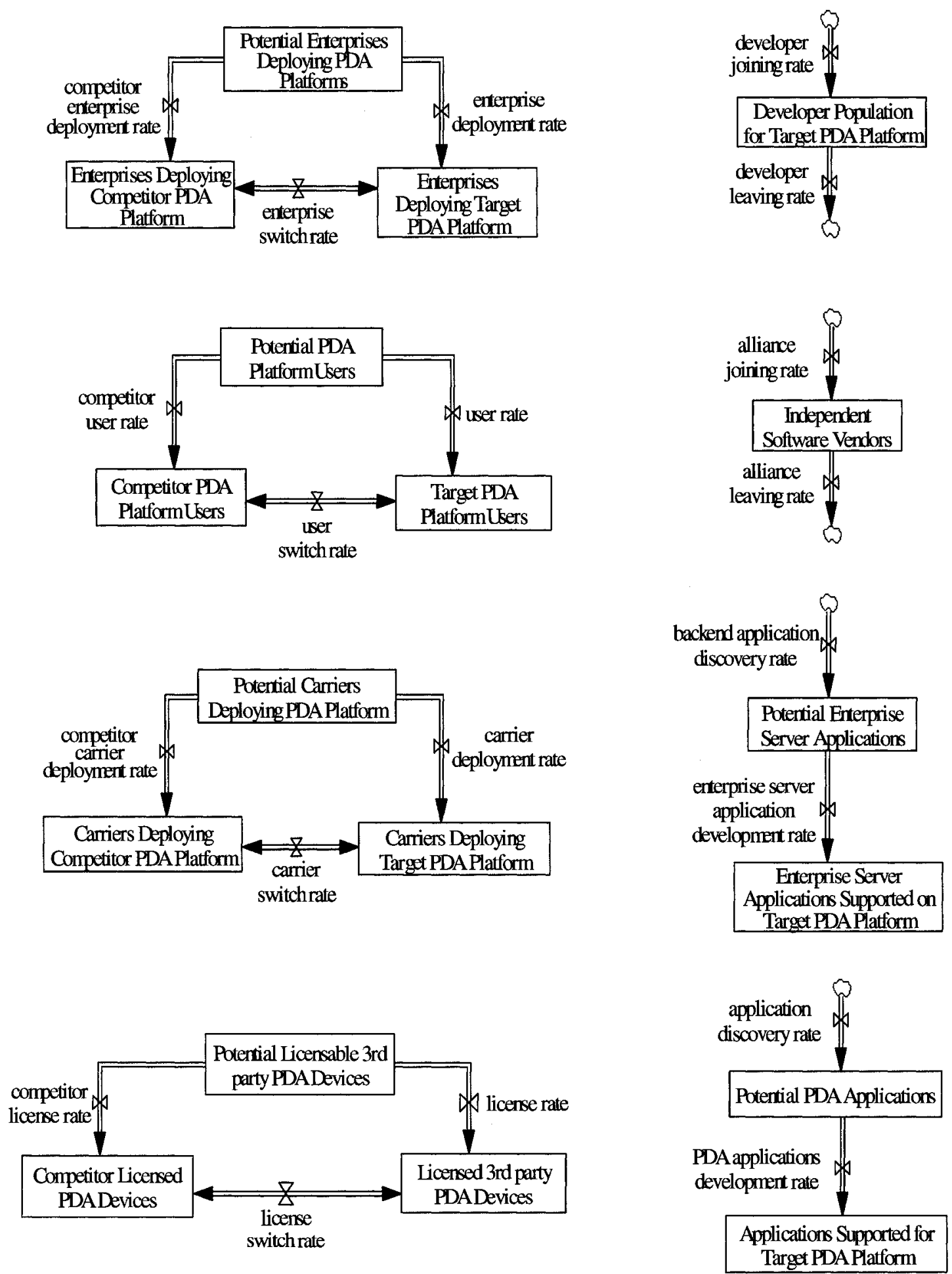

Figure 10: Dynamic resource view of enterprise wireless PDA market 
The key highlights in the dynamic resource structure are as follows:

1) The Enterprises Deploying Target PDA Platform increase as the attractiveness of the platform increases and the enterprise word of mouth feedback increase.

2) The Carriers Deploying Target PDA Platform increase as the attractiveness of the platform increases and the Carriers word of mouth feedback increase.

3) The Developer Population increases as more alliances with independent software vendors increase.

4) The Enterprise Server Applications Supported on Target PDA Platform increased by enterprise server application support rate and decrease as the stock Enterprise Existing Server Software decreases.

5) The attractiveness of the wireless PDA platform for the Enterprises increases as the Enterprise Server Applications Supported on Target PDA Platform increase.

6) The Switching Costs Due to Adoption of Target PDA Platform increases as Enterprises Deploying Target PDA Platform and Carriers Deploying Target PDA Platform increase.

7) The resource transition between stocks takes time (i.e., delay).

8) The enterprise switching rate, carrier switching rate, PDA user switching rate and license switching rate can increase or decrease as sources of lock-in are lowered or increased. 


\subsection{Behavioral foundations of the causal model}

The premise of the model is that the factors influencing the success of a enterprise wireless PDA platform is driven by the attractiveness or usefulness of the enterprise wireless PDA platform and how well the enterprise wireless PDA platform can lock-in its users while continuing to meet the individual enterprises' needs. This research provides the endogenous factors in the enterprise wireless PDA market whose interactions explain the how and the why of the enterprise wireless PDA platform success.

The following behavioral foundations form the basis for the model. First, enterprises have existing infrastructure that is core to the day-to-day operations. They want to leverage these existing infrastructures. Second, enterprises have elaborated selection process for selecting the wireless PDA platform. They often seek input from other enterprises and PDA users before selecting a wireless PDA platform. Third, Enterprises are cautious about the switching costs and lock-in. They want to avoid switching between different enterprise wireless PDA platforms. Fourth, each stakeholder in the enterprise wireless PDA market has different sources of lock-in.

\subsection{Dynamic hypothesis}

The dynamic hypothesis in a system dynamics study is a statement of system structure that appears to have the potential to generate the problem behavior (Richardson \& Pugh, 1981: 55). 
What is the role of network effects in the success of a wireless PDA platform? Figure 11 shows that the Enterprise Server Application Development Rate and PDA Application Development Rate increase as the number of Potential Enterprise Server Applications and Potential PDA Applications that can be supported on the Target PDA Platform increases (reinforcing loops R1 and R2). The rate of application development rate is affected by the application popularity, months to develop application, total developers, number of tools and simulators available.

The success of an enterprise wireless PDA platform depends on the attractiveness of the wireless PDA platform to the Potential Enterprises and PDA Users. In order to develop the applications supported on the Target PDA Platform, a developer population is required. Sources for this developer population is either in-house from the owner of the Target PDA Platform or from alliances, both these sources on average require 12 months adjustment time to be productive members (balancing loops B1 and B2 in Figure 11).

As the attractiveness of the Target PDA Platform increases more Enterprises, PDA Users and Carriers deploy the Target PDA Platform (reinforcing loops R3 in Figure 12, R9 in Figure 13 and R15 in Figure 14). As more Enterprises and PDA Users deploy the Target PDA Platform the word of mouth feedback increases (reinforcing loops R4 in Figure 12, R10 in Figure 13 and R16 in Figure 14). 
There may be Enterprises, PDA Users and Carriers deploying the Competitor PDA Platform (e.g., Target PDA Platform entered the market later than the Competitor PDA Platform) that may come in contact with the Enterprises, PDA Users and Carriers deploying the Target PDA Platform (reinforcing loops R6 in Figure 12, R12 in Figure 13 and R18 in Figure 14) and decide to switch to the Target PDA Platform. Alternatively, the Enterprises, PDA Users and Carriers using the Target PDA Platform may decide to switch to the Competitor PDA Platform (loops R5 in Figure 12 and R11 in Figure 13 and R17 in Figure 14). The switch rate for these Enterprises, PDA Users and Carriers depends on switch factor - the switching costs associated with switching from one wireless PDA platform to another.

In order to reduce the switching costs for Enterprises and PDA Users of the Competitor PDA Platform the Target PDA Platform can develop technologies to allow the Competitor PDA Platforms to access the features of the Target PDA Platform by licensing their technology (Figure 15). The licensing offers Enterprises and PDA Users flexibility and reduces the switching costs; it may also discourage the Competitor PDA Platforms to develop competing technologies.

The next chapter presents how the model was reviewed with experts and their reactions to the model structure. 


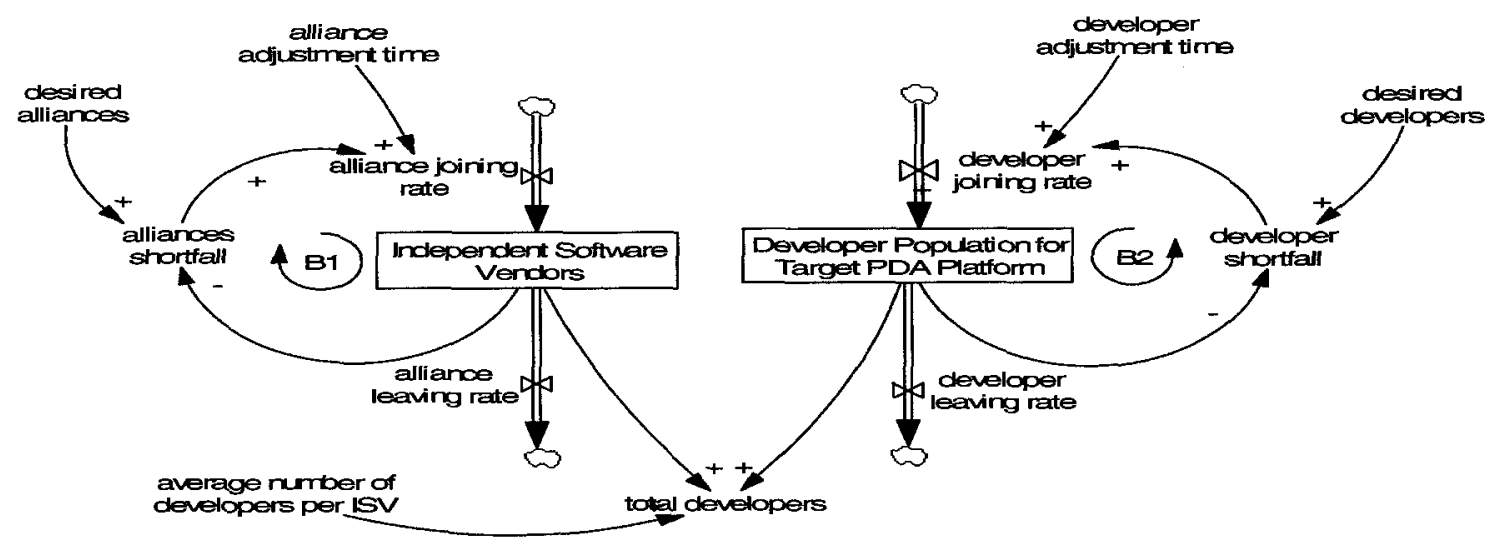

Enterprise Server and PDA Applications

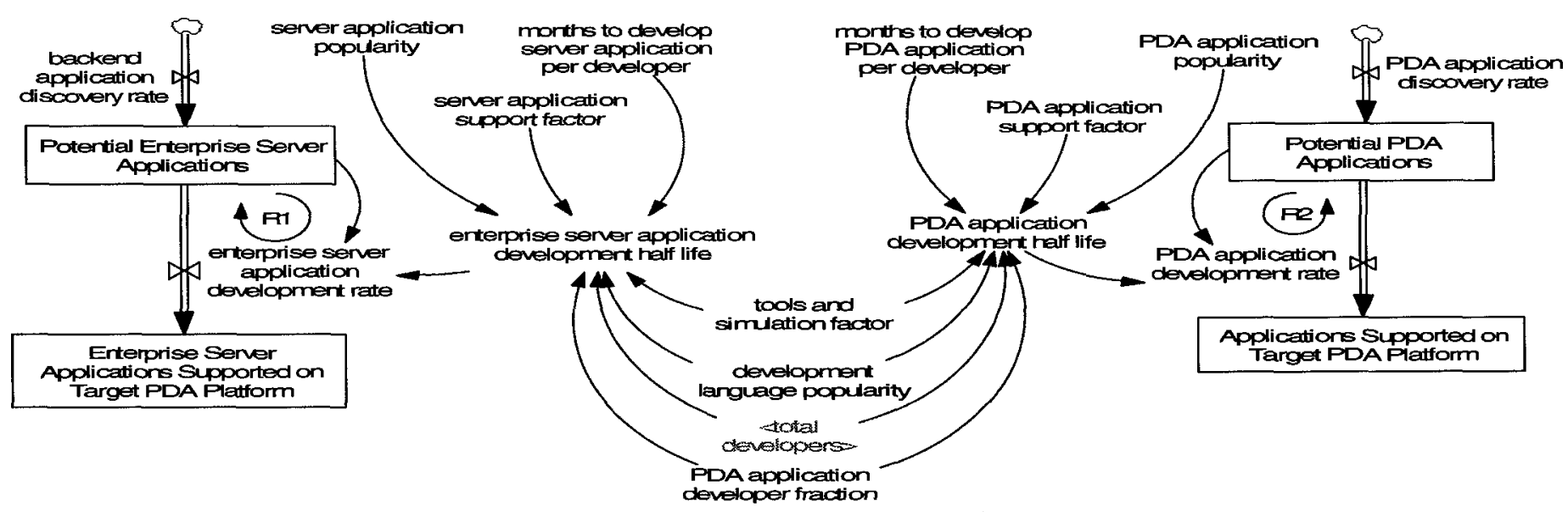

Figure 11: Feedback structure of developers, alliances, server and PDA application in enterprise wireless PDA market 
Enterprises

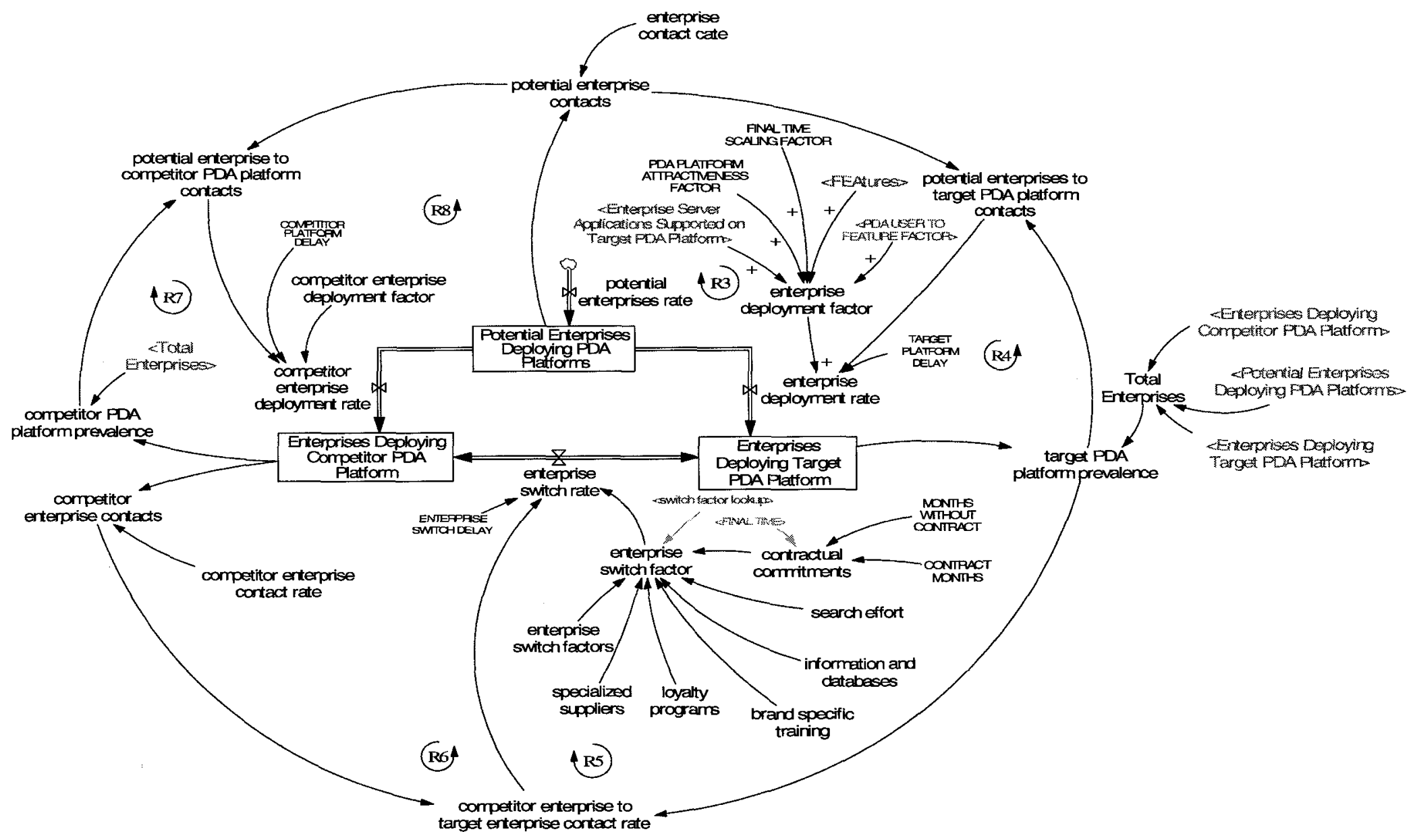

Figure 12: Feedback structure in enterprise wireless PDA market - enterprises 
PDA Users

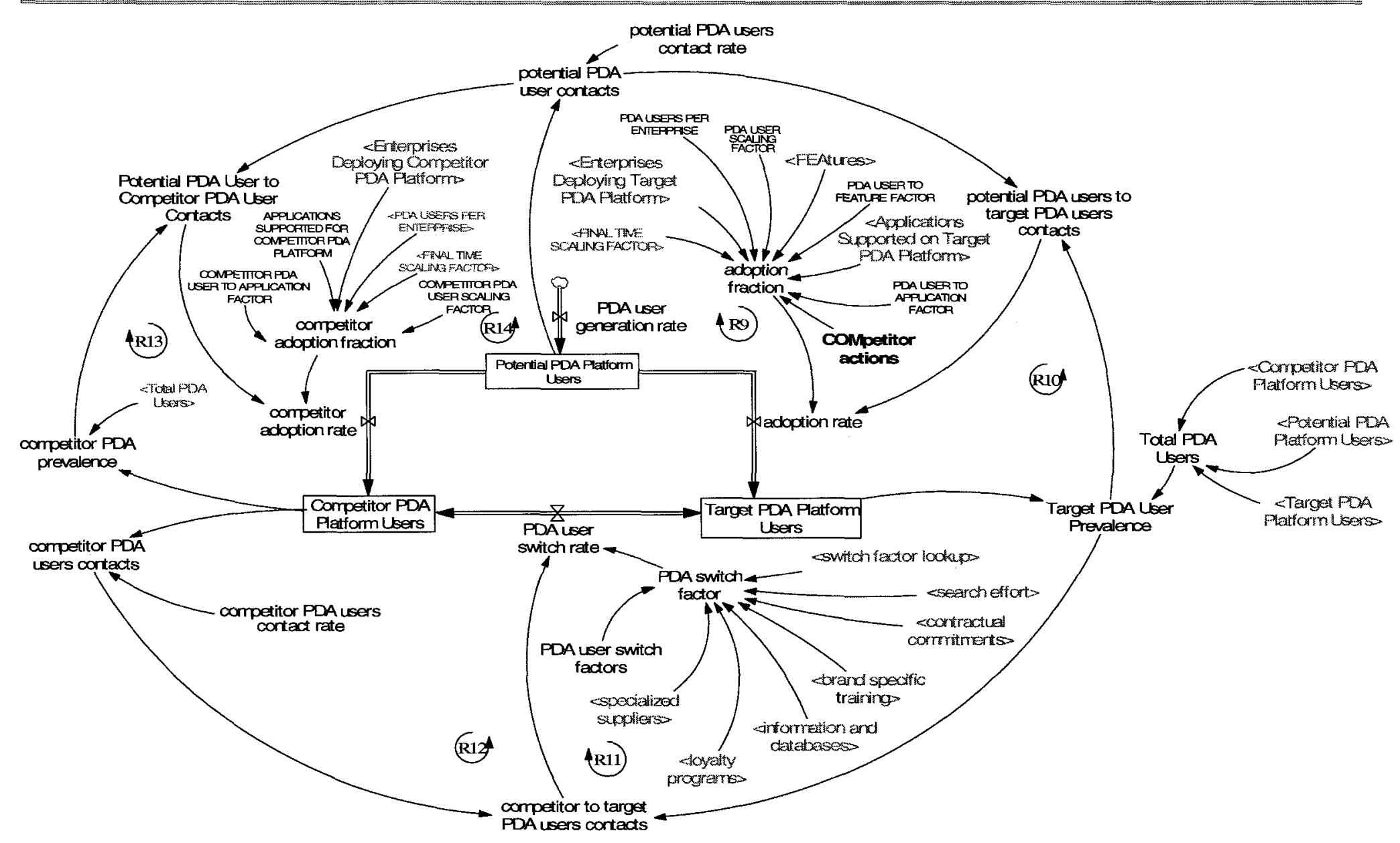

Figure 13: Feedback structure in enterprise wireless PDA market - PDA users 


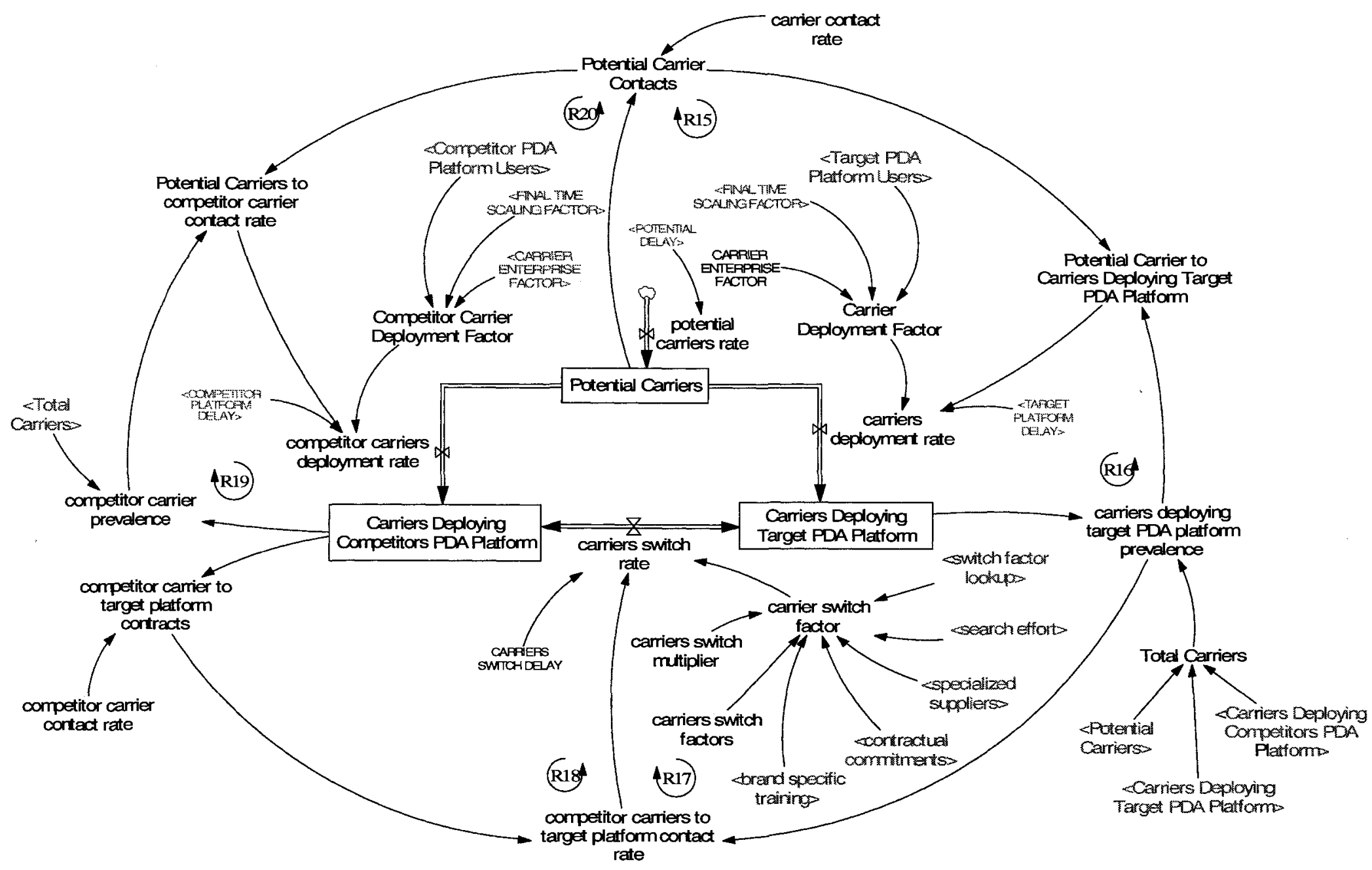

Figure 14: Feedback structure in enterprise wireless PDA market - carriers 


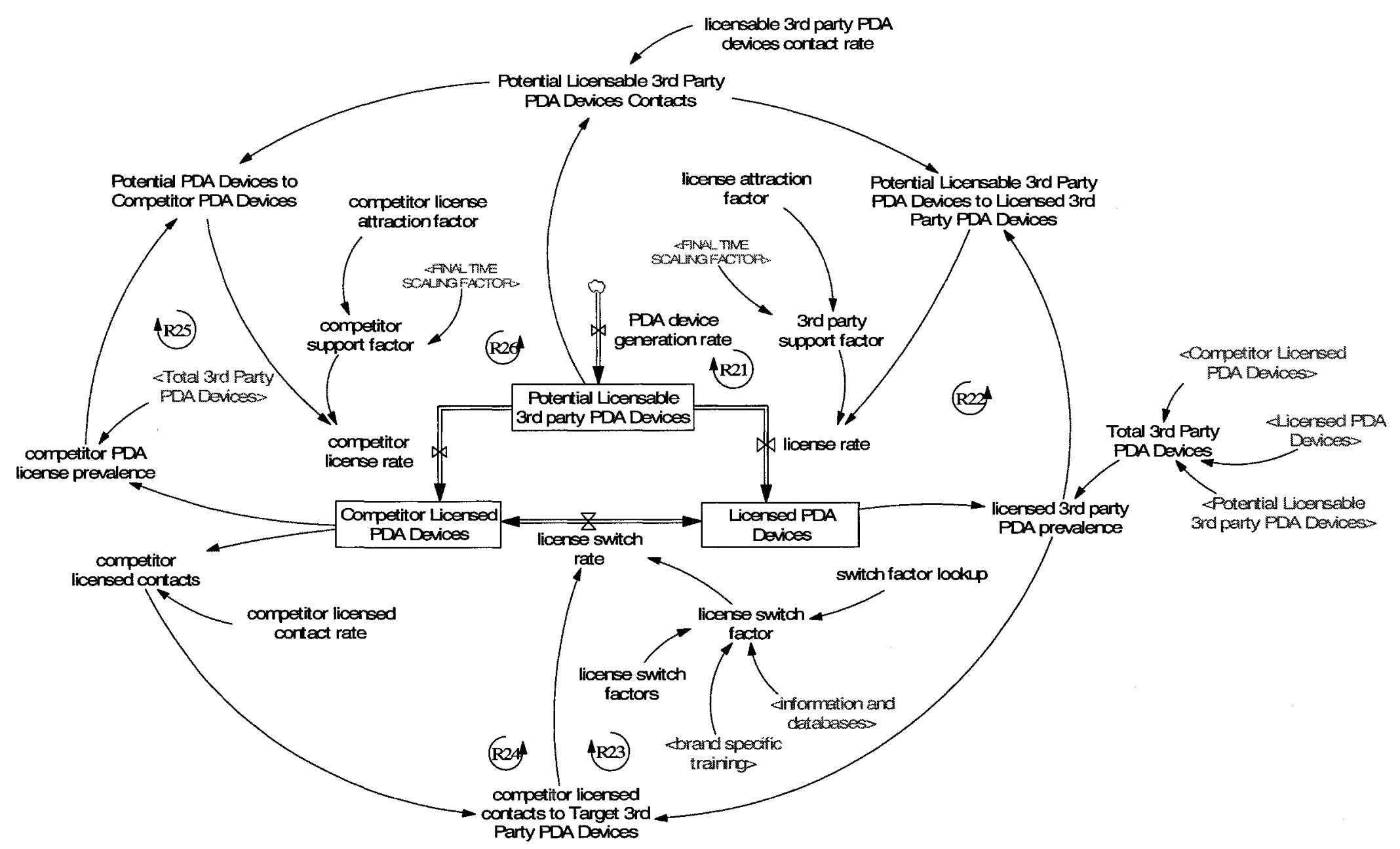

Figure 15: Feedback structure in enterprise wireless PDA market - licenses 


\section{$7 \quad$ Model review}

This chapter is organized into five sections. In the first section I present the formal system dynamics model for the enterprise wireless PDA market is reviewed with the domain experts, and why an interview based model review method was selected. In the second section I present the interview protocol. In the third section I present how the interview was administrated. In the fourth section I present a summary of the experts' feedback to the model structure. Lastly, the fifth section I present the summary of changes suggested by the experts.

\subsection{Approach to model review}

As suggested by several well known system dynamics practitioners (Sterman, 2000; Lane, 1994; Richardson \& Pugh, 1981), an iterative approach to model building was used to develop the formal model presented in chapter 6 . The goal of the model review was to determine if the hypothesized model structure is acceptable within the given boundary, assumption and constraints. The model review would also seek expert reaction to the variables used in the model and their causal relationships presented in order to build confidence in the model. 


\subsection{Interview protocol}

Drawing from Luna \& Lines (2003), interviews were used for reviewing the model. An interview workbook is used for the purposes of reviewing the model. The workbook was designed to help the participants to clearly understand the model boundary model, assumptions, limitations and definitions of the variables used. The model review booklet was developed to ensure that the concepts and terminology presented did not require the participants to be familiar with the system dynamics modeling. The model review booklet (see Appendix 3) was reviewed with an expert that was involved in the development of the formal model as a pilot run. This interview helped to refine the review booklet for its presentation structure and clarity.

The model review booklet was sent electronically to the identified domain experts. These participants were encouraged to review the introductory part of the review booklet to familiarize with the research, the subsystems in the model, its boundary, constraints and definitions of the variables used. During the interview the participant was asked if there were any questions or any clarification required before the subsystems of the model was reviewed. The model review interview was divided into the following three sections:

1) Background: This section presented a background of the research, restricts, and limitations of the model. This section also helped to ground the discussion of the model structures in the macro-world instead of the real-world. This section set the 
stage of the discussion so the participants could focus on the causal structures with in the scope of the research.

2) Microstructures: This section presented six causal loop diagrams or microstructures of the formal model. Each of these microstructures of the model was preceded with a short description of the loop, a causal loop diagram, followed with questionnaire if the participant believed that the key variables and its relationships were plausible within the constraints of the microworld.

The discussion and the walkthrough of each of these causal loops gave the researcher and each of the participants an opportunity to identify the areas that were omitted in the model and that were important for an understanding of the role of network effects and their strategic implications in the enterprise wireless PDA market.

3) Model extensions: This final section of the model review booklet encouraged the participants to suggest any other microstructures that should be included to gain further insights to understand the role of network effects and their strategic implications in the enterprise wireless PDA market. 


\subsection{Interview administration}

1) Preparation: Using the best practices of the system dynamics modeling, the formal system dynamics model was developed iteratively. After the each iteration of interview, a follow-up plan was agreed with the participants. After the formal model was ready, a model review questionnaire was prepared and tested with one of the participant and revised based on the feedback received.

2) Recruitment: Participants for reviewing the model were recruited by e-mail. Some of the participants participated in the review helped during the development of the formal model. Information for reviewing the model was e-mailed to each participant ahead of time and a mutually agreeable time for the review was arranged.

3) Data capture: The model review was conducted using a questionnaire. Researcher captured the summary of the discussion including the participant's feedback to the causal loops, plausibility of the explanations, changes to the model and, further enhancements to model were captured by the researcher and later confirmed with each participant via e-mail. Each interview lasted around 1 to 2 hours; depending of the participant's background and amount of discussion generated during the model review. 


\subsection{Expert reaction to model structure}

The expert reactions to the model microstructures are summarized in this section. Reactions to the key relationships in each microstructure are tabulated; each column of the table represents the reaction of participants to a particular causal relationship or causal loop explanation. Each row summarizes an expert's reaction to various indicators of the microstructure. Changes to the model suggested by the participants are discussed in Section 7.5.

1) Alliances and developers loops: These loops depict the sources of developer population for the target PDA platform and the time required for a developer to be a productive member. Experts' reactions to the causal relationships in these loops were favorable. All experts had agreed that causal loop and the explanation was plausible.

\begin{tabular}{|c|c|c|c|}
\hline Participant & $\begin{array}{l}\text { Independent Software } \\
\text { Vendors \& alliance } \\
\text { joining rate }\end{array}$ & $\begin{array}{l}\text { Developer Population for } \\
\text { Target PDA Platform \& } \\
\text { developer joining rate }\end{array}$ & $\begin{array}{l}\text { Causal loop } \\
\text { explanation }\end{array}$ \\
\hline 1 & $\mathrm{P}$ & $\mathrm{P}$ & $\mathrm{P}$ \\
\hline 2 & $\mathrm{P}$ & $\mathrm{P}$ & $\mathrm{P}$ \\
\hline 3 & $\mathrm{P}$ & $\mathrm{P}$ & $\mathrm{P}$ \\
\hline
\end{tabular}

Legend:: P: Plausible, U: Uncertain, N: Not Plausible

Table 9: Experts' reactions to alliances and developer loops

- Independent Software Vendors \& alliance joining rate: All the participants agreed that the relationship was plausible. One of the participants wondered if the 
alliance joining rate is better represented as a factor of platform popularity instead of a constant.

- Developer Population for Target PDA Platform \& developer joining rate:

All the participants agreed that the relationship was plausible. One of the participant wondered if the model differentiated the developer population for target PDA platform to include only the R\&D community or the support and marketing employees as well.

- Causal loop explanation: All the participants agreed that the explanation of the causal relationship was plausible. One of the participant wondered if the model should include the factors affecting the alliances and developers leaving rate instead of modeling as a constant.

2) Enterprise Server Applications \& PDA Applications loops: These loops depict how the enterprise server applications like Oracle database; and handheld applications like internet browser are supported on the target wireless PDA platform. These applications are the applications that do not have an enterprise server backend application (e.g., Yahoo IM). Experts' reactions to the causal relationships in these loops were favorable. All the experts had agreed that causal loop and the explanation was plausible. 


\begin{tabular}{|c|l|l|c|}
\hline Participant & $\begin{array}{l}\text { Enterprise Server } \\
\text { Applications Supported } \\
\text { on Target PDA Platform } \\
\text { \& enterprise server } \\
\text { application development } \\
\text { rate }\end{array}$ & $\begin{array}{l}\text { Applications Supported } \\
\text { on Target PDA } \\
\text { Platform \& PDA } \\
\text { application } \\
\text { development rate }\end{array}$ & $\begin{array}{l}\text { Causal loop } \\
\text { explanation }\end{array}$ \\
\hline 1 & P & P & P \\
\hline 2 & P & P & P \\
\hline 3 & P & P & P \\
\hline
\end{tabular}

Legend:: P: Plausible, U: Uncertain, N: Not Plausible

Table 10: Experts' reactions to enterprise server and PDA application loops

- Enterprise Server Applications Supported on Target PDA Platform \& enterprise server application development rate: All the participants agreed that the relationship was plausible.

- Applications Supported on Target PDA Platform \& application development rate: All the participants agreed that the relationship was plausible.

- Causal loop explanation: All the participants agreed that the explanation of the causal relationship was plausible.

3) Enterprise adoption and switching loop: These loops depicts (i) how an enterprise either become an enterprise that deploy the Target Wireless PDA Platform or the Competitor Wireless PDA Platform and (ii) factors that cause lock-in to a wireless PDA platform. Experts' reactions to the causal relationships in these loops were favorable. All the experts had agreed that causal loop and the explanation was plausible. 


\begin{tabular}{|c|l|l|c|}
\hline Participant & $\begin{array}{l}\text { Enterprises Deploying } \\
\text { Target PDA Platform } \\
\text { \& enterprise } \\
\text { deployment rate }\end{array}$ & $\begin{array}{l}\text { Enterprises Deploying } \\
\text { Competitor PDA Platform } \\
\text { \& competitor enterprise } \\
\text { deployment rate }\end{array}$ & $\begin{array}{l}\text { Causal loop } \\
\text { explanation }\end{array}$ \\
\hline 1 & $\mathrm{P}$ & $\mathrm{P}$ & $\mathrm{P}$ \\
\hline 2 & $\mathrm{P}$ & $\mathrm{P}$ & $\mathrm{P}$ \\
\hline 3 & $\mathrm{P}$ & $\mathrm{P}$ & $\mathrm{P}$ \\
\hline
\end{tabular}

Legend:: P: Plausible, U: Uncertain, N: Not Plausible

Table 11: Experts' reactions to enterprise adoption and switching loop

- Enterprise Deploying Target PDA Platform \& enterprise deployment rate:

All the participants agreed that the relationship was plausible.

- Enterprises Deploying Competitor PDA Platform \& competitor enterprise development rate: All the participants agreed that the relationship was plausible.

- Causal loop explanation: All the participants agreed that the explanation of the causal relationship was plausible. One of the participant recommended updating the model to include new enterprises joining the stock of Potential Enterprises Deploying PDA Platforms instead of using a fixed number. This change was made early in the process and was incorporated for the rest of the interviews. One of the participant wondered if the number of enterprise wireless PDA platforms in the market may reduce the pressure to switch. Another participant wondered if the switching rate is influenced by the number of enterprise PDA platforms in the market. 
4) PDA user adoption and switching loop: These loops depicts how a PDA user become either a user that adopt the Target Wireless PDA Platform or the Competitor Wireless PDA Platform and factors that cause lock-in to a wireless PDA platform. Experts' reactions to the causal relationships in these loops were favorable. All experts had agreed that causal loop and the explanation was plausible.

\begin{tabular}{|c|c|c|c|}
\hline Participant & $\begin{array}{l}\text { Target PDA Platform } \\
\text { Users \& adoption rate }\end{array}$ & $\begin{array}{l}\text { Competitor PDA Platform } \\
\text { Users \& competitor } \\
\text { adoption rate }\end{array}$ & $\begin{array}{c}\text { Causal loop } \\
\text { explanation }\end{array}$ \\
\hline 1 & $\mathrm{P}$ & $\mathrm{P}$ & $\mathrm{P}$ \\
\hline 2 & $\mathrm{P}$ & $\mathrm{P}$ & $\mathrm{P}$ \\
\hline 3 & $\mathrm{P}$ & $\mathrm{P}$ & $\mathrm{P}$ \\
\hline
\end{tabular}

Legend:: P: Plausible, U: Uncertain, N: Not Plausible

Table 12: Experts' reactions to PDA user adoption and switching loop

- Target PDA Platform Users \& adoption rate: All the participants agreed that the relationship was plausible.

- Competitor PDA Platform Users \& competitor adoption rate: All the participants agreed that the relationship was plausible.

- Causal loop explanation: All the participants agreed that the explanation of the causal relationship was plausible. One of the participant recommended updating the model to include new PDA users joining the stock of potential PDA platform users instead of using a fixed number. This change was made early in the process and was incorporated for the rest of the interviews. One of the participant wondered if the causal relationship can occur without including the cost of 
ownership of the platform and how the health of economy may influence the causal loop.

5) Carrier adoption and switching loop: These loops depicts how a carrier become either a carrier that deploy the Target Wireless PDA Platform or a carrier that deploy the Competitor Wireless PDA Platform and factors that cause lock-in to a wireless PDA platform. Experts' reactions to the causal relationships in these loops were favorable. All experts had agreed that causal loop and the explanation was plausible.

\begin{tabular}{|c|c|l|c|}
\hline Participant & $\begin{array}{l}\text { Carriers Deploying } \\
\text { Target PDA Platform } \\
\text { \& adoption rate }\end{array}$ & $\begin{array}{l}\text { Carriers Deploying } \\
\text { Competitor PDA } \\
\text { Platform \& competitor } \\
\text { adoption rate }\end{array}$ & $\begin{array}{c}\text { Causal loop } \\
\text { explanation }\end{array}$ \\
\hline 1 & $\mathrm{P}$ & $\mathrm{P}$ & $\mathrm{P}$ \\
\hline 2 & $\mathrm{P}$ & $\mathrm{P}$ & $\mathrm{U}$ \\
\hline 3 & $\mathrm{P}$ & $\mathrm{P}$ & $\mathrm{P}$ \\
\hline
\end{tabular}

Legend:: P: Plausible, U: Uncertain, N: Not Plausible

Table 13: Experts' reactions to carrier adoption and switching loop

- Carriers Deploying Target PDA Platform \& carrier deployment rate: All the participants agreed that the relationship was plausible.

- Carriers Deploying Competitor PDA Platform \& competitor carriers'

deployment rate: All the participants agreed that the relationship was plausible.

- Causal loop explanation: All except one of the participants agreed that the explanation of the causal relationship was plausible. One of the participant 
recommended updating the model to include new carriers joining the stock of Potential Carries instead of using a fixed number. One of the participant wondered what may be true carrier switching costs as they support more than one wireless PDA platform.

6) License adoption and switching loop: This loop depicts how the licensable $3^{\text {rd }}$ party PDA devices become either a licensed $3^{\text {rd }}$ party PDA device or a competitor licensed PDA device. Experts' reactions to the causal relationships in these loops were favorable. All experts had agreed that causal loop and the explanation was plausible.

\begin{tabular}{|c|c|c|c|}
\hline Participant & $\begin{array}{l}\text { Licensed PDA Devices } \\
\text { \& license rate }\end{array}$ & $\begin{array}{l}\text { Competitor Licensed } \\
\text { PDA Devices \& } \\
\text { competitor license rate }\end{array}$ & $\begin{array}{l}\text { Causal loop } \\
\text { explanation }\end{array}$ \\
\hline 1 & $\mathrm{P}$ & $\mathrm{P}$ & $\mathrm{P}$ \\
\hline 2 & $\mathrm{P}$ & $\mathrm{P}$ & $\mathrm{P}$ \\
\hline 3 & $\mathrm{P}$ & $\mathrm{P}$ & $\mathrm{P}$ \\
\hline
\end{tabular}

Legend:: P: Plausible, U: Uncertain, N: Not Plausible

Table 14: Experts' reactions to $3^{\text {rd }}$ party PDA device licensing and switching loop

- Licensed PDA Devices \& license rate: All the participants agreed that the relationship was plausible.

- Competitor Licensed PDA Devices \& competitor license rate: All the participants agreed that the relationship was plausible.

- Causal loop explanation: All the participants agreed that the explanation of the causal relationship was plausible. 


\subsection{Indicated changes to the model}

The experts' reaction to the six micro-structures is summarized in Table 15. The experts gave strong support for most of the indicated relationships and causal loop explanations. A change was suggested early in the modeling process to include new enterprises and PDA users joining the stock of potential enterprises and users, instead of modeling as a fixed size. This change has been incorporated to represent a more realistic scenario and had received favorable support from the experts.

\begin{tabular}{|c|l|l|c|c|c|c|}
\hline Participant & $\begin{array}{l}\text { Alliances } \\
\text { and } \\
\text { Developers }\end{array}$ & $\begin{array}{l}\text { Enterprises } \\
\text { Server and } \\
\text { PDA } \\
\text { Applications }\end{array}$ & $\begin{array}{l}\text { Enterp } \\
\text { rises }\end{array}$ & $\begin{array}{l}\text { PDA } \\
\text { Users }\end{array}$ & Carriers & Licenses \\
\hline 1 & $\mathrm{P}$ & $\mathrm{P}$ & $\mathrm{P}$ & $\mathrm{P}$ & $\mathrm{P}$ & $\mathrm{P}$ \\
\hline 2 & $\mathrm{P}$ & $\mathrm{P}$ & $\mathrm{P}$ & $\mathrm{P}$ & $\mathrm{U}$ & $\mathrm{P}$ \\
\hline 3 & $\mathrm{P}$ & $\mathrm{P}$ & $\mathrm{P}$ & $\mathrm{P}$ & $\mathrm{P}$ & $\mathrm{P}$ \\
\hline
\end{tabular}

Legend:: P: Plausible, U: Uncertain, N: Not Plausible

Table 15: Experts' reaction to the causal loop explanation

During the second phase of interviews, participants were encouraged to make suggestions for extending the formal model of the dynamics of enterprise wireless PDA market to gain further insights. The following is a summary of the recommendations:

1) Model relationships: The experts suggested that the hypothesized relationships in the micro-structures of the model would be closer to their expectations if the model 
included the impact of market economic conditions on enterprises and PDA users' adoption patterns and switching.

2) Model indicators: Following is a summary of changes suggested during the discussions of the model development:

- One of the participants suggested including the PDA device end of life replacements.

- Another participant suggested that the fixed number of enterprises and PDA users in the market does not represent the real life scenario. To represent a real life scenario, the model should consider new enterprises and PDA users entering the market. 


\section{$8 \quad$ Model testing}

This chapter is organized into three sections. The goal of modeling is to help clients of the model make better decisions, based on the best available model (Sterman, 2000). In the first section I present the model goals. In the second section I present the model boundary, limitations and, assumptions. Lastly, in the third section I present the tests performed for the formal system dynamics model.

\subsection{Model goals}

A model must have a clear purpose. Without a clear purpose a model cannot be built, calibrated, maintained or understood. The goal of modeling effort is to improve understandings of the relationships between feedback structure and dynamic behavior of a system (Richardson \& Pugh, 1981: 38). The formal system dynamics model used in this research was built in order to:

- Understand the causes underlying the success of an enterprise wireless PDA platform.

- Identify the key variables and relationships of the adoption of the wireless PDA platform and sources of lock-in.

- Identify the key feedback process driving the adoption of wireless PDA platform and sources of lock-in for each stakeholder in the enterprise wireless PDA market.

- Explore the role of time delays on the success of an enterprise wireless PDA platform. 


\subsection{Model boundary}

A clear understanding of the purposes of a modeling effort helps to answer questions relating to the system boundary such as what should be included and what should be excluded. Without a purpose, there can be no answer to the question of what system components are important. Without a purpose, it is impossible to define the system boundary (Richardson \& Pugh, 1981).

Any solution implemented to correct a problem without the full understanding of the feedbacks operating in the system can result in policy resistance, the tendency for interventions to be delayed, diluted, or defeated by the response of the system to the intervention itself. This is because the system reacts to the solution implemented. These unanticipated consequences, as Forrester call it "counter intuitive"; result in policy resistance (Sterman, 2000).

Treating a concept as exogenous, or omitting it, cuts all feedbacks involving that variable. Models with narrow boundaries do not capture the system's responses to policies, leaving the clients to discover them as unforeseen side effects in the real world. Narrow system boundaries are the single greatest sources of policy resistance - the tendency for interventions to be delayed, diluted, or defeated by the response of the system to the intervention itself (Sterman, 2000: 851). 
The question facing clients and modelers is not whether a model is true but whether it is useful. Sterman (2000: 890) says:

"Models fail because more basic questions about the suitability of the model to the purpose aren't asked, because the model violates basic physical laws such as conservation of matter, because a narrow boundary cut critical feedbacks, because the modelers kept the assumptions hidden from the clients, or because the modelers failed to include important stakeholders in the modeling process."

The formal system dynamics model used in this research has important boundaries. It only models the enterprise wireless PDA market in the North America. The enterprise wireless PDA markets in the other parts of the world is considered to have different dynamics and attempting to model the whole enterprise wireless PDA market would not only add complexity, it would also be impossible to collect the necessary data and gain access to the experts for interviews - a key source of input to the modeling process. Further more, during the research proposal phase; I have been guided by well known experts in the systems dynamics field that a complex model is not necessary to gain the insights. For example, in response to the posting for input for the proposed research on the Systems Dynamics Society news group, Eliot Rich $^{28}$ had suggested in his e-mail: “... I would recommend that you try to work with simple models rather than develop complex ones. You will get most of what you want from simple, and they will be easier to explain and support."

\footnotetext{
${ }^{28}$ Eliot Rich works as an Assistant Professor in the Department of Information Technology Management, School of Business, University at Albany.
} 
Table 16 lists the boundary chart of the formal model. This table summarizes the boundary of the model by listing the key variables that are included endogenously, which are exogenous, and which are excluded from the model. 


\begin{tabular}{|c|c|c|}
\hline Endogenous & Exogenous & Excluded \\
\hline Independent Software Vendors & Enterprise Contact Rate & Profits \\
\hline $\begin{array}{l}\text { Developer Population for Target } \\
\text { PDA Platform }\end{array}$ & $\begin{array}{l}\text { Contractual } \\
\text { commitments }\end{array}$ & $\begin{array}{l}\text { Social or coolness } \\
\text { factors }\end{array}$ \\
\hline $\begin{array}{l}\text { Potential Enterprise Server } \\
\text { Applications }\end{array}$ & Brand specific training & Status symbol \\
\hline $\begin{array}{l}\text { Enterprise Server Applications } \\
\text { supported on Target PDA Platform }\end{array}$ & $\begin{array}{l}\text { Competitor Enterprise } \\
\text { Contact Rate }\end{array}$ & Pricing \\
\hline Potential PDA Applications & Loyalty Programs & Revenues \\
\hline $\begin{array}{l}\text { Applications supported on Target } \\
\text { PDA Platform }\end{array}$ & $\begin{array}{l}\text { Potential PDA Users } \\
\text { Contact Rate }\end{array}$ & $\begin{array}{l}\text { Technological } \\
\text { advantages }\end{array}$ \\
\hline $\begin{array}{l}\text { Potential Enterprises Deploying } \\
\text { PDA Platforms }\end{array}$ & Search Effort & $\begin{array}{l}\text { Total cost of } \\
\text { ownership }\end{array}$ \\
\hline $\begin{array}{l}\text { Enterprises Deploying Competitor } \\
\text { PDA Platform }\end{array}$ & $\begin{array}{l}\text { Competitor Users } \\
\text { Contact Rate }\end{array}$ & PDA retirement \\
\hline $\begin{array}{l}\text { Enterprises Deploying Target PDA } \\
\text { Platform }\end{array}$ & $\begin{array}{l}\text { Information and } \\
\text { databases }\end{array}$ & \\
\hline Target PDA Users & Specialized Suppliers & \\
\hline $\begin{array}{l}\text { Carriers Deploying Competitor } \\
\text { PDA Platform }\end{array}$ & $\begin{array}{l}\text { Competitor Carrier } \\
\text { Contact Rate }\end{array}$ & \\
\hline Potential Carriers & Carriers Contact Rate & \\
\hline $\begin{array}{l}\text { Carriers Deploying Target PDA } \\
\text { Platform }\end{array}$ & Total Enterprises & \\
\hline \multirow[t]{2}{*}{ Competitor PDA Users } & Total Carriers & \\
\hline & Total PDA Users & \\
\hline
\end{tabular}

Table 16: Formal system dynamics model boundary chart 
Richardson \& Pugh (1981) say that in setting the system boundary one considers what system components are necessary to generate the behavior of interest, excluding where possible, and aggregating where useful for simplicity.

The following are the assumptions and limitations of the model:

1) Assumptions: The formal system dynamics model has the following key assumptions:

- Wireless PDA devices are not replaced or retired. Only new devices are added.

- Switching costs are the same for each stakeholder.

- Data used for the model development to be obtained using publically available information (e.g., news reports, company quarterly financial reports).

2) Time frame: The model simulates the nine years during which the RIM BlackBerry platform was introduced - a time period when the leading incumbent enterprise wireless PDA platform, Palm, lost its lead and the time when the challenger enterprise wireless PDA platform, BlackBerry, gained top position.

3) Limits: The model is based on qualitative data from interviews with domain experts, literature review, and case studies. For some of the key variables (e.g., switching costs), there is no numerical data available and additional effort to obtain qualitative data is not considered warranted. Hence, industry averages, domain expert input and best judgment were used to estimate a few key parameters. Additionally, the model considers the network effects from the perspective of the enterprise wireless PDA 
manufacturer. The researcher did not access other stakeholders (e.g., Carriers) in the enterprise wireless PDA market to incorporate their input in the modeling.

4) Level of aggregation: The model focuses on North America. This focus was chosen to meet the goals of the formal model detailed earlier. Adding too much detail in the model will dramatically increase the complexity and considered not to bring any additional benefits for the purposes of this research.

The boundaries and level of aggregation chosen affect the reach and extant of the insights that can be derived from the model.

\subsection{Model testing}

Model testing begins at the start of the project and is iterative and multidimensional. Testing is an integral part of the iterative model building process. No one test is adequate. Rather, a wide range of tests helps to assess the robustness and limitations of the model (Sterman, 2000).

Model testing builds confidence that the model is appropriate for the purpose. System dynamics modelers have developed a wide variety of specific tests to uncover flaws and improve models. Not all tests suggested in the literature may be appropriate for every modeling exercise (Sterman, 2000). The following tests were performed on the formal model developed in this research. 
1) Boundary adequacy test: Boundary adequacy tests assess the appropriateness of the model boundary for the purpose the model is being developed. Various tools and procedures that are available for this test include: model boundary charts, subsystem diagrams, causal diagrams, stock and flow maps, model equation review. To meet this test, the formal model develops a plausible hypothesis of the problem behavior based on evidence from interviews, literature review and a case study.

2) Structure assessment test: Structure assessment tests ask whether the model is consistent with knowledge of the real system relevant to the purpose. Structure assessment focuses on the level of aggregation, the conformance of the model to basic physical realities such as conservation laws, and the realism of decision rules for the agents (Sterman, 2000: 863). This test was developed during the model review stage with participants highly knowledgeable in the enterprise wireless PDA market. The results were satisfactory based on the model review in sections 7.4 and 7.5 .

3) Dimensional consistency test: Dimensional consistency test ensures the units of measure for each variable and the equations in the model are consistent (e.g., variables with incorrect combinations of units). The formal model's dimensional consistency was tested (i) using dimensional consistency software ${ }^{29}$ (ii) every equation was verified for dimensional consistency without the inclusion of arbitrary scaling factors that have no real world meaning. Tests (i) and (ii) were satisfactory.

${ }^{29}$ Vensim PLE contains a built-in tool to run this test 
4) Extreme conditions test: Models should be robust in extreme conditions.

Robustness under extreme conditions means the model should behave in a realistic fashion no matter how extreme the inputs or policies imposed on it may be (Sterman, 2000: 869). 


\section{Model simulation and scenario analysis}

This chapter is organized into three sections. In the first section I present the results of running the formal system dynamics model. The base run was calibrated using the quarterly results of the enterprise wireless PDA platform upon which the formal model is based. In the second section I present other scenarios based on (i) the time of entry of the target PDA platform in the market and (ii) switching costs. Finally, in the third section I present the discussion of the simulation runs.

\subsection{Base run}

The base run was calibrated using the quarterly results of the enterprise wireless PDA platform upon which this research is based. Several key parameters (e.g., number of Enterprises Deploying Target PDA Platform, Applications Supported on Target PDA Platform) in the base run were calibrated using the quarterly results of the enterprise wireless PDA platform upon which the formal SD model is based.

The formal SD model also contained several other parameters like contact rate, developer adjustment time, average number of developers per independent software vendor and switching costs (e.g., information and databases, brand specific training). These parameters were qualitative and existed to capture the various factors that were at play in the enterprise wireless PDA market. The values of these parameters were best estimates - often with input from experts in the enterprise wireless PDA market. The base run was 
setup to have low switching costs for switching from the Competitor PDA Platform to the Target PDA Platform ${ }^{30}$.

\subsubsection{Key parameters}

Table 17 lists a summary of key parameters along with their default values used for the base run.

${ }^{30}$ Lower switching costs to switch from Competitor PDA Platform to the Target PDA Platform indicate that the Competitor PDA Platform is modular compared to the Target PDA Platform 


\begin{tabular}{|c|c|c|}
\hline Parameter name & Default value & Units \\
\hline Average number of developers per ISV & 10 & developers \\
\hline Developer adjustment time & 12 & months \\
\hline Alliance adjustment time & 24 & months \\
\hline Desired alliances & 300 & alliances \\
\hline Desired developers & 5,000 & developers \\
\hline Developer population for target PDA platform & 4,800 & developers \\
\hline $\begin{array}{l}\text { Months to develop PDA application per } \\
\text { developer }\end{array}$ & 500 & months \\
\hline Potential enterprise server applications & 10 & applications \\
\hline $\begin{array}{l}\text { Months to develop server application per } \\
\text { developer }\end{array}$ & 1,200 & months \\
\hline Potential PDA applications & 1,000 & applications \\
\hline PDA users per enterprise & 50 & $\begin{array}{l}\text { PDA users/ } \\
\text { enterprises }\end{array}$ \\
\hline Competitor platform delay & 0 & months \\
\hline Enterprise switch delay & 12 & months \\
\hline Target platform delay & 12 & months \\
\hline Potential enterprises deploying PDA platforms & 200,000 & enterprises \\
\hline Total enterprises & 200,000 & enterprises \\
\hline $\begin{array}{l}\text { Applications supported for competitor PDA } \\
\text { platform }\end{array}$ & 150 & applications \\
\hline Potential PDA users & $10,000,000$ & PDA users \\
\hline Total PDA users & $10,000,000$ & PDA users \\
\hline
\end{tabular}

Table 17: Parameters and default values for the base run 


\subsubsection{Model behavior metrics}

The following model variables were used to measure the patterns of virtual enterprise wireless PDA market (micro-world):

- Enterprises Deploying Target PDA Platform: Cumulative number of enterprises deploying the target PDA platform.

- Enterprises Deploying Competitor PDA Platform: Cumulative number of enterprises deploying the competitor PDA platform.

- Target PDA Platform Users: Cumulative number of users using the target PDA devices.

- Competitor PDA Platform Users: Cumulative number of users using the competitor PDA devices.

- Carriers Deploying Target PDA Platform: Cumulative number of carriers deploying Target PDA platform.

- Carriers Deploying Competitors PDA Platform: Cumulative number of carriers deploying the competitor PDA platform.

- Developer Population For Target PDA Platform: Number of in-house developers for the target PDA platform.

- Independent Software Vendors: Number of ISVs contributing to the development of applications on Target PDA platform.

- Enterprise Server Applications Supported on Target PDA Platform: Cumulative number of server applications supported on the target PDA platform. 
- Applications Supported For Target PDA Platform: Cumulative number of PDA applications (PDA only application without enterprise server component) supported on the target PDA platform.

The success of the target PDA platform was measured using the following variables: Enterprises Deploying Target PDA Platform, Target PDA Platform Users, and Carriers Deploying Target PDA Platform.

\subsubsection{Base run behavior}

Figure 16, Figure 17 and Figure 18 in Appendix 2 show the summary of the simulation results from the base run. Summary of the metrics of the base run scenario are as follows:

- The Enterprises Deploying Target PDA Platform, Target PDA Platform Users and Carriers Deploying Target PDA Platform continue to grow. At the end of the simulation each of these parameters reach $16 \%^{31} ; 34 \%$ and $14 \%$ respectively.

- The enterprise switch rate continues to increase resulting in Enterprises Deploying Competitor PDA Platform, Competitor PDA Platform Users and Carriers Deploying Competitors PDA Platform switch to the target PDA platform.

- The Target PDA Platform was able to attract the Enterprises, PDA Users and Carriers to switch to the Target PDA Platform. The Competitor PDA Platform start losing to the Target PDA Platform after 100 months.

\footnotetext{
${ }^{31}$ Reflecting RIM market share in September 2008. Source: "RIM doubles market share in tough quarter", last accessed: November 02, 2008. http://www.financialpost.com/story-printer.html?id=777632
} 


\section{$9.2 \quad$ Scenario analysis}

This section presents scenario design and simulation of several scenarios. The model behavior in each scenario provides insights on the role of network effects and their strategic implications in enterprise wireless PDA market.

Drawing from the literature (Shapiro \& Varian, 1999; Arthur, 1996; Lee et. al., 2006;

Suraz, 2005), this research proposes four scenarios based on switching costs and time of market entry. The analysis of the model behavior of the scenario sheds light on the role of network effects and switching costs in the success of an enterprise wireless PDA platform.

\subsubsection{Target PDA Platform market entry, switching costs scenarios}

The simulations presented in this subsection analyze the model behavior under different market entry time periods and different switching cost scenarios. The key variables controlling the model for these scenarios are: target platform delay, enterprise switch multiplier, PDA user switch multiplier and, carrier switch multiplier. Table 18 presents the resulting scenarios.

1) Target platform delay: This variable represents the number of months since the start of the simulation after which the Target PDA Platform enters the market. 
2) Enterprise switch multiplier, PDA user switch multiplier and, carrier switch multiplier: These qualitative variables represent the switching costs each stakeholder in the enterprise PDA market. Evidence from the interviews suggests that switching costs for each of the stakeholder in the enterprise wireless PDA market apply at different factor (see Chapter 5). For example, the switching costs for an individual PDA user are far lower than the switching costs for an enterprise.

\begin{tabular}{|l|l|l|l|}
\cline { 3 - 4 } \multicolumn{2}{c|}{} & \multicolumn{2}{l|}{ Target PDA platform market entry } \\
\cline { 3 - 4 } \multicolumn{2}{c|}{} & Late $^{32}$ & Early \\
\hline \multirow{2}{*}{$\begin{array}{l}\text { Switching } \\
\text { costs }\end{array}$} & Low $^{34}$ & Scenario 1 & Scenario 3 \\
\cline { 2 - 4 } & High $^{35}$ & Scenario 2 & Scenario 4 \\
\hline
\end{tabular}

Table 18: Market entry and switching costs scenarios

\subsubsection{Comparison of market entry, switching costs scenarios with base run}

Figure 19, Figure 20 and Figure 21 in Appendix 2 show the summary of the simulation results for these four scenarios compared with the base run. Table 19 presents a summary of the behaviors observed.

\footnotetext{
${ }^{32}$ Twelve months after the Competitor PDA Platform

${ }^{33}$ At the same time as the Competitor PDA Platform

${ }^{34}$ Switching costs for switching from Competitor PDA Platform to Target PDA Platform are low and same as the base run

${ }^{35}$ Switching costs for switching from Competitor PDA Platform to Target PDA Platform are twice as the base run
} 
Following is a summary of important observations from each of these scenarios:

\section{Scenario 1:}

- This scenario is essentially same as the base run. The Target PDA Platform was able to attract Enterprises, PDA Users and Carriers to switch from Competitor PDA Platform to the Target PDA Platform.

- Competitor PDA Platform starts losing to the Target PDA Platform after 100 months.

- Target PDA Platform captured 16\% of Enterprises, $6 \%$ of PDA users and 15\% of Carriers at the end of the simulation.

- Competitor PDA Platform peaked at time 100 by capturing $80 \%$ of Enterprises and start loosing to the Target PDA Platform.

\section{Scenario 2:}

- Target PDA Platform had limited success in attracting Enterprises, PDA Users and Carriers from the potential pool as the word of mouth feedback works in favor for Competitor PDA Platform.

- Target PDA Platform was unable to switch Enterprises, PDA Users and Carriers using Competitor PDA Platform to the Target PDA Platform.

- Competitor PDA Platform captured 94\% of Enterprises, 51\% of PDA users and $83 \%$ of Carriers at the end of the simulation. 


\section{Scenario 3:}

- Target PDA Platform was able to attract the Enterprises, PDA Users and Carriers to switch to the Target PDA Platform.

- Competitor PDA Platform looses to the Target PDA Platform. Peaks at 68 months by capturing $25 \%$ of Enterprises and eventually looses completely to the Target PDA Platform at the end of the simulation.

\section{Scenario 4:}

- Both the Competitor PDA Platform and the Target PDA Platform managed to attract Enterprises, PDA users and Carriers to their respective Platforms depending on the attractiveness of the respective platforms.

- Competitor PDA Platform manages to sustain most of its installed base (similarly Target PDA Platform manages to sustain most of its installed based depending on the switching costs).

- Competitor PDA Platform peaks at 86 months by capturing 56\% of Enterprises and starts loosing to the Target PDA Platform.

The simulation results for the above scenarios seem to be counter-intuitive, as these results suggest that the enterprise wireless PDA platform with high switching costs seem to capture larger market share. Would this be possible? The following section introduces an external market shock, a sudden reduction in the switching costs, to explore the behavior of the system. 


\begin{tabular}{|l|l|r|c|c|c|}
\cline { 2 - 6 } \multicolumn{2}{c|}{} & Total stock & $\begin{array}{c}\text { Target } \\
\text { stock } \\
\%\end{array}$ & $\begin{array}{c}\text { Competitor } \\
\text { stock } \\
\%\end{array}$ & $\begin{array}{c}\text { Potential } \\
\text { stock } \\
\%\end{array}$ \\
\hline \multirow{4}{*}{ Base run } & Enterprise & 740,113 & 16 & 79 & 5 \\
\cline { 2 - 6 } & PDA users & $128,900,900$ & 6 & 44 & 50 \\
\cline { 2 - 6 } & Carriers & 1,753 & 15 & 69 & 15 \\
\hline \multirow{4}{*}{ Scenario 1 } & Enterprise & 740,113 & 16 & 79 & 5 \\
\cline { 2 - 6 } & PDA users & $128,900,900$ & 6 & 44 & 50 \\
\cline { 2 - 6 } & Carriers & 803 & 36 & 47 & 17 \\
\hline \multirow{3}{*}{ Scenario 3 } & Enterprise & 740,109 & 2 & 94 & 4 \\
\cline { 2 - 6 } & PDA users & $128,900,926$ & 1 & 51 & 48 \\
\cline { 2 - 6 } & Carriers & 803 & 3 & 83 & 14 \\
\cline { 2 - 6 } & Enterprise & 740,111 & 90 & 0 & 10 \\
\cline { 2 - 6 } & PDA users & $128,901,200$ & 53 & 0 & 47 \\
\hline \multirow{3}{*}{ Scenario 4 } & Carriers & 803 & 85 & 0 & 15 \\
\cline { 2 - 6 } & Enterprise & 740,111 & 49 & 46 & 5 \\
\cline { 2 - 6 } & PDA users & $128,901,057$ & 53 & 0 & 47 \\
\hline
\end{tabular}

Table 19: Summary of results for market entry and switching costs scenarios

\subsubsection{Shocks}

The scenarios presented in the previous section suggest that the enterprise wireless PDA platform with high switching costs captures larger market share and assume that the enterprise wireless PDA systems can continue to keep the switching costs higher. Would 
this hold if the enterprise wireless PDA platforms were to face an unexpected drop in switching costs for stakeholders in the enterprise wireless PDA market?

In the following scenarios, the sudden drop in switching costs for each of the stakeholders in the enterprise wireless PDA market is modeled by applying an external shock to the switching costs factors by lowering the switching costs at year 2 of the simulation. The scenarios presented in this subsection introduce the shocks to the base run scenario. The model behavior for the sudden drop in switching costs scenarios is presented in Figure 22, Figure 23 and Figure 24. Table 20 presents a summary of the behaviors observed.

The simulations presented in this subsection analyze the model behavior under different shock scenarios.

\section{Scenario 5:}

- Shock: Target PDA Platform lowers the switching costs for Enterprises to switch from Competitor PDA Platform to Target PDA Platform by $50 \%$ at time 24 or year 2 of the simulation.

- Target PDA Platform was able to capture $71 \%$ of the Enterprises, compared to the $16 \%$ in the base run.

- There is no change to the number of PDA Users ${ }^{36}$ and Carriers using the Target PDA Platform - remained at $6 \%$ and $15 \%$ respectively.

\footnotetext{
${ }^{36}$ However, if the average number of PDA users per Enterprise is increased from 50 to 100 , the Target PDA Platform Users increase from $6 \%$ to $10 \%$ when compared with the base run
} 


\section{Scenario 6:}

- Shock: Target PDA Platform lowers the switching costs for PDA Users to switch from Competitor PDA Platform to Target PDA Platform by $50 \%$ at time 24 or year 2 of the simulation.

- Target PDA Platform was able to capture $30 \%$ of the PDA users, compared to the $6 \%$ in the base run.

- Target PDA Platform was able to capture $16 \%$ of the Carriers - slightly higher than the $15 \%$ in the base run.

- There is no change to the number of Enterprises using the Target PDA Platform remained at $16 \%$.

\section{Scenario 7:}

- Shock: Target PDA Platform lowers the switching costs for Carriers to switch from Competitor PDA Platform to Target PDA Platform by 50\% at time 24 or year 2 of the simulation.

- Target PDA Platform was able to capture $63 \%$ of the Carrier, compared to the $15 \%$ in the base run.

- There is no change to the number of Enterprises and PDA users using the Target PDA Platform - remained at $16 \%$ and $6 \%$ respectively.

\section{Scenario 8:}


- Shock: Target PDA Platform lowers the switching costs for all stakeholders Enterprises, PDA users and Carriers to switch from Competitor PDA Platform to Target PDA Platform by $50 \%$ at time 24 or year 2 of the simulation.

- Target PDA Platform was able to capture $71 \%$ of the Enterprises, $30 \%$ of the PDA users and $64 \%$ of the Carriers, compared to the $16 \%, 6 \%$ and $15 \%$ in the base run.

Following noticeable observations were made when the system is impacted with an external shock of sudden lowering of the switching costs:

- Lowering the switching costs, even if it is only marginal, for all the stakeholders at once, resulted in attracting most adopters compared to lowering the switching costs independently for each stakeholder.

- If the Target PDA Platform can only lower the switching costs for one stakeholder, the simulation results suggest that focusing on PDA users will attract more adopters. As more PDA users switch to the Target PDA Platform, it will also result in more Carriers switching to the Target PDA Platform.

- Lowering the switching costs for the enterprises alone does not have significant impact, if the average number of PDA users per enterprise is low. 


\begin{tabular}{|c|c|c|c|c|c|}
\hline & & Total stock & $\begin{array}{c}\text { Target } \\
\text { stock } \\
\%\end{array}$ & $\begin{array}{c}\text { Competitor } \\
\text { stock } \\
\%\end{array}$ & $\begin{array}{c}\text { Potential } \\
\text { stock } \\
\%\end{array}$ \\
\hline \multirow[t]{3}{*}{ Base run } & Enterprise & 740,113 & 16 & 79 & 5 \\
\hline & PDA users & $128,900,900$ & 6 & 44 & 50 \\
\hline & Carriers & 1,753 & 15 & 69 & 15 \\
\hline \multirow[t]{3}{*}{ Scenario 5} & Enterprise & 740,111 & 71 & 23 & $\overline{6}$ \\
\hline & PDA users & $128,900,900$ & 6 & 44 & 50 \\
\hline & Carriers & 1,753 & 15 & 69 & 15 \\
\hline \multirow[t]{3}{*}{ Scenario 6} & Enterprise & 740,113 & 16 & 79 & 5 \\
\hline & PDA users & $128,900,800$ & 30 & 14 & 56 \\
\hline & Carriers & 1,753 & 16 & 69 & 15 \\
\hline \multirow[t]{3}{*}{ Scenario 7} & Enterprise & 740,113 & 16 & 79 & 5 \\
\hline & PDA users & $128,900,900$ & 6 & 44 & 50 \\
\hline & Carriers & 1,753 & 63 & 19 & 18 \\
\hline \multirow[t]{3}{*}{ Scenario 8} & Enterprise & 740,111 & 71 & 23 & 6 \\
\hline & PDA users & $128,900,900$ & 30 & 14 & 56 \\
\hline & Carriers & 1,753 & 64 & 18 & 18 \\
\hline
\end{tabular}

Table 20: Summary of results for market shock scenarios 


\subsection{Discussion}

The notable findings of the overall simulation runs are as follows:

- Switching costs play a significant role in the continued success of an enterprise wireless PDA platform. These findings hold well regardless of the time of entry in the market.

- Word of mouth feedback play significant role in the enterprise wireless PDA platform adoption decisions.

- Independent software vendor's contribution to an enterprise wireless PDA platform is most important at the early phases of the platform development. Simulation results suggest that during the later stages of the platform development, the loss of ISV's contribution to the enterprise wireless PDA platform does not significantly impact the number of applications available or impact the platform adoption.

- When the switching costs for switching from Competitor PDA Platform to Target PDA Platform are suddenly lowered (as in Scenario 8), the Competitor PDA Platform may be able to lower the rate at which its users are switching by offering incentives to stay with the Competitor PDA Platform. 


\section{Conclusions, limitations, and future research}

The objective of this research was to develop and simulate a model of network effects in enterprise wireless PDA market using SD framework. The model captured the network effects and sources of lock-in for each stakeholder in this market. The model helped understand the role of network effects and their strategic implications for the success of an enterprise wireless PDA platform.

This chapter is organized into three sections. Section 1 provides the answers to the research questions. Section 2 provides the conclusions of this research. Section 3 describes the contribution to the academic literature and management practice. Section 4 describes limitations of this research. Lastly section 5 provides suggestions for future research.

\subsection{Answers to research questions}

The following are the answers to the research questions of this thesis:

1) How do network effects in the enterprise wireless PDA market affect stakeholders?

The stakeholders in the enterprise wireless PDA market namely - Enterprises, Enterprise wireless PDA platform manufacturers, PDA users, and Carriers - are affected by network effects in the following ways: Enterprises select broadly used 
applications (e.g., Microsoft Outlook) and choose the formats for storing documents and information (e.g., Adobe PDF, MS-Office) that they can exchange freely.

Enterprise wireless PDA platform manufacturers in their efforts to market their wireless PDA platform to larger market segment, attempt to support technologies (e.g., GSM, Wi-Fi), applications, and complementary products (e.g., Bluetooth, Flash memory) that are popular and have a large user base. Enterprise wireless PDA platform manufacturers want to attract a large developer population and attempt to reduce the time and effort in learning to develop applications for its platform by supporting popular development languages (e.g., Java, J2ME), tools and integrated development environments (e.g., Eclipse). Enterprise wireless PDA platform manufacturers, while trying to lock-in the Enterprises and PDA Users to its wireless PDA platform, attempt to reduce the switching costs for switching from the competitor's PDA platform to its platform.

Enterprises and PDA users value compatibility and do not want to be locked-in with technologies that are not compatible with other enterprises and PDA users they interact with. It is evident from this study that the word of mouth feedback plays a significant role in the adoption decisions of enterprises and PDA users.

Carriers support the enterprise wireless PDA platforms which are widely adopted by Enterprises and PDA users. As more Enterprises and PDA users start to adopt the wireless PDA platform, more Carriers start supporting that wireless PDA platform as 
they attempt to capitalize the momentum of the wireless PDA platform adoption and do not want to be left behind.

\section{2) How do sources of lock-in and switching costs impact stakeholders?}

Using the definitions of sources of lock-in from Shapiro \& Varian (1998), each of the stakeholders in the enterprise wireless PDA market has different sources of lock-in and associated switching costs. Results of the simulation indicate that if a competitor wireless PDA platform vendor can lower switching costs for only one stakeholder, focusing on PDA user will help attract more adopters. As more PDA users switch to the competitor platform, carriers are pressured to switch.

Enterprise wireless PDA platform companies can choose lock-in factors that they want and that they can control to attract the wireless PDA users to switch from the competitor wireless PDA platform or lock-in on target wireless PDA platform. For

example, a wireless PDA platform vendor may choose a combination of the following strategies to attract Enterprises and Wireless PDA users away from competitor platform:

a) Information and databases: Provide migration software for transfer of information and databases from competitor's platform to make switching easier.

b) Brand specific training: Provide free training, partner with $3^{\text {rd }}$ party training centers to make training conveniently available, offer certification programs, etc. 
c) Specialized suppliers: Offer flexibility in the negotiations for new features or open up interfaces so Enterprises can develop their enhancements.

d) Contractual commitments: Offer longer contract terms so enterprises and PDA users may not switch to different wireless PDA platform or to a different wireless carrier.

e) Search costs: Wireless PDA platform vendors may approach enterprises that are either considering adopting a wireless PDA platform or already using competitor's wireless PDA platform and provide necessary information so the search costs for enterprises may be reduced compelling enterprises to adopt target wireless PDA platform or switch away from the competitor wireless PDA platform.

f) Loyalty programs: Wireless PDA platform vendors may offer incentive programs such as free training for every 50 new wireless PDA devices purchased etc.

Table 21 summarizes the sources of lock-in and associated switching costs for each of the stakeholder in the enterprise wireless PDA market. 


\begin{tabular}{|c|c|c|c|}
\hline $\begin{array}{l}\text { Sources of } \\
\text { lock-in }\end{array}$ & Switching costs & Enterprises and PDA users & Carriers \\
\hline $\begin{array}{l}\text { Brand } \\
\text { specific } \\
\text { training }\end{array}$ & $\begin{array}{l}\text { Cost for time and effort re- } \\
\text { training and lost productivity }\end{array}$ & $\begin{array}{l}\text { Cost to re-train employees for supporting } \\
\text { and using the new wireless PDA } \\
\text { platform. } \\
\text { Associated loss of productivity learning } \\
\text { and being adept at it. }\end{array}$ & $\begin{array}{l}\text { Cost to re-train employees } \\
\text { for supporting the new } \\
\text { wireless PDA platform. } \\
\text { Associated loss of } \\
\text { productivity. }\end{array}$ \\
\hline $\begin{array}{l}\text { Contractual } \\
\text { commitments }\end{array}$ & Cost for breaking contract & $\begin{array}{l}\text { Enterprises and wireless PDA users often } \\
\text { have commitments for minimum service } \\
\text { duration. }\end{array}$ & $\begin{array}{l}\text { - Carriers may have volume } \\
\text { commitments with wireless } \\
\text { PDA platform vendors. }\end{array}$ \\
\hline $\begin{array}{l}\text { Information } \\
\text { \& databases }\end{array}$ & $\begin{array}{l}\text { Cost for transferring the } \\
\text { information and any loss of } \\
\text { information during the transfer } \\
\text { to a new wireless PDA platform }\end{array}$ & $\begin{array}{l}\text { Enterprises and PDA users accumulate } \\
\text { information and databases over time. } \\
\text { Transferring this information and } \\
\text { databases to the new platform can be } \\
\text { expensive and often unlikely to get } \\
\text { transferred perfectly. }\end{array}$ & $\begin{array}{l}\text { Not considered a } \\
\text { significant factor. }\end{array}$ \\
\hline $\begin{array}{l}\text { Loyalty } \\
\text { programs }\end{array}$ & $\begin{array}{l}\text { Cost associated with possible } \\
\text { lost benefits for continued use }\end{array}$ & $\begin{array}{l}\text { Possible loss of perks for continued use } \\
\text { (e.g., free upgrades, training). }\end{array}$ & $\begin{array}{l}\text { Not considered a } \\
\text { significant factor. }\end{array}$ \\
\hline Search costs & $\begin{array}{l}\text { Cost for time and effort } \\
\text { involved in identifying a new } \\
\text { wireless PDA platform that } \\
\text { match the needs }\end{array}$ & $\begin{array}{l}\text { Potential risks associated with picking an } \\
\text { unknown supplier. }\end{array}$ & $\begin{array}{l}\text { Potential risks associated } \\
\text { with picking an unknown } \\
\text { supplier. }\end{array}$ \\
\hline $\begin{array}{l}\text { Specialized } \\
\text { suppliers }\end{array}$ & $\begin{array}{l}\text { Cost for getting enhancements } \\
\text { from the enterprise wireless } \\
\text { PDA platform manufacturer }\end{array}$ & $\begin{array}{l}\text { As enterprises and PDA users buy the } \\
\text { wireless PDA platform and } \\
\text { complementary equipment, they get } \\
\text { dependent on the Enterprise wireless } \\
\text { PDA platform manufacturer to provide } \\
\text { enhancements and ongoing support. }\end{array}$ & $\begin{array}{l}\text { Carriers become dependent } \\
\text { on the Enterprise wireless } \\
\text { PDA platform } \\
\text { manufacturer to provide } \\
\text { enhancements and ongoing } \\
\text { support. }\end{array}$ \\
\hline
\end{tabular}

Table 21: Sources of lock-in and switching costs for enterprises, PDA users and carriers 


\subsection{Conclusions}

1) Success of an enterprise wireless PDA platform has an endogenous component. The success of an enterprise wireless PDA platform is impacted by two key feedback processes: (i) the word-of-mouth feedback, which accelerates the number of enterprises and users adopting the enterprise wireless PDA platform (ii) switching costs, which lock-in the stakeholders.

2) Product architecture impacts performance and lock-in. Integrated product architecture not only helps the product performance it also helps lock-in the stakeholders - especially when the demands of the market are higher than what technology can deliver.

3) Time delays matter. The simulation results show how the shortening and lengthening of critical time delays (e.g., entry delay, switching delay) in the enterprise wireless PDA market have a significant impact on the success of an enterprise wireless PDA platform.

4) The simulation results suggest that displacing an integrated enterprise PDA platform is difficult. An incumbent enterprise PDA platform with an integrated solution would relatively have more time to react to the competitor's actions, as replacing an integrated solution would take longer time in the market.

5) This research demonstrates each stakeholder in the enterprise wireless PDA market has different sources of lock-in. Sources of lock-in for Enterprises and PDA Users are: Brand specific training, Contractual commitments, Information and databases, 
Specialized suppliers, Loyalty programs, Search costs; sources of lock-in for Carriers are: Brand specific training, Contractual commitments, Specialized suppliers, Search costs.

\subsection{Contribution}

This research makes at least three contributions to the academic literature and management practice:

1) A system dynamics model showing the key feedback loops between the key stakeholders in the enterprise wireless PDA market. Based on the system dynamics model, I find the existence of positive feedbacks reinforce adoption of a wireless PDA platform. As an enterprise adopts a wireless PDA platform the switching costs associated with the adoption of that wireless PDA platform reinforce the positive feedback and effectively lock in. A successful enterprise wireless PDA platform locks-in its adopters; it also lowers the switching costs for the competitor enterprise wireless PDA platform.

2) Identification, analysis and strategic implications of network effects, lock-in and switching costs on stakeholders in enterprise wireless PDA platform. Table 8 provides a summary and mapping of insights from the literature review and case study. The system dynamics modeling and simulation runs give the following key findings: 
- If a competitor wireless PDA platform can lower switching costs for only one stakeholder, focusing on PDA users will help attract more adopters. As more PDA users switch to the competitor platform, carriers are pressured to switch.

- Independent software vendors (ISVs) make very important contribution to success of an enterprise wireless PDA platform. ISVs are critical at early phase of platform development, without ISVs a PDA platform does not take-off.

- Loss of ISV's contribution to an enterprise wireless PDA platform at later phases does not significantly impact number of applications available or impact platform adoption.

- Time of entry and current dominant design in the market significantly affect success of an enterprise wireless PDA platform.

- Stakeholders are less concerned with lock-in in underserved markets where performance demands exceed what current technology can offer.

- Success of an enterprise wireless PDA platform depends on how effectively it can reduce switching costs of competitor platform for all stakeholders, while lockingin stakeholders to its own platform.

- Displacing an integrated enterprise wireless PDA platform is difficult, thus an incumbent with an integrated solution has more time to react to competitor actions.

- Product architecture impacts performance and lock-in.

It is noticeable from the above findings generated from the SD modeling and simulation that, SD helps identify and study the feedback loops between stakeholders 
in the enterprise wireless PDA market, similarly SD help identify and study the impact of time delays in the enterprise wireless PDA market.

3) A list of strategic actions by two important wireless PDA platforms involving network effects. The case study focuses on two important enterprise wireless PDA platform companies in the North America. The case provides a list of strategic actions by RIM and Palm Inc., which form the basis for the research to study the role of network effects in the success and failure of an enterprise wireless PDA platform.

\subsection{Limitations}

This research has the following limitations:

1) Limitations of sample size: This research was based on voluntary interviews with respondents from wireless PDA manufacturing and wireless telecommunications manufacturing companies with years of experience in this field. The selected respondents were contacted using the contacts of the researcher, thesis supervisor and contacts of the previously contacted respondents. Though there was an initial show of interest from other wireless PDA manufacturer the difficulty in communicating remotely has limited the selection of the respondents to the participants where a faceto-face interview is possible.

2) Limitations of sample selection: This research does not include interviews with other wireless PDA platform manufacturers (e.g., Palm, Microsoft). Researcher had access to only one of the wireless PDA platform vendor. Interviews with other stakeholders 
(e.g., Wireless carriers) would be beneficial. Also, this research specifically focuses on the enterprise wireless PDA market in the North America. It would be beneficial to include other markets, specifically the emerging markets like India and China.

3) Limitations of qualitative data: The model relies on the subjective judgment of the researcher and few research respondents to provide best estimation for the parameter values. On one hand some of the variables used in the model are truly qualitative, for example switching costs; the other variables are calibrated only based on publically available data of one wireless PDA platform company of the interview respondents. It would be valuable if the researcher had access to quantitative data to enhance and calibrate the model and to test the historical data to simulations. However, it may be argued that such numerical data may not be possibly available from all stakeholders due to its confidential nature.

\subsection{Future research}

This research can be extended in the following areas:

- Open source software (OSS) is considered to increase the diffusion of innovation using network effects (von Hippel \& von Krogh, 2003). Linux is commanding $16.1 \%$ market share, $2^{\text {nd }}$ place in worldwide PDA and smart phone OS (Cozza \& Kort, 2007). It would have been beneficial to have researched the role of OSS in the enterprise wireless PDA market and how it influences the network effects in this market. 
- Adoption of technological innovations is influenced by social icon or status symbol (Pereira, 2002; Kulviwat, Bruner II \& A1-Shuridah, 2006). It would be beneficial to extend this research to include the social aspects on the adoption of enterprise wireless PDA platform.

- Enterprise wireless PDA adoption under new business models, e.g., advertisements based.

- Extend the model to make it a predictive model using qualitative data 


\section{References}

Alchian, A.A. 1995. Vertical integration and regulation in the telephone industry. Managerial and Decision Economics, 16: 323-326.

Anthony, S.A., \& Christensen, C.M. 2005. How you can benefit by predicting change. Financial Executive, March: 36-41.

Arthur, B. 1996. Increasing returns and the new world of business. Harvard Business Review, 74(4): 100-109.

Asvanund, A., Clay, K., Ramayya, K., \& Smith, M.D. 2004. An empirical analysis of network externalities in peer-to-peer music-sharing networks. Information Systems Research, 15(2): 155-174.

Birke, D., \& Swann, G.M.P. 2006. Network effects and their choice of mobile phone operator. Journal of Evolutionary Economics, 16(1/2): 65-84.

Cain, M.W. 2007. Market scope for e-mail systems 2007. Gartner, 1-10.

Chakravorti, B. 2004. The new rules for bringing innovation to market. Harvard Business Review, 82(3): 58-67. 
Christensen, C.M., \& Raynor, M. 2003. The innovator's solution. Boston-MA: Harvard Business School Press.

Christensen, C.M., Raynor, M., \& Verlinden, M. 2001. Skate to where the money will be. Harvard Business Review, 79(10): 72-81.

Coyle, G. 1999. Qualitative modeling in system dynamics or what are the wise limits of quantification? Keynote address to the conference of the System Dynamics Society, Wellington.

Cozza, R., \& Kort, T. 2007. Dataquest insight: Worldwide PDA and smartphone shipments soar $42.7 \%$ in 2006. Gartner, 1-14.

Davis, J.P., Eisenhardt, E.M., \& Bingham, C.B. 2007. Developing theory through simulation methods. Academy of Management Review, 32(2): 480-499.

Economides, N., \& Katsamakas, E. 2006. Two-sided competition of proprietary vs. open source technology platforms and implications for the software industry. Management Science, 52(7): 1057-1071.

Farrell, J., \& Klemperer, P. 2007. Coordination and lock-In: Competition with switching costs and network effects. In M. Armstrong \& R. Porter (Eds.), Handbook of Industrial Organization, 3: 1967-2072. North-Holland: Elsevier. 
Farrell, J., \& Shapiro, C. 1988. Dynamic competition with switching costs. Journal of Economics, 19(1): 123-137.

Foddy, W. 1993. Constructing questions for interviews and questionnaires: Theory and practice in social research. Cambridge, UK: Cambridge University Press.

Forrester, J.W. 1994. System dynamics, systems thinking, and soft OR. System Dynamics Review, 10(2-3): 245-256.

Forrester, J.W. 1995. The beginning of system dynamics. McKinsey Quarterly, 4: 4-16.

Größler, A., J.H. Thun, \& Milling, P.M. 2001. Diffusion of goods considering network effects: A system dynamics-based approach. Paper presented at $18^{\text {th }}$ International Conference of the System Dynamics Society, Bergen.

Katz, M.L., \& Shapiro, C. 1986. Technology adoption in the presence of network externalities. Journal of Political Economy, 94(4): 822-841.

Katz, M.L., \& Shapiro, C. 1994. Systems competition and network effects. Journal of Economic Perspectives, 8(2): 93-115.

Kulviwat, S., Bruner II, G.C., \& Al-Shuridah, O. 2008. The Role of Social Influence on Adoption of High Tech Innovations: The Moderating Effect of Public/Private 
Consumption. Journal of Business Research, in press, doi:10.1016/j.jbusres.2007.04.014

Lecocq, X., \& Demil, B. 2006. Strategizing industry structure. Strategic Management Journal, 27: 891-898.

Lee, E., Lee, J., \& Lee, J. 2006. Reconsideration of the winner-take-all hypothesis: Complex networks and local bias. Management Science, 52(12): 1838-1848.

Luna, L. \& D. Lines. 2003. Collecting and analyzing qualitative data for system dynamics: methods and models. System Dynamics Review, 19(4): 271-296.

Majumdar, S.K., \& Venkataraman, S. 1998. Network effects and their adoption of new technology: Evidence from the US telecommunications industry. Strategic Management Journal, 19: 1045-1062.

Nair, H., Chintagunta, P., \& Dube, J. 2004. Empirical analysis of indirect network effects in the market for personal digital assitant. Quantitative Marketing and Economics, 2: $23-58$.

Oliva, R., Sterman, J.D., \& Giese, M. 2003. Limits of growth in the new economy: exploring the 'get big fast' strategy in e-commerce. System Dynamics Review, 19(2): 83-117. 
Oliver, R.W. \& Scheffman, D.T. 1995. The regulation of vertical relationships in the us telecommunications industry. Managerial and Decision Economics, 16(4): 327348.

Pereira, R.E. 2002. An adopter-centered approach to understanding adoption of innovations. European Journal of Innovation Management, 5(1): 40-49.

Porter, M. 1980. Industry structure and competitive strategy: Keys to profitability. Financial Analysts Journal, 36(4): 30-41.

Richard, G.P. \& Pugh, A.L. 1981. Introduction to system dynamics modeling with DYNAMO. Cambridge: MIT Press.

Satyanarayanan, M. 1996. Fundamental challenges in mobile computing. Proceedings of the fifteenth annual ACM symposium on principles of distributed computing, Philadelphia.

Shapiro, C., \& Varian, H.R. 1999. Information rules - A strategic guide to the network economy. Boston-MA: Harvard Business School Press.

Srinivasan, R., Lilien, G.L., \& Rangaswamy, A. 2004. First in, first out? The effects of network externalities on pioneer survival. Journal of Marketing, 68: 41-58. 
Sterman, J. 2000. Systems dynamics modeling: tools for learning in a complex world. New York: Irwin/McGraw-Hill.

Sterman, J.D., Henderson, R., Beinhocker, E.D., \& Newman, L.I. 2007. Getting big too fast: Strategic dynamics with increasing returns and bounded rationality. Management Science, 53(4): 683-696.

von Hippel, E., \& von Krogh, G. 2003. Open source software and the 'private-collective' innovation model: Issues for organization science. Organization Science, 14(2): 209-223.

Warren, K. 2008. Strategic Management Dynamics. John Wiley \& Sons, Chichester.

Yankee Group. 2001. From Voicephone to Smartphone: The Evolution of Wireless Intelligent Devices in Europe.

Yepez, C. 2004. Venture capital investment dynamics: Modeling the Ottawa boom-andbust. Masters thesis, Telecommunications Technology Management, Carleton University, Ottawa, Canada, K1S 5B6 
Appendices

Appendix $1 \quad$ Glossary of terms 
CDMA Code division multiple access

EDGE Enhanced data rates for global evolution

GPRS General packet radio service

GSM Global system for mobile communication

R\&D Research and design

IP Internet protocol

Os $\quad$ Operating system

PDA Personal digital assistant

UMTS Universal mobile telecommunications system 
Appendix $2 \quad$ Simulation results 
Enterprises Deploying Target PDA Platform

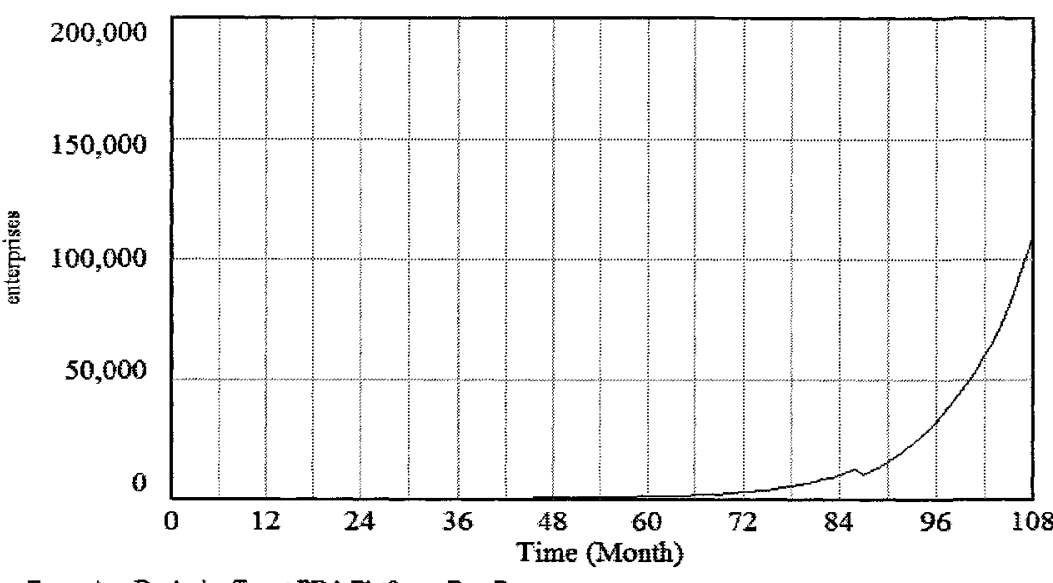

Enterpises Deploying Target PDA Platform : BaseRum
Enterprises Deploying Competitor PDA Platform

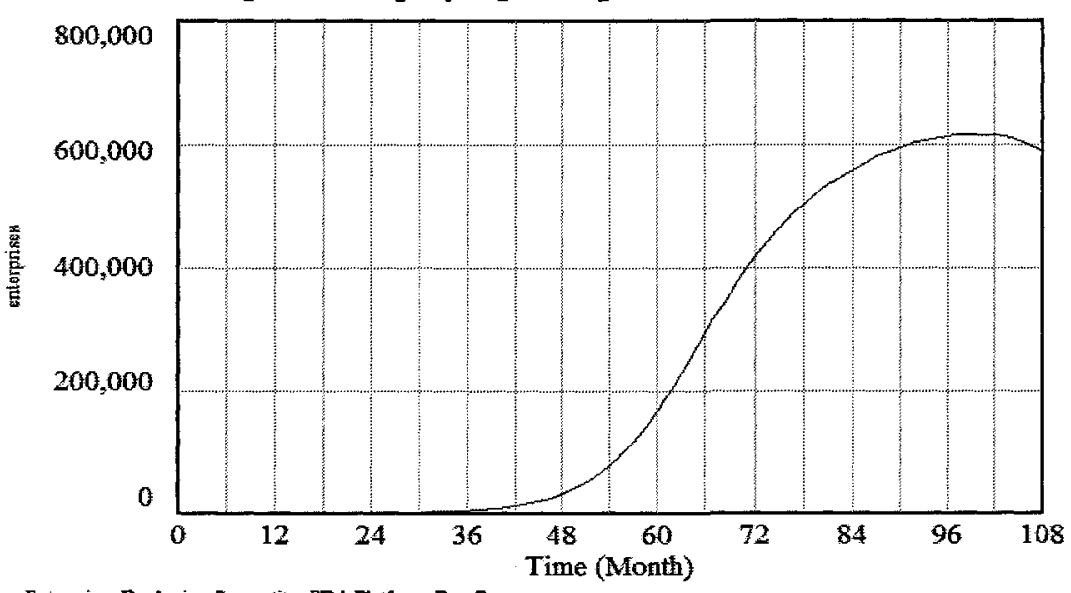

enterprise switch rate

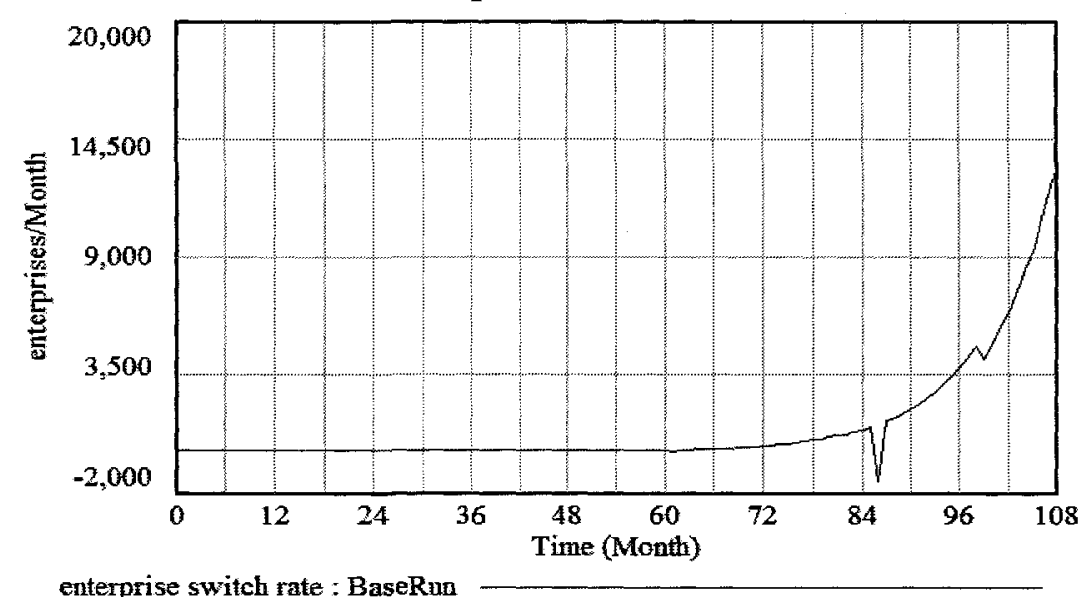

enterprise switch rate : BaseRun

Figure 16: Base run simulation results - enterprises 

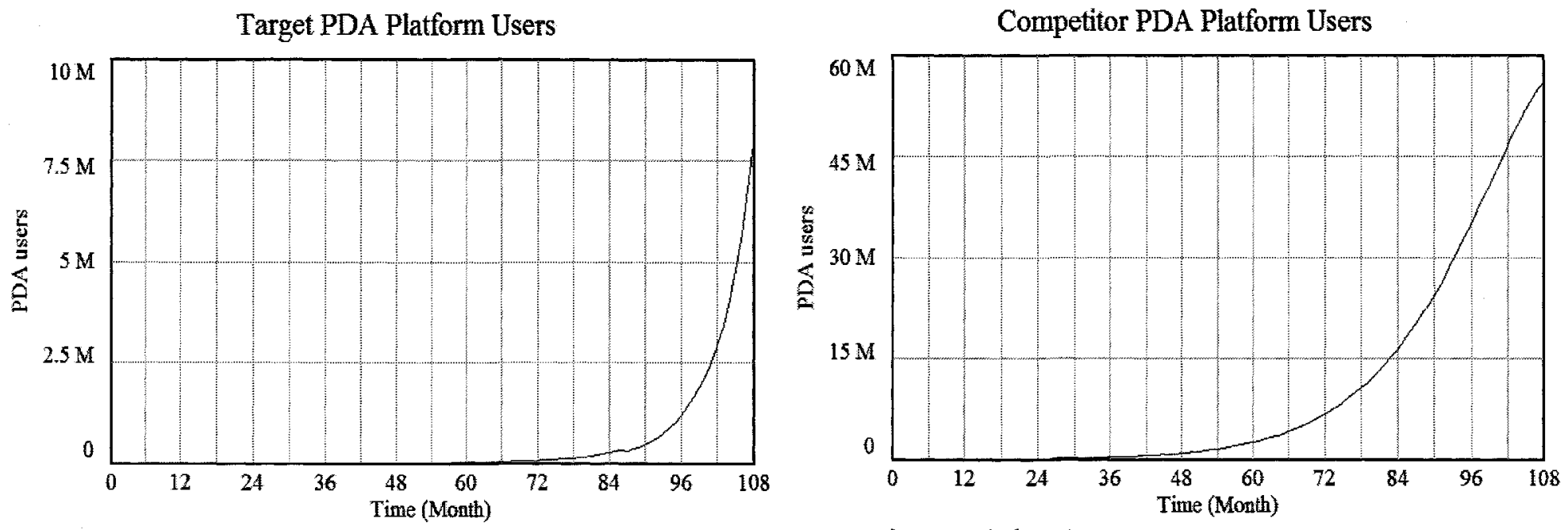

Target PDA Platform Users : BaseRun

Competitor PDA Platform Users : BaseRun

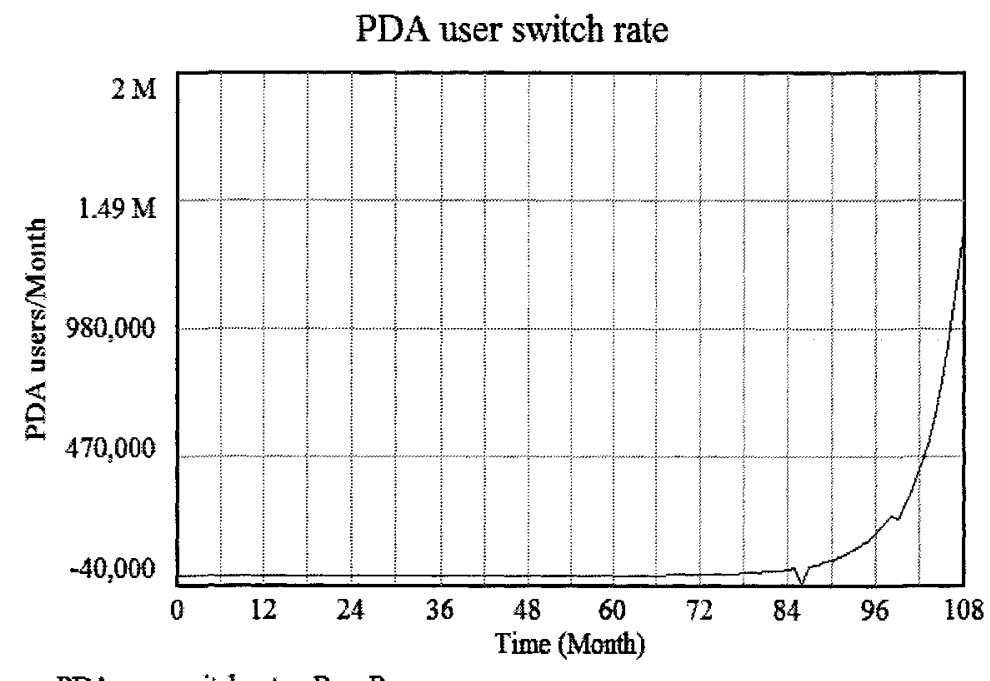

PDA user switch rate : BaseRun

Figure 17: Base run simulation results - PDA users 

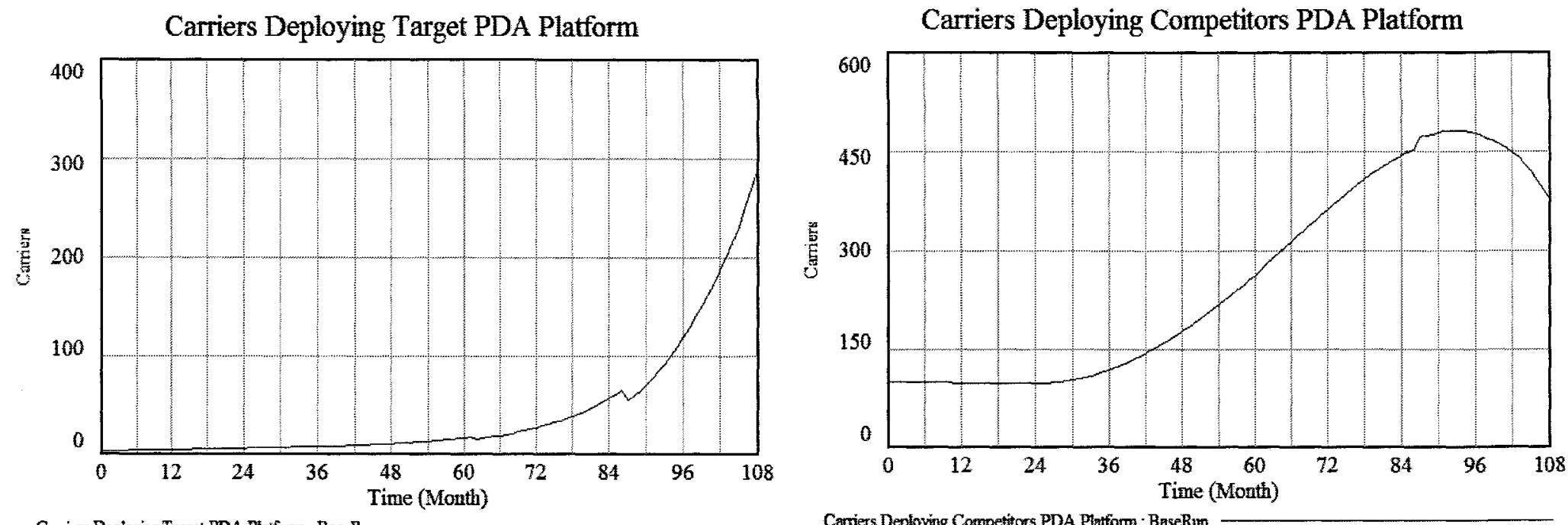

Carriers Deploying Target PDA Ptation : BaseRm

Carners Deploying Competizors PDA Plation : BaseRun

carriers switch rate

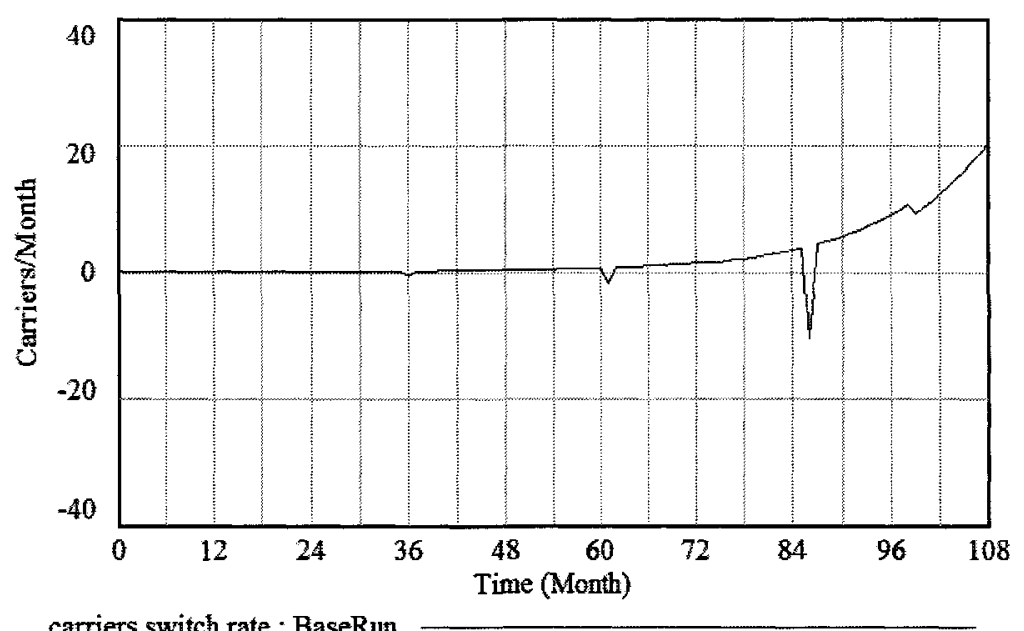

carriers switch rate : BaseRun

Figure 18: Base run simulation results - carriers 
Enterprises Deploying Target PDA Platform

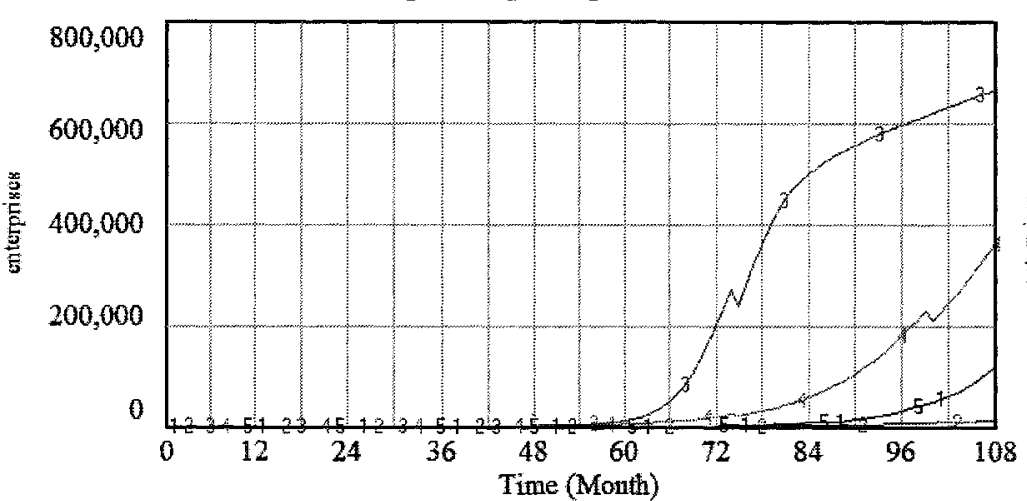

Enterpises Deployig Trge PDA Plafforn: Scenario 1

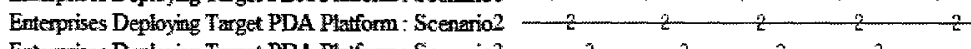

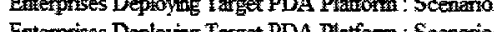

Enterprises Deploying Target PDA Platiform. Scenario

Entexpises Deploying Target PDA Plafform : BaseRum

\section{Enterprises Deploying Competitor PDA Platform}

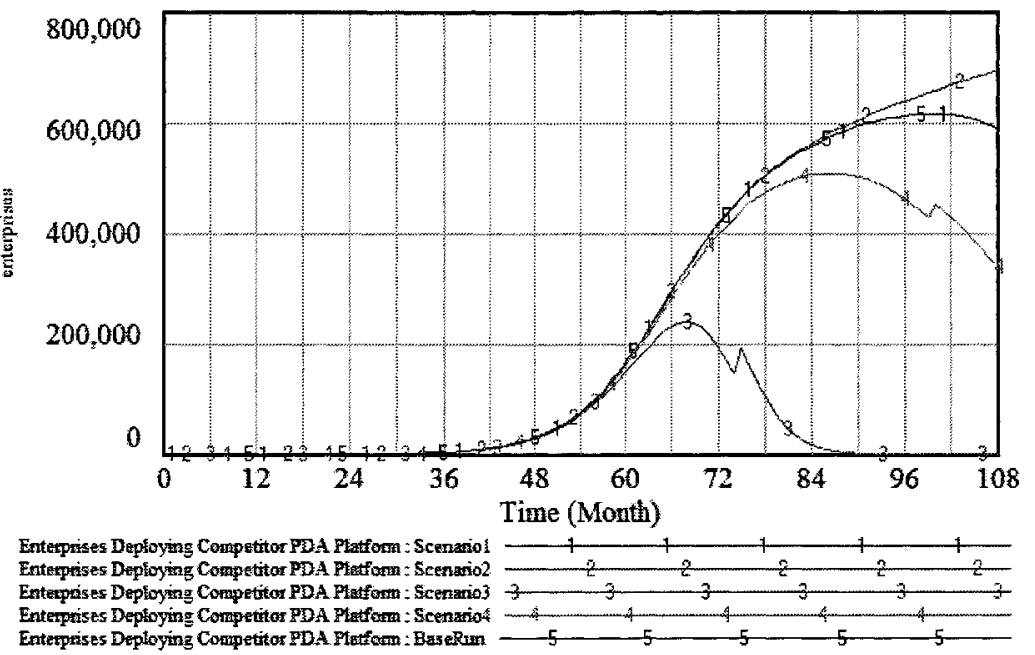

enterprise switch rate

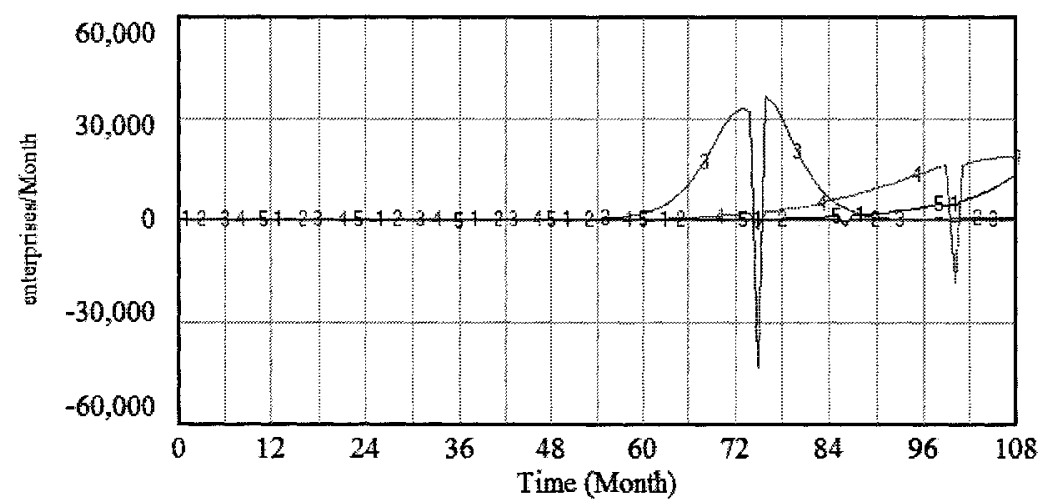

enterprise stivith rate: Sconaiol Time (Month)

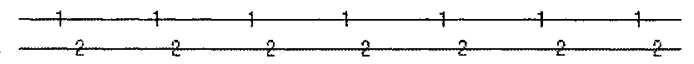

aterise som

enferprise sxitch rate : Scesario

mise switch rate: Scesanio

Figure 19: Market entry time and switching costs simulation results - enterprises 

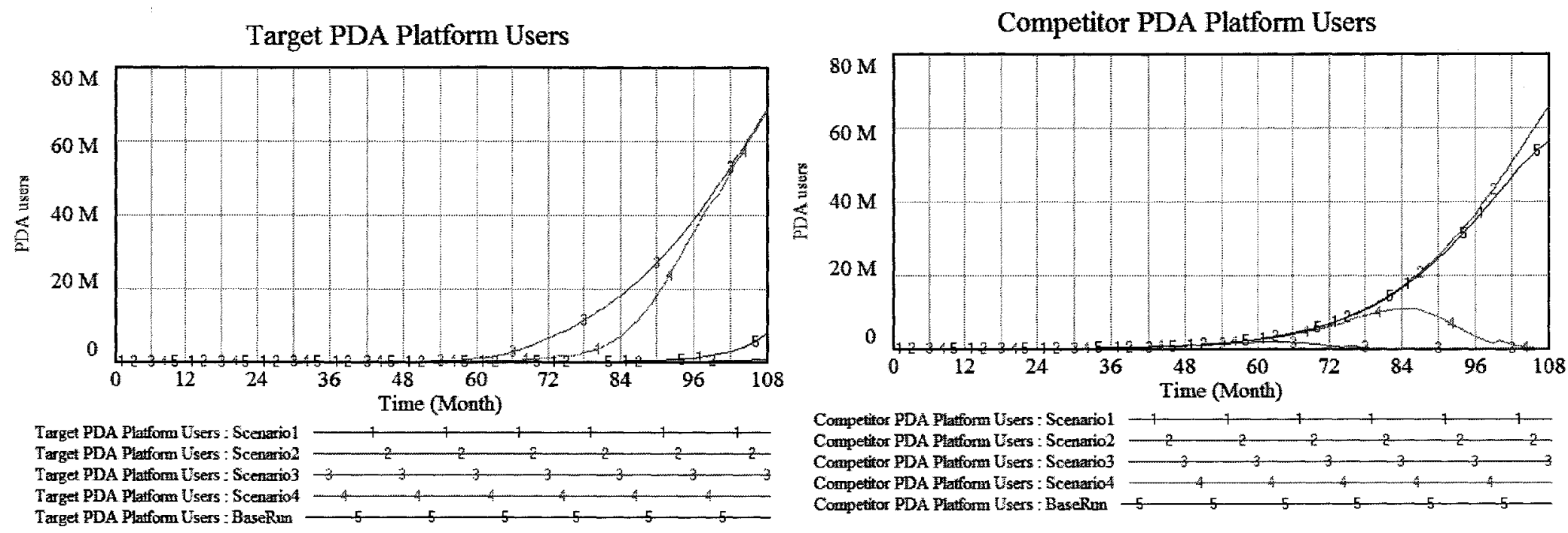

Competitor PDA Plation Users : Scenariol

Comper PDA Phofom Users: Scenatio

Compertor PDA Platorm Users : Scenarios

Competifor PDA Platform Users : BaseRen

PDA user switch rate

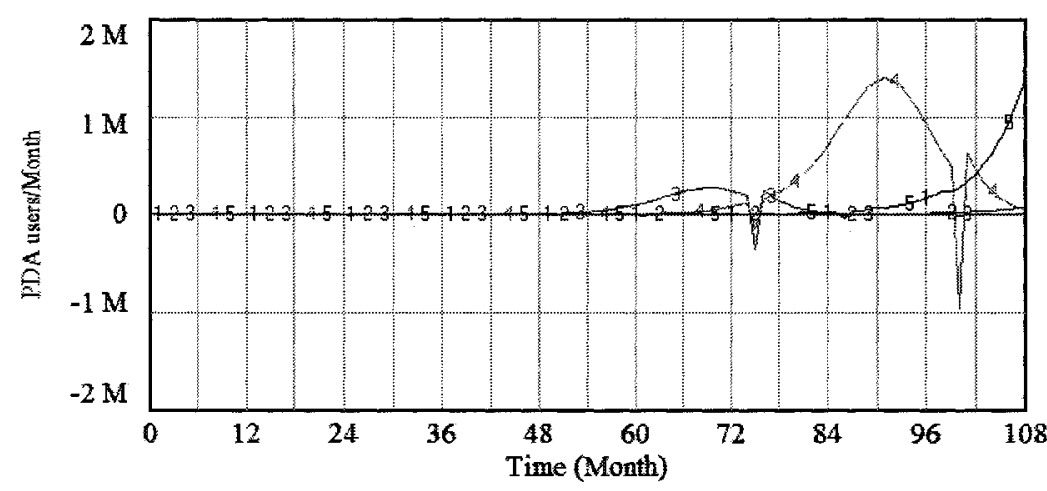

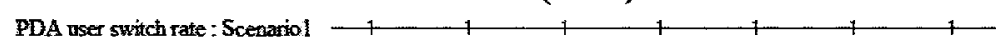

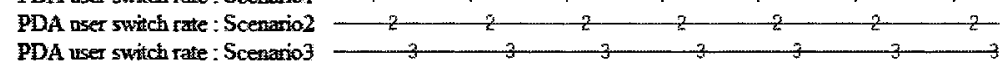

PDA wer switch rate: Scenario3

PDA user swith rate : BaseRin

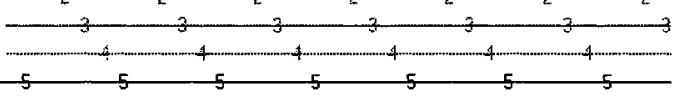

Figure 20: Market entry time and switching costs simulation results - PDA users 

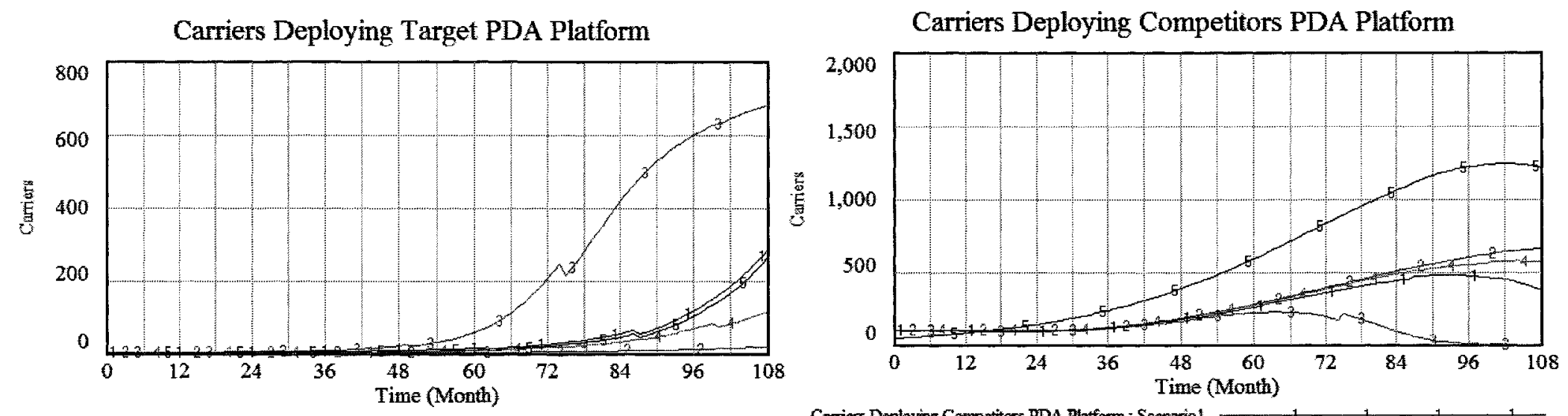

Carriers Deploying Target PDA Plaform: Scenariol Carriers Deptoying Target PDA Platform - Scenario

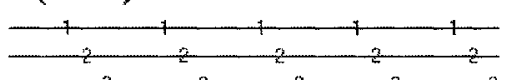

Caniers Deploying Competitors PDA Plafform: Scenariol

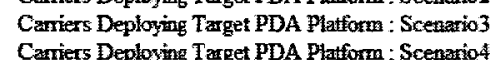

$2-2+2-2$

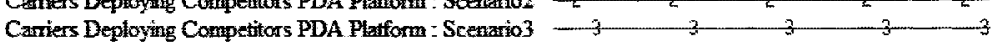

Carriers Deploying Competitors PDA Platform: Scenario

Carriers Deploying Competitors PDA Platform : BaseRum

carriers switch rate

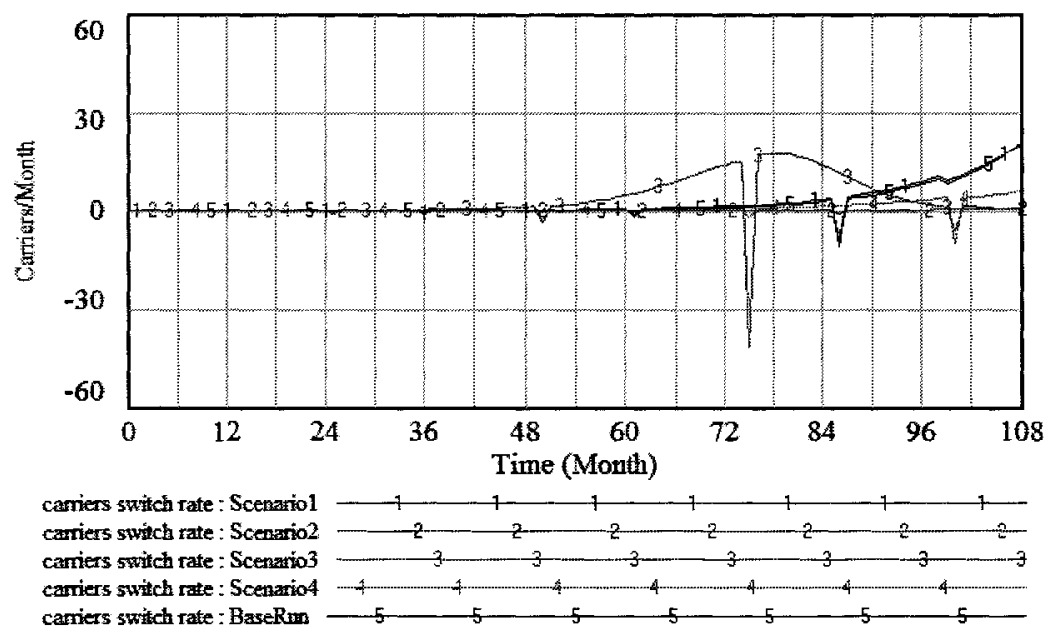

Figure 21: Market entry time and switching costs simulation results - carriers 
Enterprises Deploying Target PDA Platform

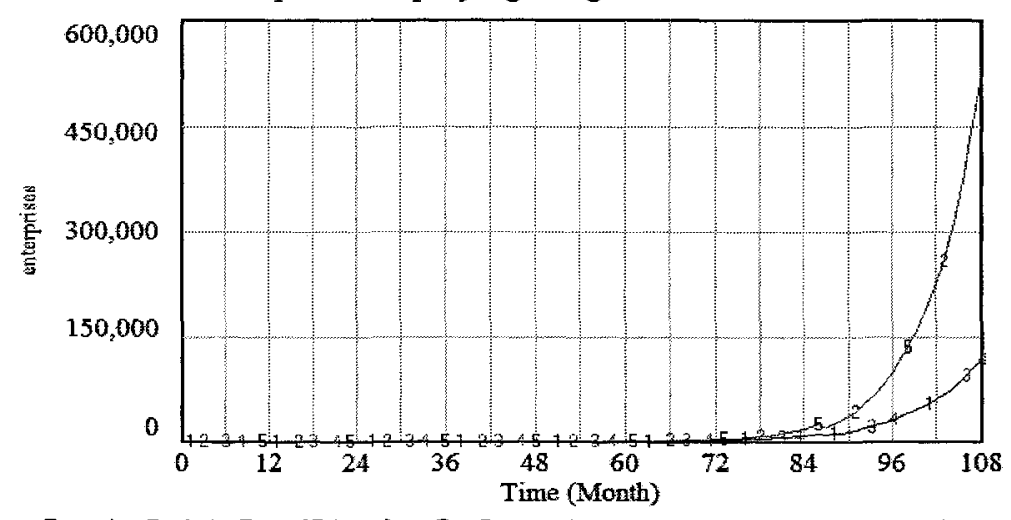

Enternises Deploying Target PDA Plattorm: BaseRum Enterprises Deploying Target PDA Platroms : Scenarios Enteeprises Deploying Target PDA Platform: Scenario 7
Enterprises Deploying Target PDA Platform: Scenario8
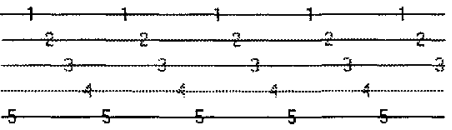

Enterprises Deploying Competitor PDA Platform

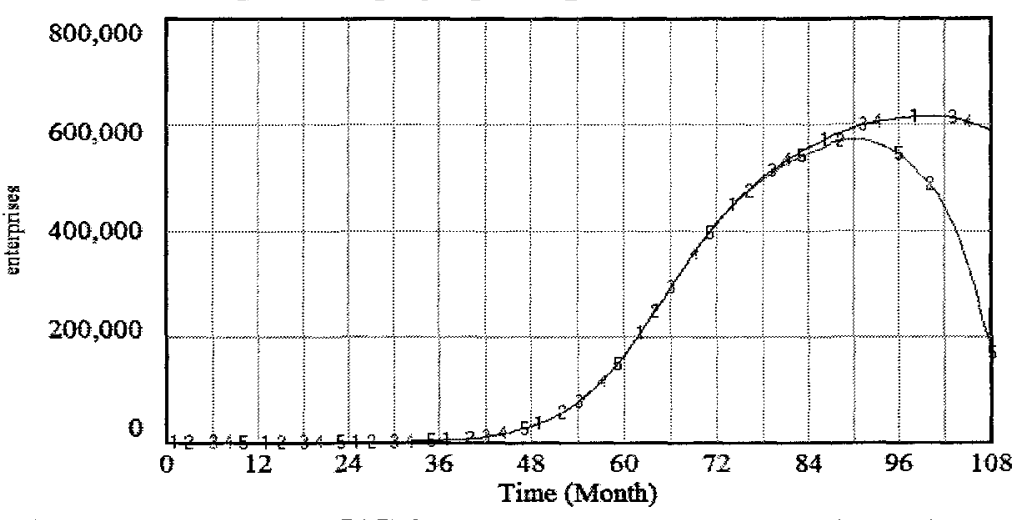

Enteryises Deptoying Competitor PDA Plaforn : BaseRur Cometitor PDA Pfatform : Scenario 5 Extexprises Deploying Competitor PDA Platform : Scenario6 Exterpises Deploying Conpetion Enterorises Deploying Corpetitor PDA Plation - Scemarios

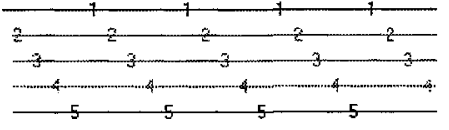

enterprise switch rate

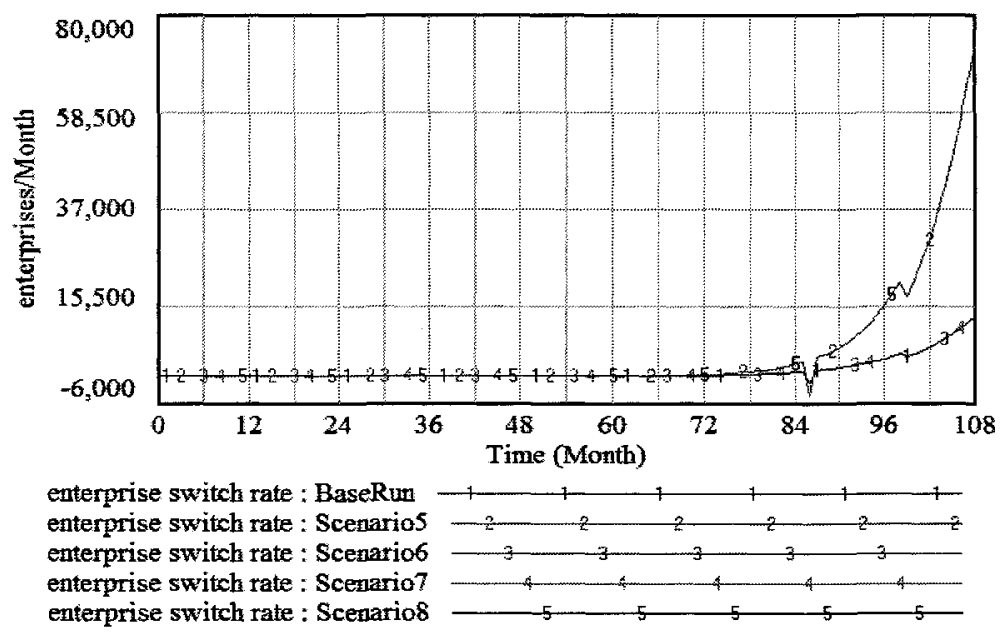

Figure 22: Market shock scenario simulation results - enterprises 

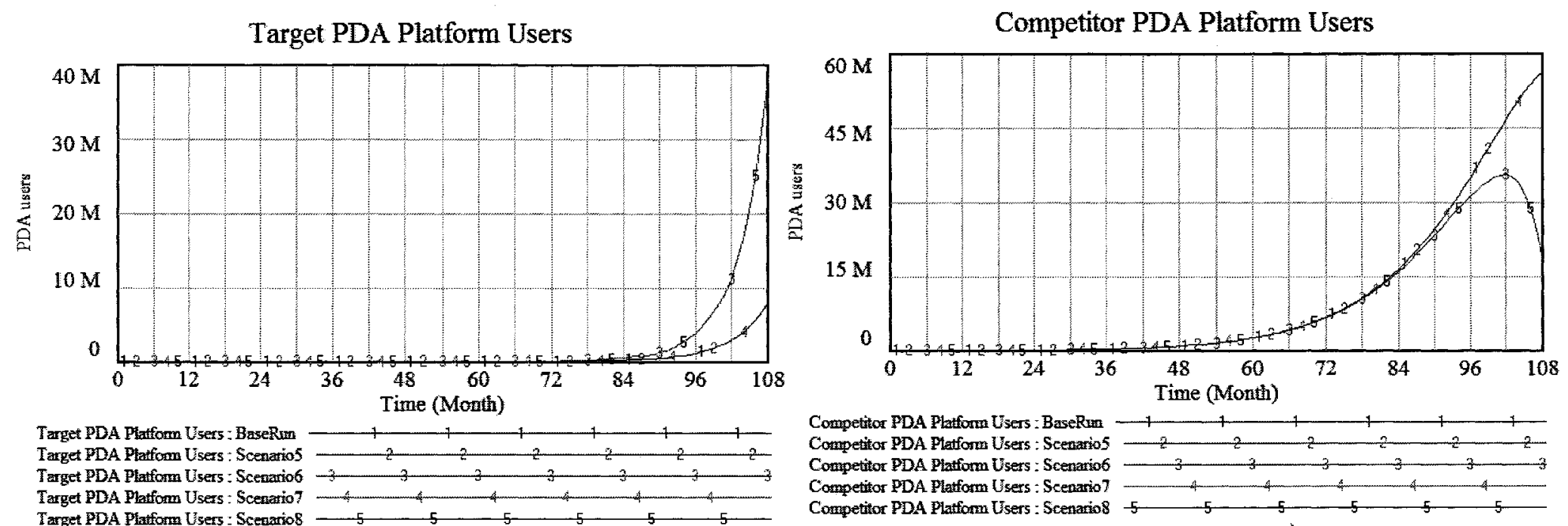

PDA user switch rate

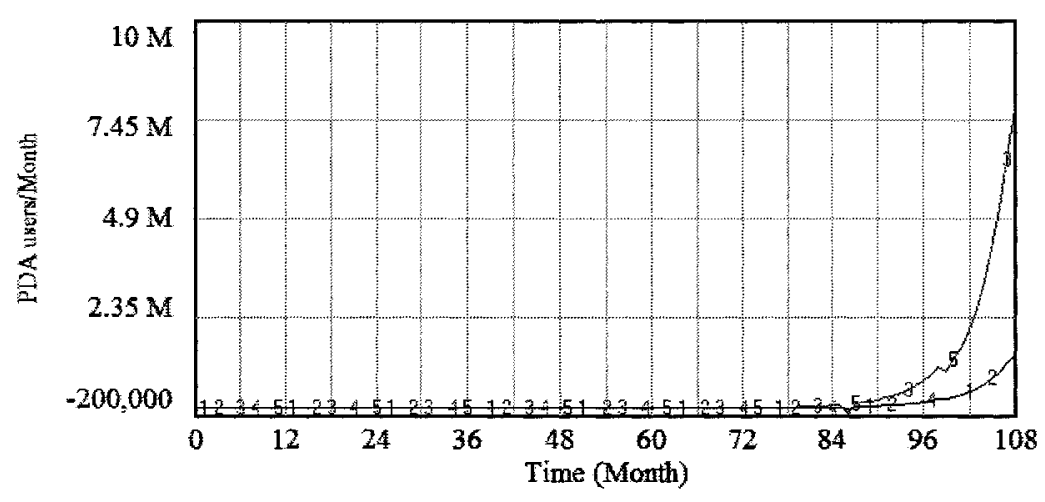

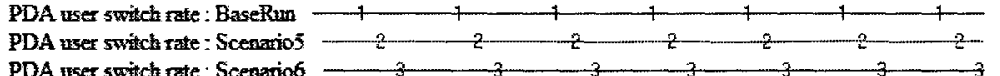

PDA user switch rate: Scenario 7
PDA user switch rate: Scenario

Figure 23: Market shock scenario simulation results - PDA users 

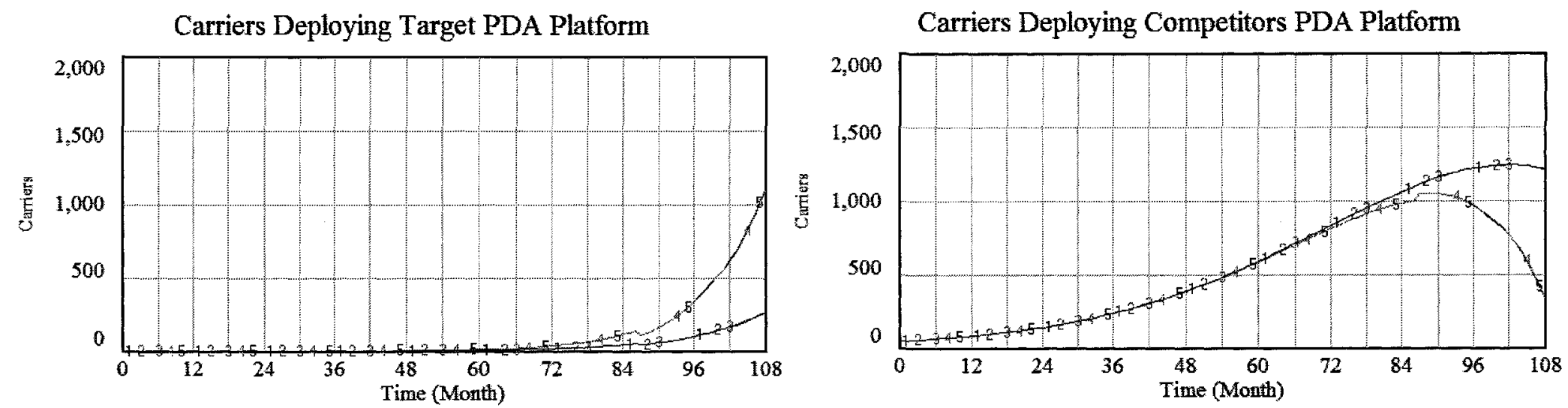

Carriers Deploying Target PDA Platform : BaseRe Carreers Deploying Target PDA Platonn : Scenarios Cariers Deploying Target PDA Blafform : Scenario6

Carriers Deploying Target PDA Platform : Sceratio?

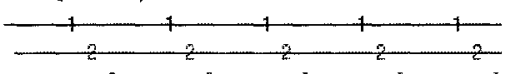

Carrers Deploying Competitors PDA Plafion : BaseRun +7

Carriers Deporing Comper 2

Carriers Deploying Comentors PDA Plaform - Scenario $63-3-3-3$

Cariess Deploying Com

Carriers Deploying Compertors PDA Platrom : Scengrio

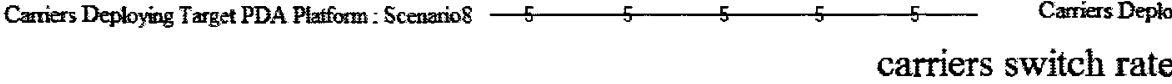

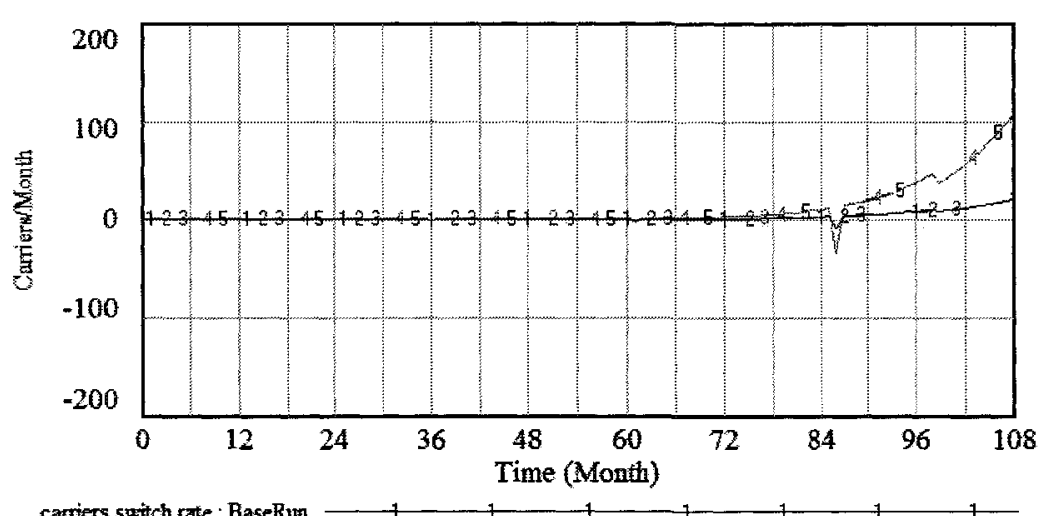

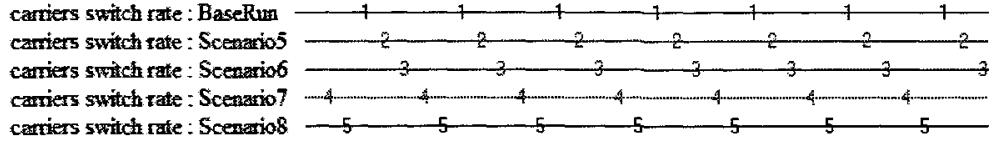

Figure 24: Market shock scenario simulation results - carriers 
Appendix 3

Model review booklet 
Network Effects in Enterprise Wireless PDA Market Model Review Booklet

\author{
Kalyan Siddam \\ Technology Innovation Management \\ Department of Systems and Computer Engineering \\ Carleton University \\ October 2008
}

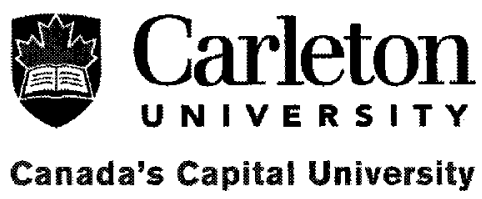




\section{Contents}

1 Introduction 1

2 The enterprise wireless PDA market 2

$\begin{array}{lll}2.1 & \text { The enterprise wireless PDA market microworld } & 2\end{array}$

2.2 Simplified view of enterprise wireless PDA market activity 3

$3 \quad$ Microworld structure review 4

3.1 Definitions 4

3.2 Resource structure of the enterprise wireless PDA microworld 6

3.3 Causal loop diagrams 9

A. Developer, Alliances Loops $\quad 9$

B. Enterprise server and PDA applications loops 10

C. Enterprises loop 12

D. PDA users loop 14

E. Carriers loop 16

F. Licensing loop $\quad 18$ 


\section{Consent form}

This booklet includes a questionnaire to be used for validating purposes. The booklet is part of field work for the master's thesis conducted by the researcher, Kalyan Siddam, from the Department of systems and Computer Engineering at Carleton University.

Signatures:

Participant,

Date

Researcher, Kalyan Siddam

Date 


\section{Introduction}

In this research, I developed a simplified microworld featuring network effects in enterprise wireless PDA market. This microworld captures network effects influencing the success of an enterprise wireless PDA platform and their strategic implications of these network effects on stakeholders. These factors changes according to the dynamics of the resource system.

This model is built using the information that knowledgeable participants like you and your colleagues provided about important aspects of the network effects in the enterprise wireless PDA market. Your input is required to review and comment on the structure of the model, components and assumptions.

Please review sections 2 and 3 for the description of the model. When we speak, I will walk you thought the subsystems of the model. At the end of describing each subsystem, I will ask about your reactions to the model and any suggestions for improvements.

Thank you for your participation, you may contact me at ksiddam@ connect.carleton.ca for any questions or information. 


\section{The enterprise wireless PDA market}

Enterprise wireless PDA market is a networked market. The network effect is the effect that the value of a product or service to one user depends on how many other users use it. Network effects can be positive or negative; direct or indirect. An example for the direct network effects is a Fax machine, exchange of files - due to use, purchasing, compatibility, etc. An example for indirect network effects is hydrogen filling stations: a lack of them due to complementary goods, services, etc. An example for the negative network effects is traffic congestion.

For the purpose of this research, a wireless PDA device refers to a wireless handheld device that offers: cellular, fax, Internet, and computing capabilities. This would include examples such as RIM's BlackBerry® 71xx and Palm's Treo® 700w. These devices are also known as smartphones.

\subsection{The enterprise wireless PDA market microworld}

The enterprise wireless PDA market microworld is based on the following assumptions:

- Enterprises have (client-server) applications that they use for their day-to-day operations

- Enterprises adopt wireless PDA platform to access these applications remotely over the wireless networks

The enterprise wireless PDA market microworld contains six basic subsystems. The resource flows between these subsystems as shown below: 


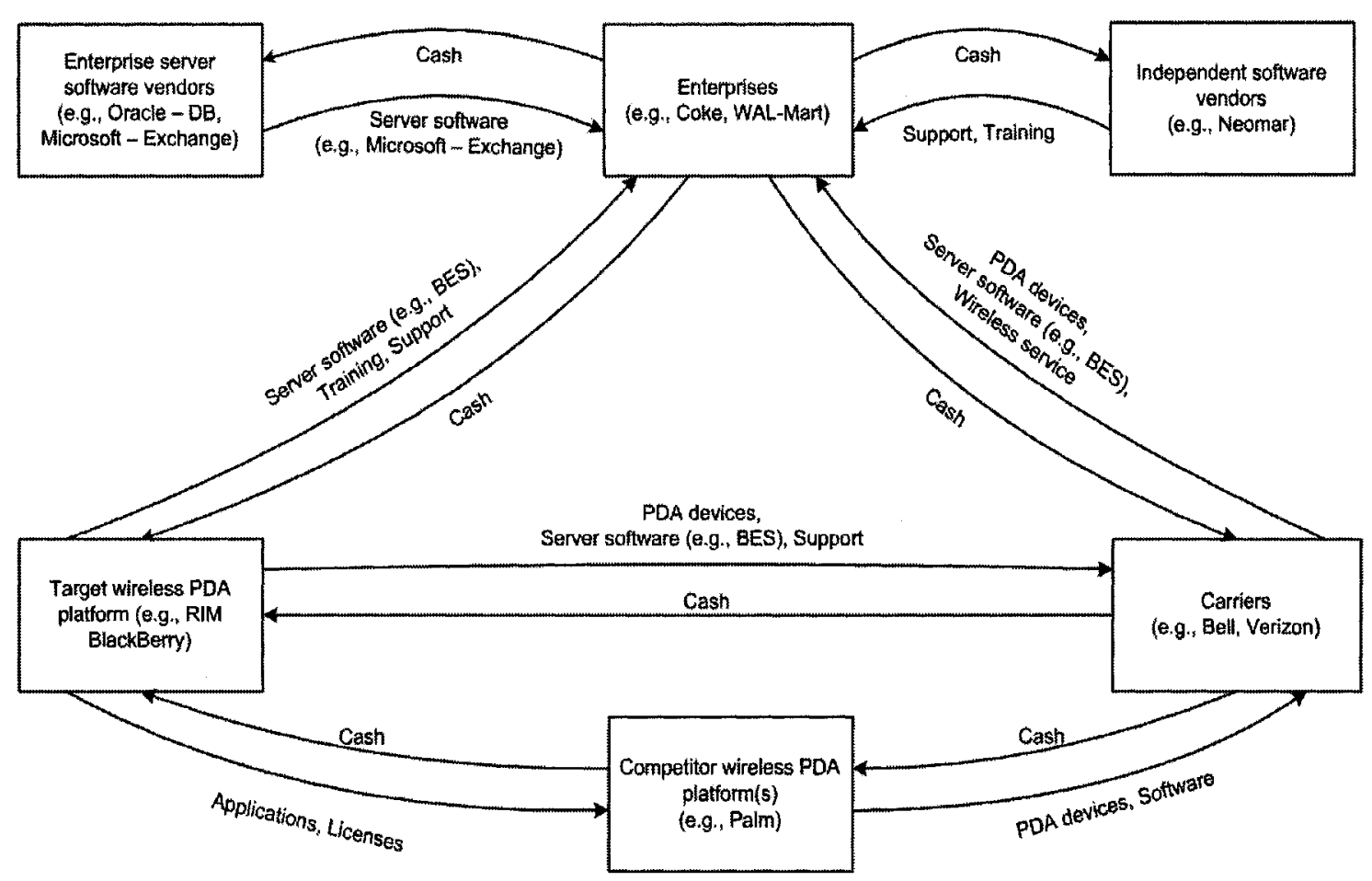

Figure 1. Subsystem diagram of enterprise wireless PDA market microworld

Each of the subsystems in the Figure 1 is described below:

- Enterprise server software vendors represent the software manufacturers (e.g., Oracle, Microsoft) that make the software applications for the Enterprises. These client-server software applications are key component for the day to day operations of Enterprises.

- Enterprises represent the companies that are deploying a wireless PDA platform. Enterprises deploy a wireless PDA platform; buy wireless PDA devices for its employees and pays on-going subscription fees to wireless service providers.

- Target wireless PDA platform represent the company that make the wireless PDA platform of interest to the research whose performance is being studied. Components of an enterprise wireless PDA platform often include backend server software, wireless PDA handset and applications that run on the handset.

- Competitor wireless PDA platform(s) represent the companies that make enterprise wireless PDA platforms that compete with Target wireless PDA platform.

- Independent software vendors represent the companies that develop software applications for the wireless PDA platforms, provide services to Enterprises for integration support, training on wireless PDA platforms.

- Carriers represent the wireless service provider companies that offer wireless (or cellular) services. Carriers are gateways between wireless PDA platform manufacturers and Enterprises. Carriers decide which wireless PDA platforms will be supported in their networks. Enterprises buy the wireless PDA devices from Carriers and also pay subscription fees to use their networks. 


\subsection{Simplified view of enterprise wireless PDA market activity}

In this microworld the enterprise wireless PDA market activity is represented by the flow of resources and cash between the market stakeholders (subsystems in Figure 1). The microworld only includes the participants described above - forming the boundary. Following are the rules for the microworld:

- Enterprises often have elaborated evaluation procedures for selecting the wireless PDA platform to ensure that it meets their requirements. Enterprises are interested in wireless PDA platforms that seamlessly integrate with their existing software applications.

- Enterprises and users often seek input from others that have deployed wireless PDA platforms. This word of mouth feedback has (positive or negative) influence on the adoption a wireless PDA platform.

- As time proceeds, more enterprises and users enter the market and want to adopt a wireless PDA platform, the word of mouth feedback gets stronger.

- Switching costs play dominant role in the adoption of enterprise wireless PDA platform. Enterprises lookout for ongoing costs (e.g., support, training) of deploying the wireless PDA platform.

- Carriers support more than one enterprise wireless PDA platforms and its subscribers pay monthly subscriptions to use the wireless services. Subscribers typically need to signup for service contracts (e.g., for 3 years).

The microworld attempts to show how these rules can interact to create the right setting for a successful wireless PDA platform to continue to be successful. 
This section walks you through the various micro structures/ causal loops, which compose the main structure of the microworld.

A. Developers and Alliances loops - depicts the developer population for the target PDA platform.

B. Enterprise Server Applications loop - depicts how the enterprise server applications are supported on the target wireless PDA platform (e.g., Oracle Database).

C. PDA applications loop - depicts how the handheld applications are supported on the target wireless PDA platform. These applications are the applications that do not have an enterprise server backend application (e.g., Yahoo IM).

D. Enterprises loop - depicts how an enterprise become either an enterprise that deploy the target wireless PDA platform or an enterprise that deploy the competitor wireless PDA platform and factors that cause lock-in to a wireless PDA platform.

E. PDA User loop - depicts how a PDA user become either a user that deploy the target wireless PDA platform or an enterprise that deploy the competitor wireless PDA platform and factors that cause lock-in to a wireless PDA platform.

F. Carriers loop - depicts how the carriers become either an enterprise that deploy the target wireless PDA platform or an enterprise that deploy the competitor wireless PDA platform and factors that cause lock-in to a wireless PDA platform.

G. Licenses loop - depicts how the licensable $3^{\text {rd }}$ party PDA devices become either a licensed $3^{\text {rd }}$ party PDA device or a competitor licensed PDA device.

Section 3.3, provides a causal loop diagram capturing the key variables and the feedback structures between them. After reviewing each of these loops, I will ask for your opinion on the explanation provided plausible within the boundary of the model. I would also seek your input on how this research may be extended so it can help more insights on the network effects in the enterprise wireless PDA market.

\subsection{Definitions}

Following are the brief definition of each of the key variables in (alphabetical order) used in the causal loop diagrams will help in understanding the causal loop diagrams.

- Alliance Adjustment Time - Average number of months for an alliance to join the ISV program and start contributing.

- Applications Supported For Competitor PDA Platform - Number of applications supported on competitor PDA platform.

- Applications Supported For Target PDA Platform - Cumulative number of PDA applications (PDA only application without server component e.g., AOL) supported on the target PDA platform.

- Average Number Of Developers Per ISV - Average number of developers working on the development for application for the Target PDA platform.

- Brand Specific Training - PDA platform specific training. 
- Carriers Deploying Competitors PDA Platform - Cumulative number of carriers deploying competitor PDA platform.

- Carriers Deploying Target PDA Platform - Cumulative number of carriers deploying Target PDA platform.

- Client-Server Application - A software development paradigm where an application (Server) on centralized sever is providing service to many remote applications (Clients) simultaneously.

- Competitor Actions - Number of competitor actions per month to attract users away from adopting the Target PDA platform.

- Competitor Delay - Number of months after which competitor wireless PDA devices appear in the market.

- Competitor Licensed PDA Devices - Cumulative number of competitor PDA devices being licensed.

- Competitor PDA Users - Cumulative number of users using competitor PDA devices.

- Complementary Products - Source of lock-in: Complementary products (e.g., accessories, dependent management systems) that an adaptor of the wireless PDA platform had purchased to enhance the functionality of the wireless PDA platform. Additional investment of time and money in these complementary products causing lock-in.

- Contractual Commitments - Source of lock-in: Contractual commitments that lock in users to a PDA platform.

- Desired Alliances - Desired number of alliances for the target PDA platform.

- Desired Developers - Desired number of developers for the target PDA platform.

- Developer Adjustment Time - Average number of months for a developer to join the development team and start contributing.

- Developer Population For Target PDA Platform - Actual number of developers for the target PDA platform.

- Development Language Popularity - Factor that describes the popularity of the development language. Higher the popularity, bigger the developer pool.

- Enterprise Server Applications Supported on Target PDA Platform Cumulative number of server applications (e.g., SAP) supported on the target PDA platform.

- Enterprise Switch Delay - Number of months after which the enterprises start switching between PDA platforms.

- Enterprises Deploying Competitor PDA Platform - Cumulative number of enterprises deploying competitor PDA platform.

- Enterprises Deploying Target PDA Platform - Cumulative number of enterprises deploying target PDA platform.

- Independent Software Vendors - Number of ISVs contributing to the development of applications on Target PDA platform.

- Information And Databases - Source of lock-in: Information and databases that lock in users to a PDA platform.

- Licensed $3^{\text {rd }}$ party PDA Devices - Cumulative $3^{\text {rd }}$ party PDA devices that are licensed for the Target PDA platform. 
- Loyalty Programs - Source of lock-in: Loyalty programs (e.g., points program) that attracts and keeps customers.

- Months To Develop PDA Application Per Developer - Average number of months to develop support for a PDA application if one developer develops the application.

- Months To Develop Server Application Per Developer - Average number of months to develop support for a server application on PDA if one developer develops the application.

- PDA Application Popularity - Popularity of PDA application. Higher the popularity, sooner it is supported on the target PDA platform.

- PDA Platform Attractiveness Factor - Factor that models the attractiveness of the development language. Higher the attractiveness, higher the deployment rate.

- PDA Users Per Enterprise - Average number of users per enterprise.

- Popular File Formats - Number of popular file formats (e.g., PDF, Word, MP3) the wireless PDA platform compliant to. Higher the compliance higher the adoption.

- Potential Carriers - Potential carriers that could deploy either Target PDA platform or the Competitor PDA platform.

- Potential Enterprise Server Applications - Potential server applications that can be supported on the Target PDA platform.

- Potential Enterprises Deploying PDA Platforms - Potential enterprises that could deploy either Target PDA platform or the Competitor PDA platform.

- Potential Licensable $3^{\text {rd }}$ party PDA Devices - Potential licensable $3^{\text {rd }}$ party PDA devices that could deploy either Target PDA platform or the Competitor PDA platform.

- Potential PDA Applications - Potential handheld applications (PDA only application without server component) that can be supported on the Target PDA platform.

- Potential PDA Users - Potential PDA users that could deploy adopt Target PDA platform or the Competitor PDA platform.

- Search Effort - Source of lock-in: Effort (cost) for finding a suitable PDA platform that meet the needs of a potential PDA adaptor.

- Server Application Popularity - Popularity of server application. Higher the popularity, sooner it is supported on the target PDA platform.

- Specialized Suppliers - Source of lock-in: Specialized supplier (e.g., RIM) that an adaptor of the wireless PDA platform had purchased the system from. The adaptor of wireless PDA platform continues to depend on the specialized supplier for upgrades, feature enhancements, etc. causing lock-in.

- Standards Compliance - Number of standards (e.g., FIPS, GSM, WAP) the wireless PDA platform compliant to. Higher the compliance higher the adoption.

- Target PDA Users - Cumulative number of users using target PDA devices.

- Total $3^{\text {rd }}$ Party PDA Devices - Total number of $3^{\text {rd }}$ party devices in the model

- Total Carriers - Total number of carriers in the model.

- Total Developers - Total number of developers (from ISVs and Target PDA Platform).

- Total Enterprises - Total number of enterprises in the model.

- Total PDA Users - Total number of PDA users in the model. 


\subsection{Resource structure of the enterprise wireless PDA microworld}

The following figure depicts a dynamic resource system view of the enterprise wireless PDA market microworld. The boxes represent the stocks of resources and the valves represent the inflows and outflows of those resources.
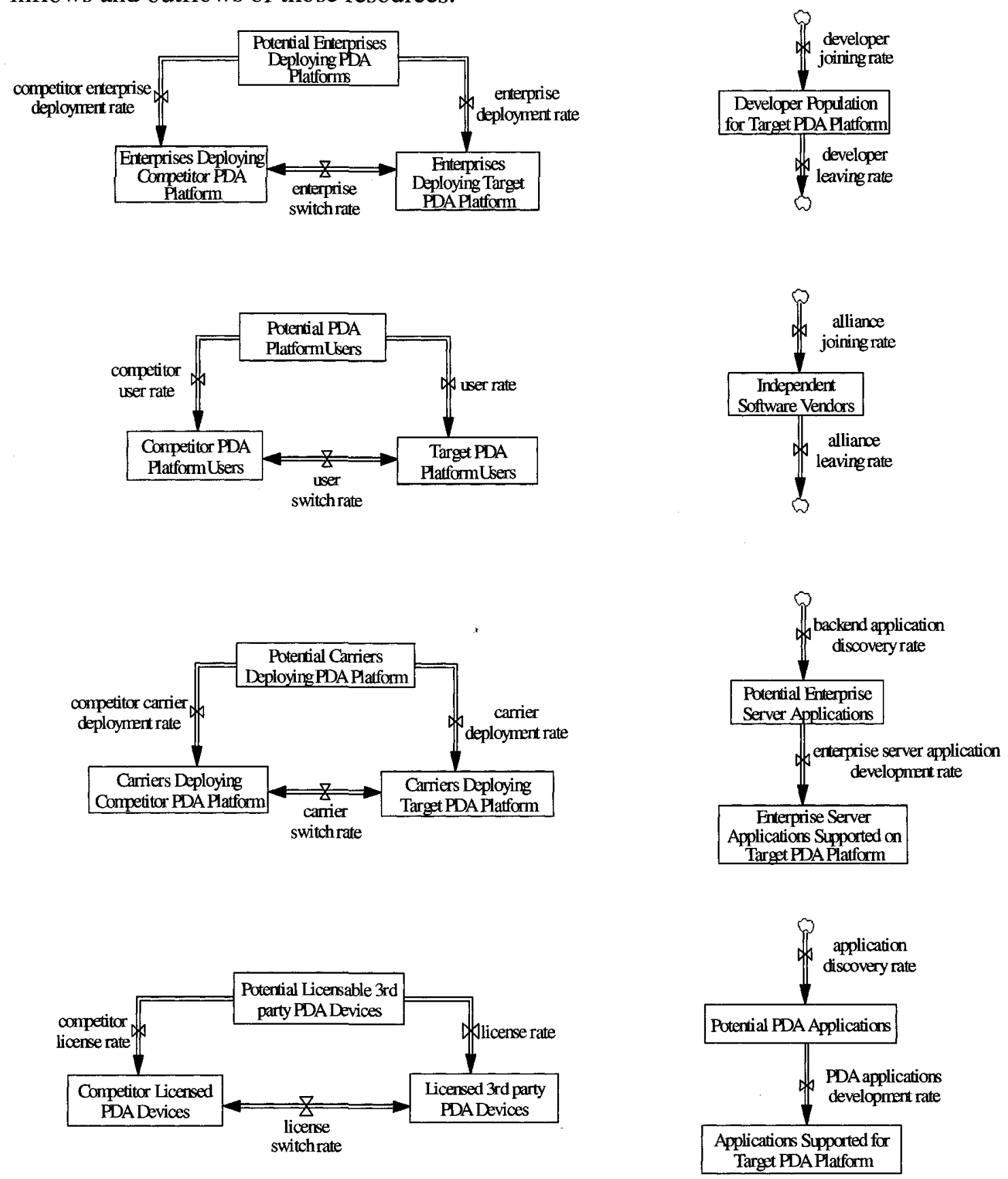

Figure 2. Dynamic resource view of enterprise wireless PDA market 
Key highlights in the dynamic resource structure:

1) 'Enterprises Deploying Target PDA Platform' increases as the attractiveness of the platform increases and the enterprise word of mouth feedback increase.

2) 'Carriers Deploying Target PDA Platform' increases as the attractiveness of the platform increases and the carrier word of mouth feedback increase.

3) 'Developer Population' increases as more alliances with independent software vendors increase.

4) 'Enterprise Server Applications Supported on Target PDA Platform' increased by 'enterprise server application support rate' and decrease as the stock 'Enterprise Existing Server Software' decreases.

5) The attractiveness of the wireless PDA platform for the Enterprises increases as the 'Enterprise Server Applications Supported on Target PDA Platform' increase.

6) 'Switching Costs Due to Adoption of Target PDA Platform' increases as 'Enterprises Deploying Target PDA Platform' and 'Carriers Deploying Target PDA Platform' increase.

7) Resource transition between stocks takes time (i.e., delay).

8) 'enterprise switching rate', 'carrier switching rate', 'PDA user switching rate' and 'license switching rate' can increase or decrease as sources of lock-in are lowered or increased.

Causal loop diagrams in the following section provide a simplified view of the microworld.

\footnotetext{
$* * *$ We can review the following sections when we meet $* * *$
} 


\subsection{Causal loop diagrams}

\section{A. Developer, Alliances Loops}

The loops in the following figure depict the Developer Population For Target PDA Platform and the Independent Software Vendors. There are two sources for the developers, i) the developer population from owner of the Target PDA Platform and ii) the Independent Software Vendors (ISVs) that are developing applications for the Target PDA Platform.

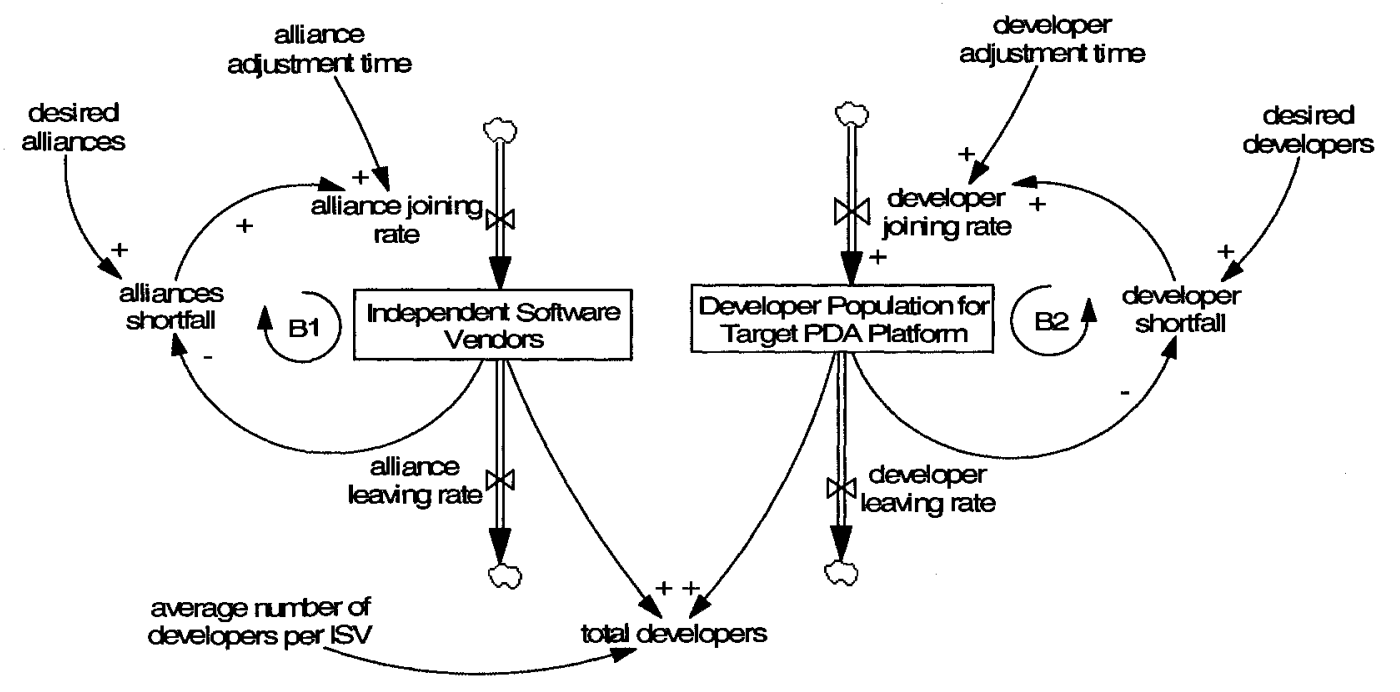

Figure 3. Developer and Alliances loops

\section{What happens?}

It would take time for each of the developer and ISV to be a contributing member. There is a desired level of alliances and developers (B1 and B2). Furthermore, the accumulation of ISVs reduces the attractiveness of the Target PDA Platform (e.g., too crowded or not profitable). Similarly, the stock of developers reduces as developers leaving (e.g., due to attrition).

\section{Your thoughts about these loops:}

Q1. Is the structure of the loop plausible? Does it match your beliefs about how the enterprise wireless PDA would work in a scenario such as this microworld?

a) Is the relationship of Independent Software Vendors with alliance joining rate and alliance leaving rate plausible?

- Why or why not?

b) Is the relationship of Developer Population for Target PDA Platform with developer joining rate and developer leaving rate plausible?

- Why or why not?

Q2. Is the explanation of what happens in the loop plausible?

- Why or why not? 


\section{B. Enterprise server and PDA applications loops}

The loops in the following figure depict the applications for the target PDA platform. There are two types of applications i) the Enterprise Server Applications - applications that have their backend server at the enterprise (e.g., Oracle DB, SAP) and ii) the PDA applications applications that do not have a backend sever at server at enterprise (e.g., Yahoo IM, Internet browser).

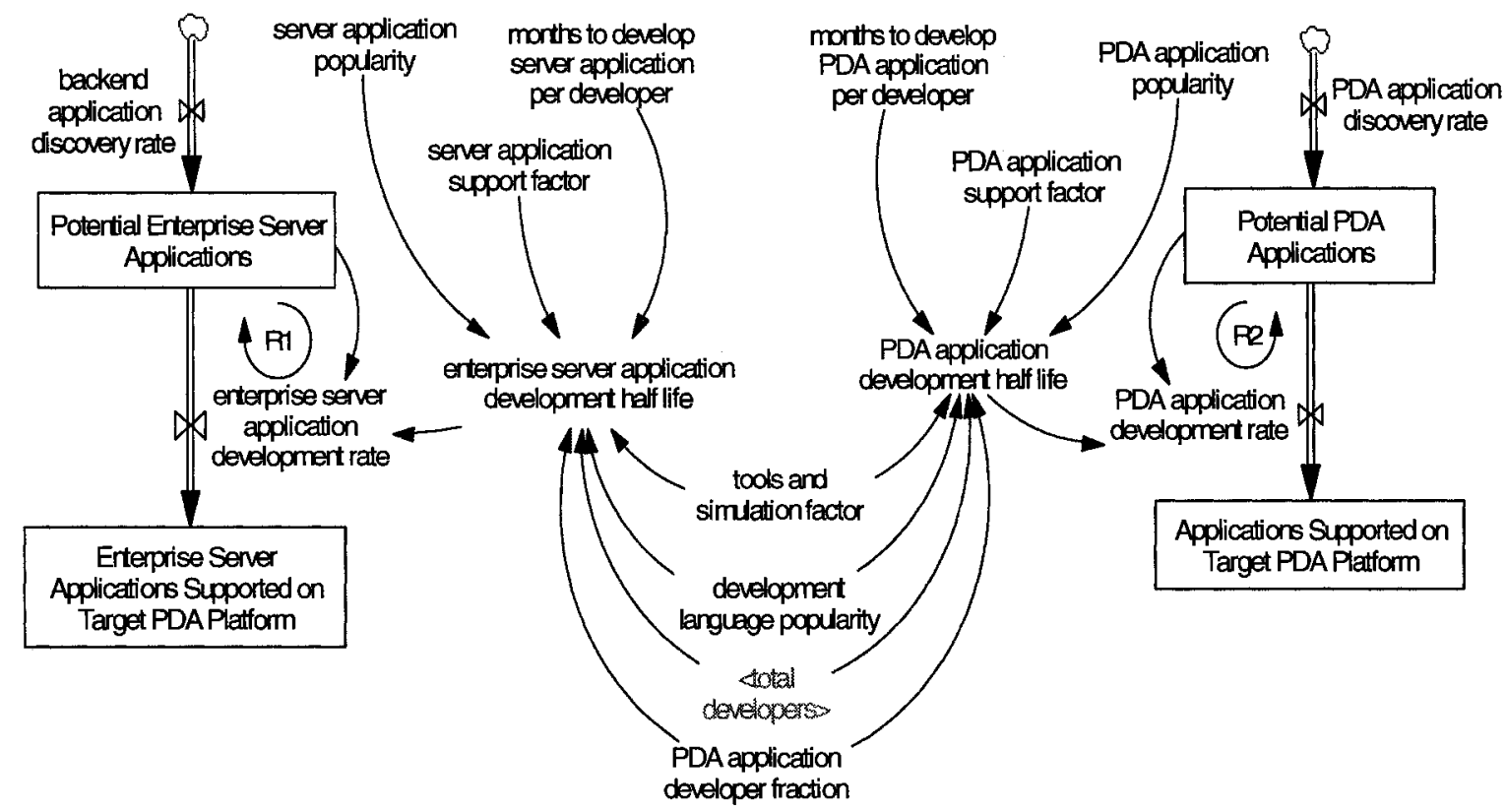

Figure 4. Enterprise server and PDA applications loops

\section{What happens?}

Development starts with a stock of Potential Enterprise Server Applications, these applications become Enterprise Server Applications Supported on Target PDA Platform at enterprise server application development rate. Similarly Potential PDA Applications become Application Supported on Target PDA Platform at PDA application development rate.

The rate of applications being supported on the target PDA platform is affected by the accumulation in the stock of potential applications. Higher the application popularity (i.e., more number of users using that application) sooner it is supported on the target PDA platform. Other factors that positively influence the rate at which an application is supported include the development language popularity (e.g., Java vs. proprietary), total developers, number of tools and simulators (e.g., Eclipse plug-in).

\section{Your thoughts about these loops}

Q1. Is the structure of the loops plausible? Does it match your beliefs about the rate at which wireless PDA applications become a supported on a target PDA platform in a scenario such as this microworld? 
a) Is the relationship of Enterprise Server Applications Supported on Target PDA Platform with enterprise server application development rate plausible?

- Why or why not?

b) Is the relationship of Applications Supported on Target PDA Platform with PDA application development rate plausible?

- Why or why not?

Q2. Is the explanation of what happens in the loop plausible?

- Why or why not? 


\section{Enterprises loop}

The loops in the following figure depict the enterprises deploying the wireless PDA platform. Enterprises can either be deploying the Target PDA Platform or Competitor PDA Platform. Moreover, it is assumed that enterprises do not stop using a wireless PDA platform and enterprise may switch between the PDA platforms enterpise

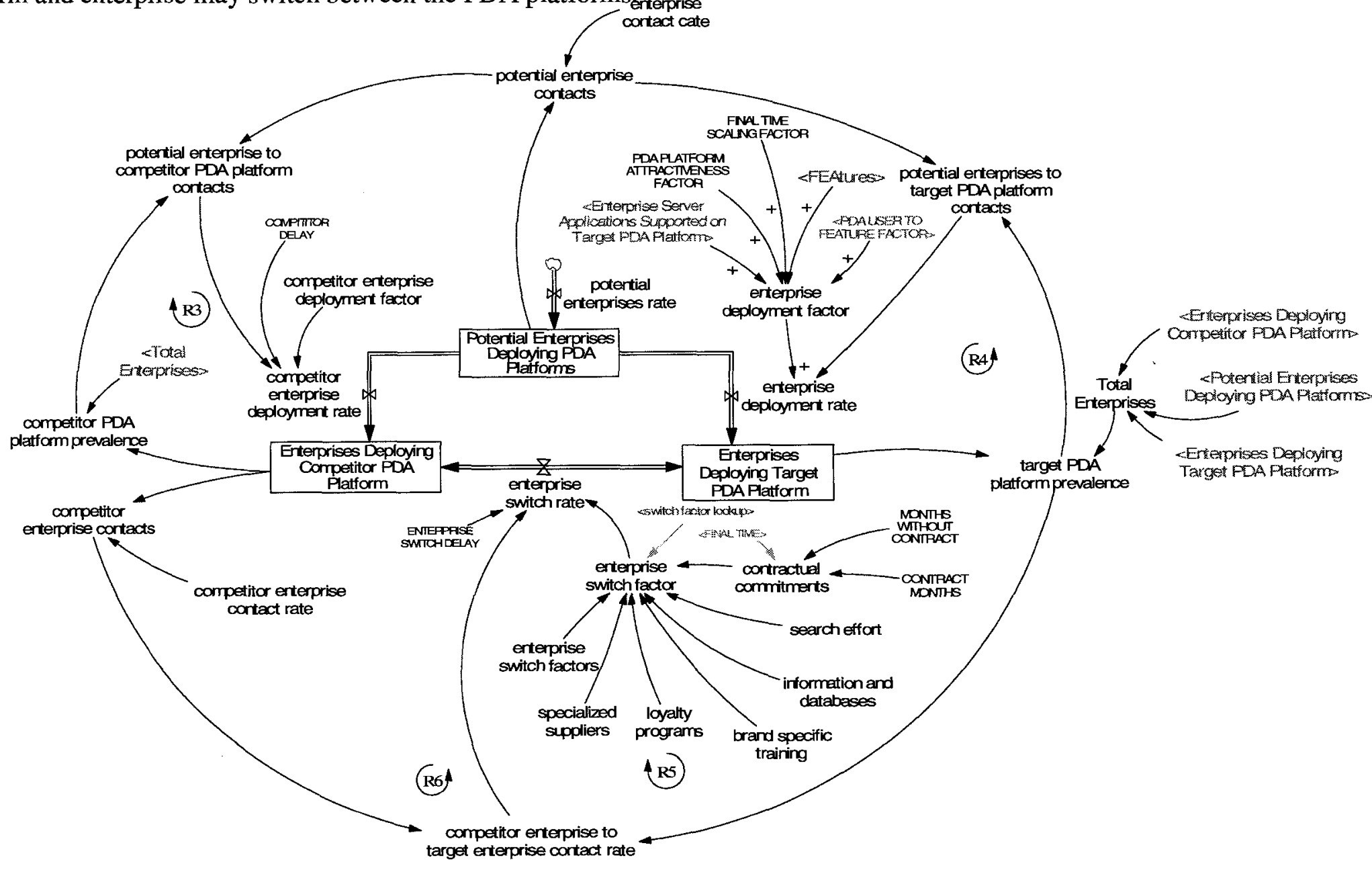

Figure 5. Enterprise loop 


\section{What happens?}

Development starts with a stock of Potential Enterprises Deploying PDA Platform. These enterprises become Enterprise Deploying Target PDA Platform at enterprise deployment rate. Similarly Potential Enterprises Deploying PDA Platform can become Enterprises Deploying Competitor PDA Platform at competitor enterprise development rate.

The enterprise deployment rate - rate at which enterprises deploying the target PDA platform is affected by the accumulation in the stock of Potential Enterprises Deploying PDA Platforms. As well as, number of Enterprise Server Applications Supported on Target PDA Platform, PDA Platform Attractiveness Factor, Standards Compliancy (e.g., GSM, XML, and Wi-Fi), and Popular File Formats supported, and finally number of Complementary Products.

\section{Your thoughts about these loops}

Q1. Is the structure of the loop plausible? Does it match your beliefs about the rate at which enterprises deploy wireless PDA platform in a scenario such as this microworld?

a) Is the relationship of Enterprise Deploying Target PDA Platform with enterprise deployment rate plausible?

- Why or why not?

b) Is the relationship of Enterprises Deploying Competitor PDA Platform with competitor enterprise development rate plausible?

- Why or why not?

Q2. Is the explanation of what happens in the loop plausible?

- Why or why not? 


\section{PDA users loop}

The loops in the following figure depict the PDA users adopting the wireless PDA platform. Potential PDA Platform Users can either adopt the Target PDA Platform and become Target PDA Platform Users; or adopt Competitor PDA Platform and become Competitor PDA Platform Users. Moreover, it is assumed that PDA users do not stop using a wireless PDA platform and PDA users may switch between the PDA platforms.

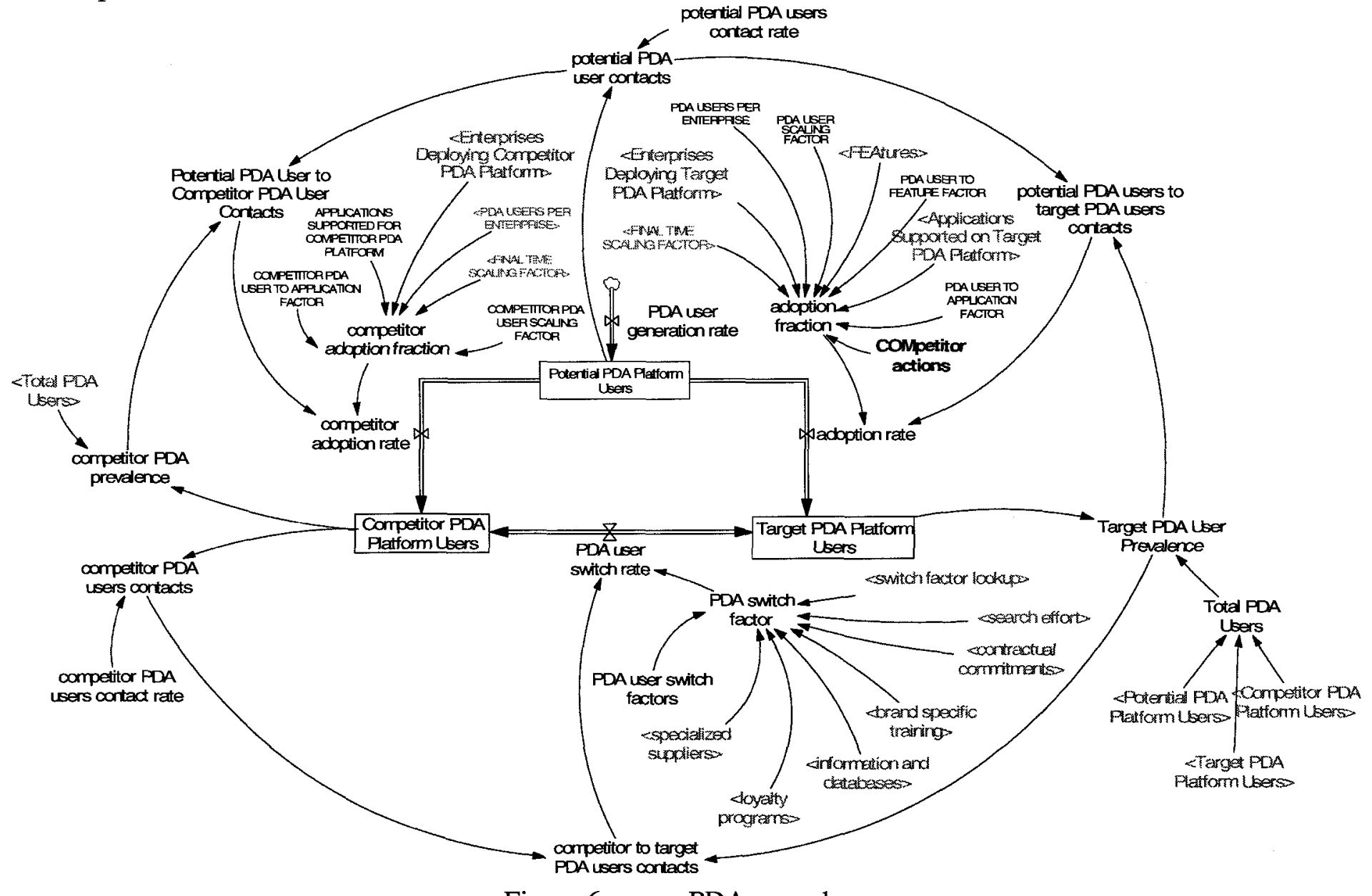

Figure 6. $\quad$ PDA users loop 


\section{What happens?}

Development starts with a stock of Potential PDA Platform Users. These PDA users become Target PDA Platform Users at adoption rate. Similarly Potential PDA Platform Users can become Competitor PDA Platform Users at competitor adoption rate.

The adoption rate - rate at which PDA users deploying the target PDA platform is positively influenced by the accumulation in the stock of Potential PDA Platform Users. As well as, number of Enterprises Deploying Target PDA Platform, Applications Supported on Target PDA Platform, and finally negatively influenced by Competitor actions.

\section{Your thoughts about these loops}

Q1. Is the structure of the loop plausible? Does it match your beliefs about the rate at which PDA users adopt wireless PDA platform in a scenario such as this microworld?

a) Is the relationship of Target PDA Platform Users with adoption rate plausible?

- Why or why not?

b) Is the relationship of Competitor PDA Platform Users with competitor adoption rate plausible?

- Why or why not?

Q2. Is the explanation of what happens in the loop plausible?

- Why or why not? 


\section{E. Carriers loop}

The loops in the following figure depict the Carriers adopting the wireless PDA platform. Potential Carriers can either adopt the Target PDA Platform and become Carriers Deploying Target PDA Platform; or adopt Competitor PDA Platform and become Carriers Deploying Competitor PDA Platform. Moreover, it is assumed that Carriers do not stop deploying a wireless PDA platform and Carriers may switch between the PDA platforms.

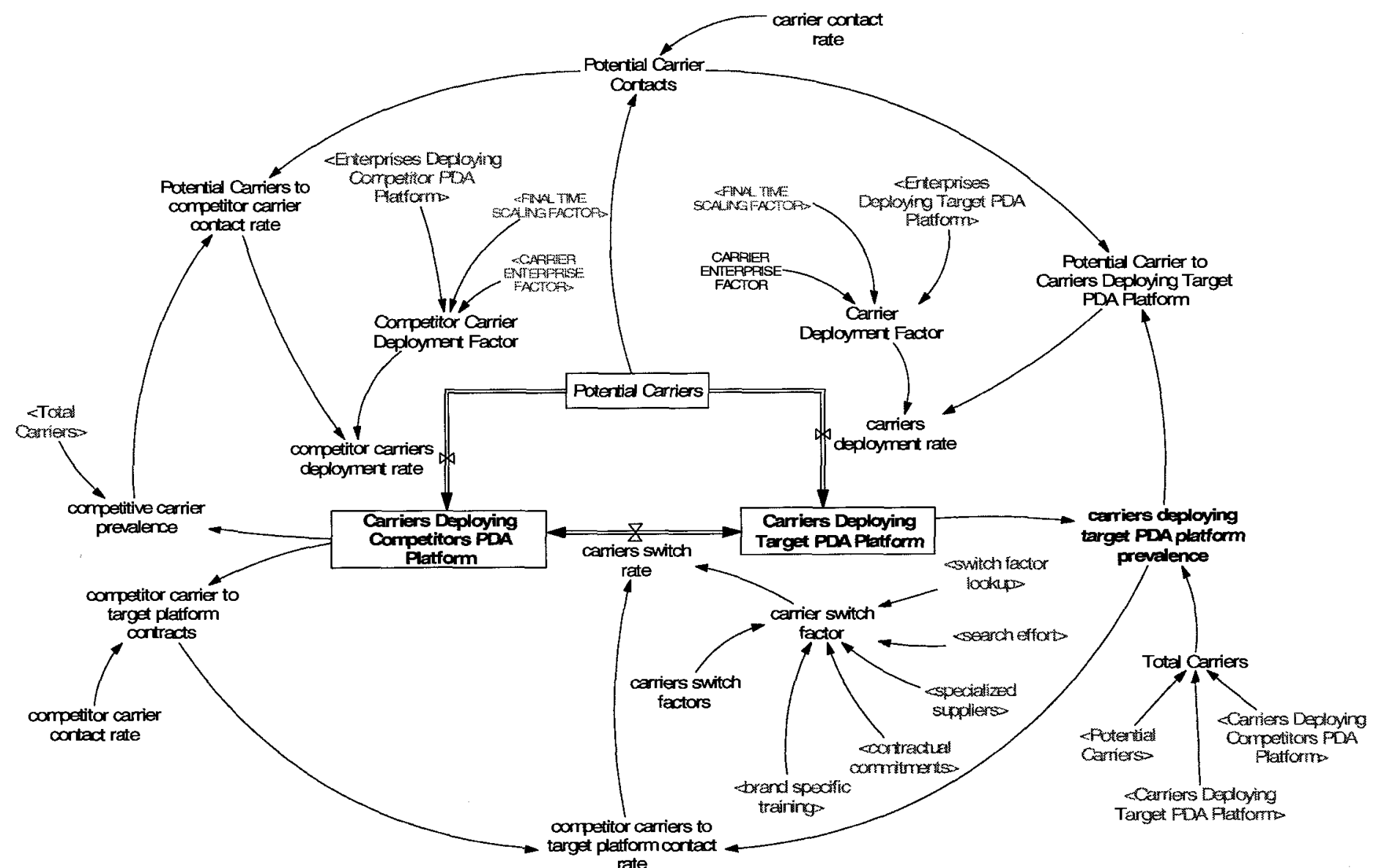

Figure 7. Carriers loop 


\section{What happens?}

Development starts with a stock of Potential Carriers. These Carriers become Carriers Deploying Target PDA Platform at carriers deployment rate. Similarly Potential Carriers can become Carriers Deploying Competitor PDA Platform at competitor carrier deployment rate.

The carriers deployment rate - rate at which Carriers deploying the target PDA platform is positively influenced by the accumulation in the stock of Potential Carriers, as well as, number of Enterprises Deploying Target PDA Platform.

\section{Your thoughts about these loops}

Q1. Is the structure of the loop plausible? Does it match your beliefs about the rate at which Carriers adopt wireless PDA platform in a scenario such as this microworld?

a) Is the relationship of Carriers Deploying Target PDA Platform with carrier deployment rate plausible?

- Why or why not?

b) Is the relationship of Carriers Deploying Competitor PDA Platform with competitor carriers deployment rate plausible?

- Why or why not?

Q2. Is the explanation of what happens in the loop plausible?

- Why or why not? 


\section{F. Licensing loop}

The loops in the following figure depict the Licensable $3^{\text {rd }}$ party PDA Devices adopting the wireless PDA platform. Potential Licensable $3^{\text {rd }}$ party PDA Devices can either adopt the Target PDA Platform and becon that PDA devices may switch between the PDA Platform and become Competitor Licensed PDA Devices. Mor PDA platforms. devices cortact rate

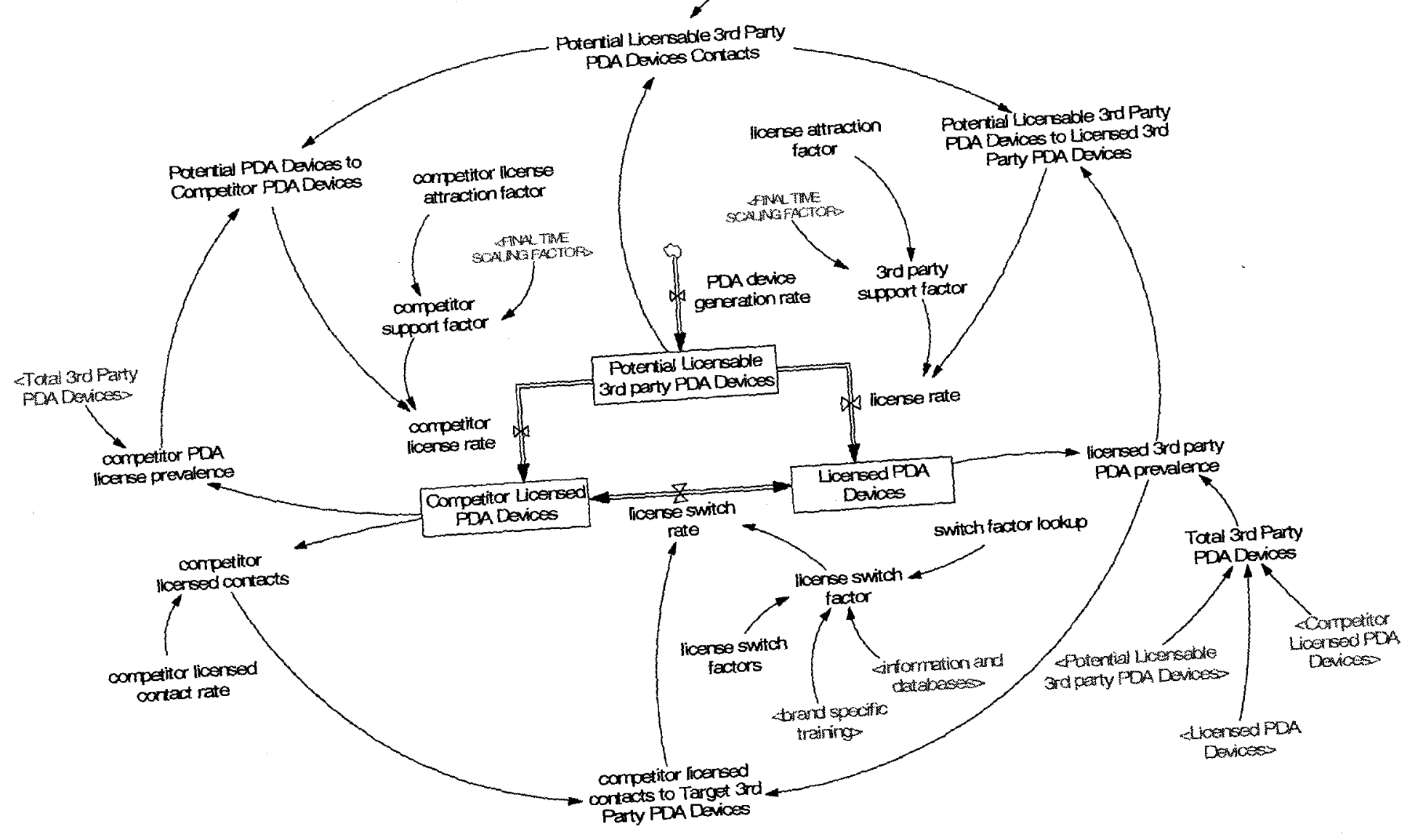

Figure 8. Licensing loop 
What happens?

Development starts with a stock of Potential Licensable $3^{\text {rd }}$ Party PDA Devices. These PDA devices become Licensed $3^{\text {rd }}$ Party Devices at license rate. Similarly Potential Licensable $3^{\text {rd }}$ Party PDA Devices can become Competitor Licensed PDA Devices at competitor license rate.

The license rate - rate at which $3^{\text {rd }}$ party PDA devices being licensed for the target PDA platform is positively influenced by the accumulation in the stock of Potential Licensable $3^{\text {rd }}$ party PDA Devices, as well as, number of license attraction factor.

\section{Your thoughts about these loops}

Q1. Is the structure of the loop plausible? Does it match your beliefs about the rate at which Carriers adopt wireless PDA platform in a scenario such as this microworld?

a) Is the relationship of Licensed PDA Devices with license rate plausible?

- Why or why not?

b) Is the relationship of Competitor Licensed PDA Devices with competitor license rate plausible?

- Why or why not?

Q2. Is the explanation of what happens in the loop plausible?

- Why or why not? 


\section{$4 \quad$ Closing questions}

Q1. Would you suggest extending the model to capture the role of network effects and their strategic implications in the enterprise wireless PDA market?
[] Yes
[] No
[] May be
[ ] Not sure

Q2. Would you suggest extending the model to capture the role of network effects and their strategic implications in the enterprise wireless PDA market? Please list most important first.

1.

2.

3.

Q3. Would you recommend any other microstructures to gain further insights? Please list most important first.

1.

2.

3. 